\title{
COLONIZAÇÃO RADICULAR E PRODUÇÃO DE MICÉLIO EXTERNO POR DUAS ESPÉCIES DE FUNGOS MICORRÍZICOS ARBUSCULARES EM SOJA SUBMETIDA A DOSES DE FÓSFORO
}

\author{
MARCO ANTONIO NOGUEIRA \\ Engenheiro Agrônomo
}

Orientadora: Prof ${ }^{\mathrm{e}}$. Dr ${ }^{\mathrm{a}}$. ELKE JURANDY BRAN NOGUEIRA CARDOSO

Dissertação apresentada à Escola Superior de Agricultura "Luiz de Queiroz", Universidade de São Paulo, para obtenção do título de Mestre em Agronomia, Área de Concentração: Solos e Nutrição de Plantas.

P IR A C I C A B A

Estado de São Paulo - Brasil

Setembro - 1997 
Dados Internacionais de Catalogação na Publicação (CIP) DIVISĀO DE BIBLIOTECA E DOCUMENTAÇĀO - Campus "Luiz de Queiroz"/USP

Nogueira, Marco Antonio

Colonizaçăo radicular e produção de micélio externo por duas espécies de fungos micorrízicos arbusculares em soja submetida a doses de fósforo / Marco Antonio Nogueira. - - Piracicaba, 1997.

92 p. : il.

Dissertação (mestrado) - Escola Superior de Agricultura Luiz de Queiroz, 1997. Bibliografia.

1. Fósforo em planta 2. Micélio 3. Micorriza 4. Soja 1. Título 
COLONIZAÇÃO RADICULAR E PRODUÇÃO DE MICÉLIO EXTERNO POR DUAS ESPÉCIES DE FUNGOS MICORRÍZICOS ARBUSCULARES EM SOJA SUBMETIDA A DOSES DE FÓSFORO

MARCO ANTONIO NOGUEIRA

Aprovada em: 30.10 .1997

Comissão julgadora:

Prof $f^{\mathrm{e}}$. Dra ${ }^{\mathrm{a}}$. Elke Jurandy Bran Nogueira Cardoso

ESALQ/USP

$\mathrm{Dr}^{\mathrm{a}}$. Rosana Faria Vieira

CNPMA/EMBRAPA

Prof ${ }^{a}$. Dr ${ }^{a}$. Siu Mui Tsai

CENA/USP

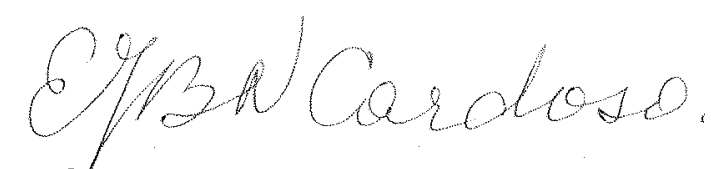

Prof ${ }^{\mathrm{e}}$. $\mathrm{Dr}^{\mathrm{a}} /$ ELKE JURANDY BRAN NOGUEIRA CARDOSO

Orientadora 
Aos meus pais, Sebastião e Maria de Lourdes e à minha irmã, Maria Sílvia, pelo apoio e confiança que sempre recebi,

OFEREÇO

À minha esposa, Cristiane, pelo incentivo nos momentos dificeis e aos nossos filhos que hão de vir,

DEDICO 


\section{AGRADECIMENTOS}

À Prof . Dr ${ }^{\mathrm{a}}$. Elke Jurandy Bran Nogueira Cardoso, pela orientação, apoio e amizade;

Aos técnicos do Laboratório de Microbiologia do Solo: Denise Lourdes Colombo Mescolotti e Luis Fernando Baldesin, pelo auxilio na instalação e condução do experimento e sobretudo pela amizade;

Ao Prof. Dr. Marcio R. Lambais, pelas sugestões e amizade;

À Coordenação do Curso de Pós-Graduação em Agronomia: Solos e Nutrição de Plantas, representada pelo Prof. Dr. Francisco Antonio Monteiro, pela atenção e colaboração no decorrer do curso;

Ao Prof. Dr. Raymond Stanley Pacovsky pela revisão crítica dos resultados, sugestões apresentadas e correção do summary;

À Eliana Maria Garcia Sabino pela correção das Referências Bibliográficas;

Aos amigos: Andréia, Arnaldo, Elizabeth, Carolina, Cleide, Cristina, Emerson, Fábio, Giovana, Gustavo, Heron, Leandra, Manoel, Marcelo, Ozinaldo, Peterson, Renata, Robinson, Rogério, Ulisses, Vânia, Winston pela alegria do convívio e colaboração;

Aos professores e funcionários do Departamento de Ciência do Solo; Ao CNPq pela bolsa de estudos. 


\section{SUMÁRIO}

Página

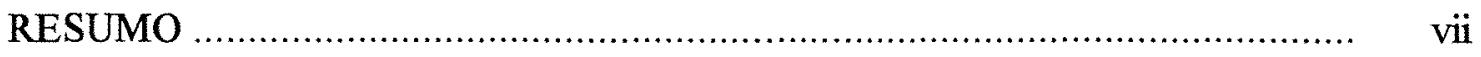

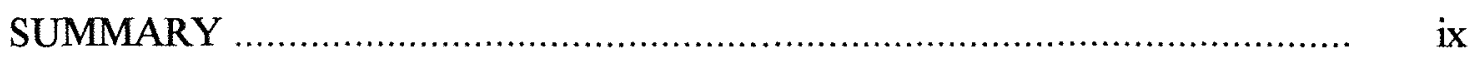

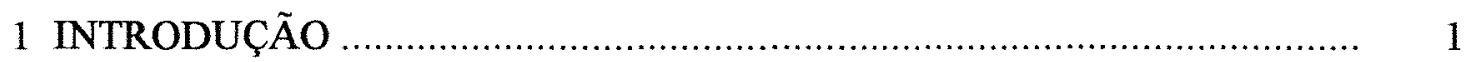

2 REVISÃO DE LITERATURA …......................................................

3 MATERIAL E MÉTODOS .............................................................. 19

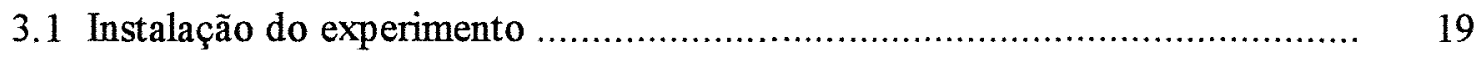

3.2 Análises laboratoriais das variáveis .......................................................... 22

3.2.1 Massa do material seco da parte aérea e vagens ....................................... 22

3.2.2 Determinação da concentração de nutrientes e total acumulado ................ 22

3.2.3 Número e massa do material seco de nódulos .......................................... 23

3.2.4 Porcentagem de colonização radicular ................................................... 23

3.2.5 Extrą̧ão do micélio extrarradicular ...................................................... 24

3.2.6 Determinação do comprimento de micélio extrarradicular ativo, pelo uso do método da fluorescência induzida com diacetato de fluoresceína (FDA), e comprimento de micélio extrarradicular total........................... 25

3.2.7 Disponibilidade de fósforo no substrato .............................................. 27

3.2.8 Análise estatística do experimento …………....................................... 27

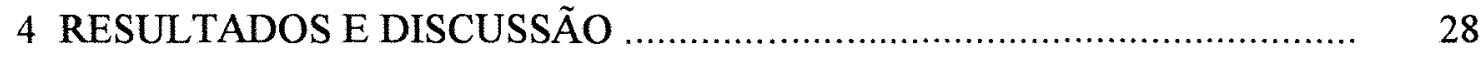

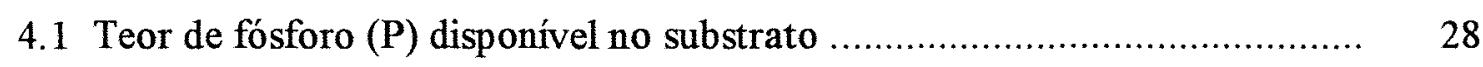

4.2 Colonização radicular (\%) .............................................................. 30

4.3 Massa do material seco da parte aérea (MSPA) …………......................... 36

4.4 Massa do material seco de vagens (MSV) …............................................ 41

4.5 Número e massa do material seco de nódulos (MSN) ................................... 43 
4.6 Comprimento de micélio extrarradicular ativo (MEA) ......................... 46

4.7 Comprimento de micélio extrarradicular total (MET) ........................ 53

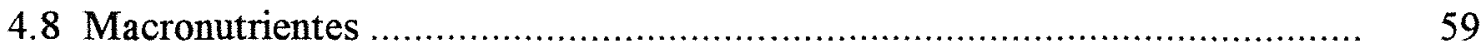

4.8.1 Nitrogênio ............................................................................ 61

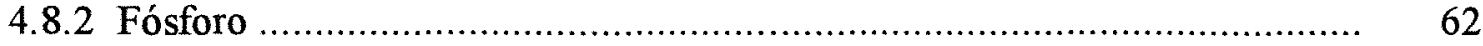

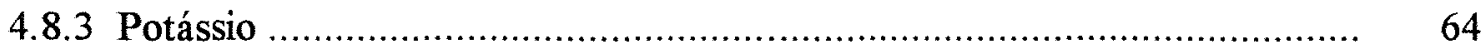

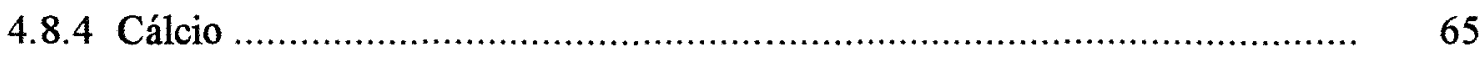

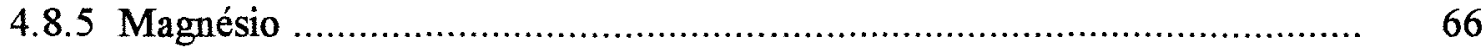

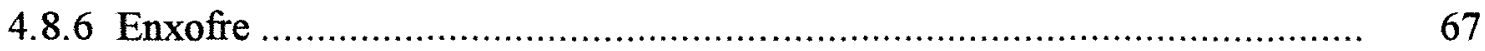

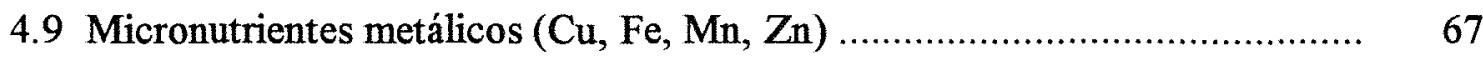

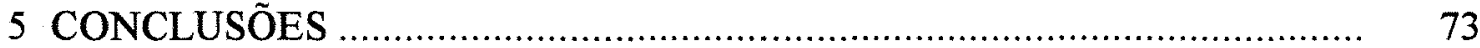

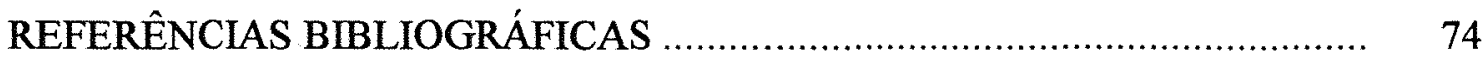

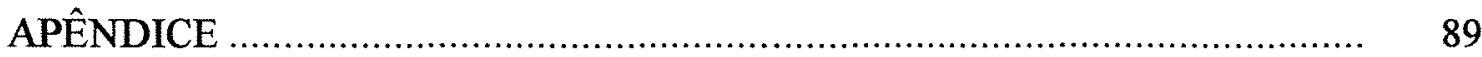




\title{
COLONIZAÇÃo Radicular e PROdUÇÃo de MIĆ́lIo EXTERNO POR DUAS ESPÉCIES DE FUNGOS MICORRÍZICOS ARBUSCULARES EM SOJA SUBMETIDA A DOSES DE FÓSFORO
}

\author{
Autor: MARCO ANTONIO NOGUEIRA \\ Orientadora: ELKE JURANDY BRAN NOGUEIRA CARDOSO
}

\section{RESUMO}

Estudou-se a associação de duas espécies de fungos micorrízicos arbusculares (FMAs) e a soja (Glycine max L. Merr., cv. IAC-8), submetida a doses crescentes de fósforo, em casa de vegetação. O delineamento experimental foi

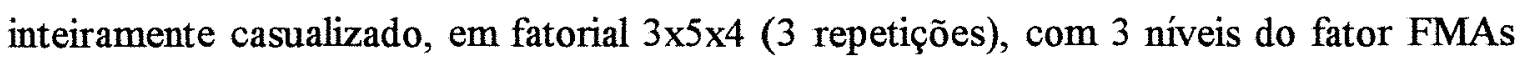
(controle, Glomus intraradices e Gigaspora margarita), 5 níveis de $\mathrm{P}(0,25,50,100$, $200 \mathrm{mg} \mathrm{kg}^{-1}$, na forma de superfosfato triplo) e 4 épocas de avaliação $(15,30,60$ e 90 dias após transplantio). As parcelas, contendo substrato esterilizado por autoclavagem, foram compostas por duas plantas inoculadas com Bradyrhizobium japonicum (estirpes Semia 587 e 5019). As variáveis analisadas foram: disponibilidade de $\mathrm{P}$ no substrato, colonização radicular pelos FMA, massa do material seco da parte aérea (MSPA) e vagens, nodulação [massa do material seco (MSN) e número], comprimento de micélio externo ativo (MEA) e total (MET), acúmulo nutrientes pela parte aérea.

A disponibilidade de $\mathrm{P}$ diminuiu com o tempo, em maior parte devido à absorção pelas plantas, sem efeitos dos FMAs. Aumento das doses de $\mathrm{P}$ afetou negativamente a colonização de ambas espécies fúngicas, embora Gi. margarita tenha apresentado, nas maiores doses, maior colonização comparando-se com $G$. intraradices. 
G. margarita foi menos eficiente em colonizar a soja por apresentar fase de crescimento lento mais prolongada, o que provavelmente causou aos 60 dias, redução transitória de crescimento das plantas a ele associadas e que receberam 50 e $100 \mathrm{mg} \mathrm{kg}^{-1} \mathrm{de} P$.

Aumentos na MSPA em relação ao controle aos 60 dias somente foram observados para $G$. intraradices nas doses 25 e $100 \mathrm{mg} \mathrm{kg}^{-1}$. Aos 90 dias, $G$. intraradices propiciou efeitos positivos até a dose de $50 \mathrm{mg} \mathrm{kg}^{-1}$, enquanto Gi. margarita apenas na dose $0 \mathrm{mg} \mathrm{kg}^{-1}$. Independente da presença dos fungos, houve tendência de diminuição da MSPA quando a dose de $P$ foi de $200 \mathrm{mg} \mathrm{kg}^{-1}$. Efeitos das doses de $P$ sobre esta variável somente foram observados nas duas últimas colheitas.

Aumento na massa e número de nódulos devido ao FMA $G$. intraradices foi observado na dose $25 \mathrm{mg} \mathrm{kg}^{-1}$ de $\mathrm{P}$. Na dose de $100 \mathrm{mg} \mathrm{kg}^{-1}$, a presença dos dois FMAs levou à redução desta variável.

O comprimento de micélio externo ativo de $G$. intraradices aumentou com o tempo. Gi. margarita apresentou pouco incremento apenas no tratamento $25 \mathrm{mg}$ $\mathrm{kg}^{-1}$ de $\mathrm{P}$, apresentando nas demais doses, valores semelhantes aos encontrados para $o$ tratamento controle sem FMA. Aumentando as doses de P, ambos apresentaram decréscimo desta variável. Para comprimento de micélio externo total, nas duas primeiras épocas Gi. margarita apresentou maiores valores, sendo superado por $G$. intraradices aos 60 dias. Efeitos mais evidentes da diminuição desta variável com os aumentos das doses de $\mathrm{P}$ foram observados aos 60 dias.

$O$ total de nutrientes na parte aérea foi influenciado pela presença dos FMAs apenas nas duas últimas épocas. G. intraradices, dependendo da dose de $\mathrm{P}$ associada, propiciou aumentos da quantidade total de N. Gi. margarita aumentou esta variável aos $90 \mathrm{~d}$ na ausência de adição de $\mathrm{P}$. Apesar da não diferença estatística, a presença dos FMAs tendeu a aumentar a variável $P$ nas menores doses e na ausência de adição deste elemento ao substrato. Aumento das doses de $\mathrm{P}$ incrementou a quantidade total de nutrientes acumulados pela parte aérea até a dose de $100 \mathrm{mg} \mathrm{kg}^{-1}$, a partir da qual decréscimos foram observados, de modo semelhante à MSPA. As concentrações de Fe e Mn nas vagens foram reduzidas pela presença dos FMAs nas baixas doses de $P$, nas quais os níveis de colonização radicular foram altos. 


\title{
ROOT COLONIZATION AND EXTERNAL MYCELIUM PRODUCTION BY TWO ARBUSCULAR MYCORRHIZAL FUNGI IN SOYBEAN GIVEN RATES OF PHOSPHORUS
}

\author{
Author: MARCO ANTONIO NOGUEIRA \\ Adviser: ELKE JURANDY BRAN NOGUEIRA CARDOSO
}

\section{SUMMARY}

An association between soybean (Glycine max L. Merr. cv. IAC 8) and two different arbuscular-mycorrhizal (AM) fungi, grown under increasing rates of phosphorus (P), was studied in a glasshouse. The experimental design was completely random, factorial design $3 \times 5 \times 4$ ( 3 replications), with 3 inoculation treatments (control, Gigaspora margarita, Glomus intraradices), 5 levels of $\mathrm{P}(0,25,50,100$ and $200 \mathrm{mg} \mathrm{kg}$ ${ }^{1}$, as triple superphosphate) and 4 harvests (15, 30, 60, 90 days after transplanting). Each parcel consisted of pot containing autoclaved-sterilized substrate and two plants, all inoculated with Bradyrhizobium japonicum (strains Semia 587 and Semia 5019). The assessed variables were: $P$ availability in substrate, root colonization by AM fungi, shoot and pod dry weight, nodulation (dry weight and number), the length of total and active external mycelium, and shoot nutrients.

$P$ availability decreased with time, mainly due to absorption by plants (c. $78 \%$ at $200 \mathrm{mg} \mathrm{kg}^{-1}$ ), with no differences due to AM fungi. Increasing $\mathrm{P}$ rates caused decreased root colonization, but Gi. margarita showed less of a decrease in root colonization under high $\mathbf{P}$ rates than did $G$. intraradices. Gi. margarita was less 
efficient in the root colonization of soybean because it grew slower than did $G$. intraradices. This probably was the cause of the temporal growth reduction in the soybean-Gi. margarita association at 60 days and rates 50 and $100 \mathrm{mg} \mathrm{kg}^{-1}$ of $\mathrm{P}$.

Shoot dry weight increased only due $G$. intraradices at 60 days at $\mathrm{P}$ rates of 25 e $100 \mathrm{mg} \mathrm{kg}^{-1}$. At 90 days, $G$. intraradices caused positive effects until a $P$ rate of $50 \mathrm{mg} \mathrm{kg}^{-1}$. At the same time, Gi. margarita caused positive effects only at $0 \mathrm{mg}$ $\mathrm{kg}^{-1}$ of $\mathbf{P}$ addition. In addition, independently of AM fungi, there was tendency for shoot dry weight to decrease at the highest $P$ rate $\left(200 \mathrm{mg} \mathrm{kg}^{-1}\right)$. Increases in shoot dry weight due to $P$ addition was observed until $100 \mathrm{mg} \mathrm{kg}^{-1}$ only at the last two harvests.

Increase of nodule dry weight and number due AM fungi was observed only at a $P$ rate of $25 \mathrm{mg} \mathrm{kg}^{-1}$ and associated with $G$. intraradices. At rate $100 \mathrm{mg} \mathrm{kg}^{-1}$, both AM fungi caused a decrease of nodule dry weight and number.

Length of active external mycelium (AEM) of $G$. intraradices increased with time. Gi. margarita showed few or no increase in AEM with the time, depending on the $P$ rate, with values similar to those found in non- $A M$ substrate. When $P$ rate was increased, AEM decreased for both AM fungi. Length of total external mycelium (TEM) for $G i$. margarita at the first two harvests was higher than that for $G$. intraradices, but TEM for $G$. intraradices surpassed by Gi. margarita at third harvest. Decrease of this variable with increase of $P$ rates was more evident at 60 days.

Shoot total nutrients were affected by AM fungi only at two last harvests. G. intraradices, depending of $\mathbf{P}$ rate, caused increase in total N. Gi. margarita increased this variable only at 90 days in no $\mathrm{P}$ addition treatment. Both AM fungi presented tendency to increase $\mathrm{P}$ amounts in shoot, at low rates of $\mathrm{P}$ addition and no $\mathrm{P}$ additions treatments. Increasing $\mathbf{P}$ rates resulted in increased shoot nutrient accumulation until about $100 \mathrm{mg} \mathrm{kg}^{-1}$, after which total shoot nutrients decreased in a fashion similar to that of shoot dry weight. On other hand, pods concentrations of Fe and $\mathrm{Mn}$ were reduced due to AM fungi under low $P$, when root colonization were high. 


\section{INTRODUÇÃO}

É fato demonstrado por inúmeros resultados de pesquisa que, sob certas condições, a interação entre fungos micorrízicos e o sistema radicular das plantas aumenta a capacidade destas em absorver nutrientes do solo, sobretudo os elementos minerais pouco móveis, como o fósforo. Isto ocorre pois o crescimento do fungo além das raizes, aumenta sua área de absorção, uma vez que as hifas atingem sítios que antes não eram alcançados pelas radicelas da planta (Zambolim \& Siqueira, 1985). Nesse contexto, deve-se salientar a importância desta interação em nossas condições, uma vez que nossos solos em geral são altamente intemperizados, ácidos, com predominância de minerais do grupo caulinita e óxidos de ferro e alumínio na fração argila, fatores favoráveis à fixação do fósforo.

O nutriente que mais tem limitado a produção, sobretudo das culturas anuais, é o fósforo, sendo que $90 \%$ das análises de solo feitas no país revelam baixos teores disponíveis, ou seja, valores menores que $10 \mathrm{mg} \mathrm{kg}^{-1}$, sendo comum encontrar solos de cerrado com $1 \mathrm{mg} \mathrm{kg}^{-1}$ (Malavolta, 1980).

A soja é uma cultura que constitui uma das principais fontes de divisas para o Brasil, sendo cultivada em quase todo o território nacional, sobre os mais diversos tipos de solo. Atualmente, a expansão das fronteiras agrícolas para a região dos cerrados têm levado ao uso de solos mais pobres em nutrientes, o que exige um maior emprego de fertilizantes, sobretudo os fosfatados, visando manter um nível de produtividade economicamente viável. Entretanto, este recurso natural não renovável é limitado e estima-se que dentro de algum tempo, as reservas de fosfato natural se esgotarão, com conseqüências desastrosas à agricultura mundial, uma vez que nenhum outro elemento pode substituí-lo nas funções que desempenha na vida da planta. Resta-nos então, a 
missão de utilizá-lo o mais racionalmente possivel, sobretudo, buscando alternativas para seu uso mais eficiente.

As associações micorrizicas têm sido consideradas como uma alternativa para maximizar a utilização dos fertilizantes fosfatados. Além de propiciar maior absorção de $\mathrm{P}$, podem ter influência na absorção de zinco (Cooper \& Tinker, 1978) e de cobre (Gildon \& Tinker, 1983), ambos de baixa mobilidade no solo.

Outro elemento, que muitas vezes limita a produção e envolve alto custo de aquisição, é o nitrogênio $(\mathrm{N})$. Porém, a associação entre leguminosas e bactérias do gênero Bradyrhizobium constitui uma forma econômica e eficiente de fornecimento deste elemento. A associação de fungos micorrízicos e leguminosas, muitas vezes pode levar à maior eficiência da fixação de nitrogênio por meio das bactérias fixadoras. Essa maior eficiência é decorrente do fato que, os fungos micorrízicos aumentam a absorção de $P$ pela planta, provavelmente o mais importante nutriente para $\mathrm{o}$ crescimento $\mathrm{e}$ nodulação eficiente das leguminosas (Barea \& Azcón-Aguilar, 1983).

Dentre os fatores que afetam o estabelecimento da simbiose, a disponibilidade de $\mathbf{P}$ no substrato é o que tem recebido mais atenção. Contudo, é conveniente salientar que as interações entre o genótipo do fungo em interação com o da planta e destes com o ambiente são as determinantes da eficiência simbiótica. Diferentes espécies de fungos micorrizicos podem se comportar de maneira diferenciada no estabelecimento da simbiose com um mesmo hospedeiro numa mesma condição ambiental. Contudo, a causa desta diferença de comportamento não é bem conhecida.

A maioria dos estudos das interações micorrízicas abordam apenas os aspectos relacionados à planta. No que se refere ao fungo, estes estudos em geral se restringem à avaliação da colonização do córtex da planta ou ainda à determinação de sua biomassa intrarradicular, o que envolve apenas parte do sistema de hifas fúngicas. $\mathrm{Na}$ maioria dos casos, a parte externa da rede micelial não é estudada, em virtude das dificuldades encontradas para extração e quantificação deste importante componente do sistema fungo-planta. Diante desta importância, estudos mais detalhados sobre o micélio extrarradicular, tal como a determinação da parte ativa da rede micelial, a qual é 
responsável pela absorção e translocação de água e nutrientes, forneceriam maiores subsídios para melhor entendimento desta interação.

Alguns autores sugerem que a diferença de eficiência entre os diversos FMAs pode ser devida a um desbalanço entre a sua biomassa interna e a externa à raiz. Assim, fungos pouco eficientes em promover o crescimento de seu hospedeiro apresentariam grande colonização interna, mas pouco crescimento externo, constituindo um dreno de $\mathrm{C}$ à planta, sem aumentar a superficie de absorção radicular.

Diante do exposto, o presente trabalho teve por objetivo avaliar a eficiência de duas espécies de fungos micorrízicos arbusculares em associação com a cultura da soja, submetida a doses crescentes de $\mathbf{P}$, no que refere à colonização radicular, produção de micélio externo ativo e total, absorção de nutrientes e nodulação, em quatro fases do seu ciclo. 


\section{REVISÃO DE LITERATURA}

A maioria das plantas estabelece associações micorrízicas, constituindo uma exceção na natureza, as que não interagem com estes fungos simbiontes (Marx \& Bryan, 1975). O termo micorriza refere-se às associações simbióticas e mutualísticas não antagônicas entre fungos do solo e radicelas das plantas, com perfeita integração morfológica, fisiológica e funcional (Silveira, 1992), na qual ambos, dependendo das condições, podem se beneficiar da interação.

Os tipos de associą̧ões micorrízicas são determinadas pela forma de colonização dos tecidos das raizes pelo fungo, a qual nunca atinge a região dos tecidos vasculares e meristemas. São classificados em endomicorrizas, ectomicorrizas, e ectoendomicorrizas, de acordo com a posição ocupada na raiz. Cada associação possui características próprias, tanto fisiológicas quanto relacionadas aos simbiontes. Nesta revisão serão abordados apenas aspectos relacionados às endomicorrizas.

Os fungos micorrízicos arbusculares (FMAs) são pertencentes à ordem Glomales (Morton \& Benny, 1990; Walker \& Trappe, 1993) sendo conhecidas três famílias, seis gêneros e cerca de 140 espécies. Na literatura internacional, as espécies Glomus sp., Gigaspora margarita e Glomus clarum são citadas como as mais encontradas em associação com soja (Caldeira, 1983).

O processo de colonização dos FMA tem sido descrito por vários autores (Carling \& Brown, 1982; Harley \& Smith, 1983; Bonfante-Fasolo, 1984; Silveira, 1992). Este processo inicia-se com o contato entre a hifa do fungo originária de um propágulo, que pode ser um esporo de resistência, fragmento de raiz micorrizada ou a própria hifa existente no solo, e o ponto de penetração na raiz de um hospedeiro suscetível. Dependendo do tipo de propágulo, o fungo pode formar um apressório e penetrar imediatamente, ou ter um crescimento micelial na superficie radicular antes de 
infectá-la. $O$ crescimento do micélio dentro da raiz restringe-se ao córtex, sendo que as ramificações das hifas ocorrem inter e intracelularmente. Poucos dias após o início da infecção, a hifa intracelular da camada mais interna do córtex sofre repetidas divisões, formando um sistema complexo de hifas ramificadas, denominadas arbúsculo. Estas estruturas permanecem envolvidas por uma plasmalema intacta do hospedeiro, constituindo os sítios preferenciais de troca de metabólitos entre os simbiontes, os quais possuem alta atividade fisiológica. Os arbúsculos têm período funcional entre 4 e 15 dias e após sua degeneração, a célula hospedeira volta à sua atividade normal. A posição terminal ou intercalar da hifa interna pode se diferenciar em vesículas, às quais são atribuídas funções de reserva, uma vez que acumulam grande quantidade de lipídios. De forma simultânea ao crescimento interno do fungo, as hifas ramificam-se pela região circunvizinha no solo (Karunarate et al., 1986), constituindo uma estrutura de absorção adicional da raiz, que é capaz de absorver $P$ na forma de ortofosfato até a $8 \mathrm{~cm}$ da raiz (Rhodes \& Gerdemann, 1975). Em solos argilosos, ácidos, o fator determinante da disponibilidade de $\mathrm{P}$ não é a mineralização, mas sim a sua capacidade de fixação deste elemento. Sob este aspecto, a presença do micélio fúngico interceptaria $\mathbf{o}$, incorporando-o à sua biomassa ou transferindo-o à planta, antes que fosse fixado (Pacovsky et al., 1985).

Estudos quantitativos do estabelecimento da simbiose micorrízica indicam um modelo de 3 fases. A primeira, de colonização lenta, compreende o tempo necessário para a germinação dos esporos, crescimento do tubo germinativo e penetração na raiz do hospedeiro. $\mathrm{Na}$ segunda, logarítmica, há um rápido desenvolvimento da micorriza e após 4 a 8 semanas, são formados novos esporos que podem germinar e infectar novas raízes, ocasionando a rapidez desta fase. A última, fase de estabilização, ocorre a partir de 30 a 60 dias da inoculação e varia conforme a planta hospedeira. Isto se dá provavelmente devido a mudanças fisiológicas produzidas nas raízes, normalmente relacionadas com o crescimento dos órgãos reprodutivos da planta, o que pode restringir direta ou indiretamente o crescimento do fungo e prevenir novas infecções (Sutton, 1973; Saif, 1977; Faquin, 1988), embora esta hipótese ainda não tenha sido comprovada. 
Embora não haja especificidade para a penetração do fungo nos tecidos do hospedeiro, a colonização e a resposta de crescimento da planta depende da interação do sistema simbionte com as mais variadas condições, tais como: luz (Hayman, 1974; Bethlenfalfay, 1982d), temperatura (Hayman, 1974), tipo de solo (Pacovsky et al., 1985; Lambais, 1987; Cardoso, 1986), espécie e/ou isolado do fungo (Abbott \& Robson, 1981; Abbott \& Robson 1984; Pacovsky et al., 1986a; Lambais \& Cardoso, 1988, 1990; Paula et al., 1990; Lambais \& Mehdy, 1996), pH (Lambais \& Cardoso, 1988), planta hospedeira (Abbott \& Robson, 1981; Pacovsky et al., 1986a, Fernandes et al., 1987); tipo de inóculo (Abbott \& Robson, 1981), volume de substrato a ser explorado (Baath \& Hayman, 1984; Pacovsky \& Fuller, 1986), densidade de raizes (Baath \& Hayman, 1984), fase de desenvolvimento do hospedeiro (Bethlenfalvay et al., 1982e), sendo que as plantas que se associam aos FMAs são aparentemente micotróficas facultativas (Smith \& Gianinazzi-Pearson, 1988). Apesar da não evidência de especificidade na relação entre os dois parceiros no que se refere à colonização, resultados de pesquisas têm indicado alto grau de "compatibilidade funcional", que determina a eficiência simbiótica da relação (Mosse, 1975; Carling \& Brown, 1980; Cardoso et al., 1986; Koide \& Schreiner, 1992).

O mais importante fator edáfico que afeta as micorrizas arbusculares (MAs) é a disponibilidade de P. Têm-se observado que a dependência micorrízica de algumas plantas é inversamente proporcional à sua disponibilidade (Cardoso et al., 1986; Siqueira \& Colozzi-Filho, 1986; Ojala et al., 1983). Ao mesmo tempo que o aumento de sua absorção é o principal mecanismo de resposta das plantas à micorrização, também exerce um efeito controlador sobre o grau de colonização das raízes pelo fungo ao nível de pós-penetração (Bethlenfalfay et al., 1982e; Siqueira et al., 1984; Siqueira, 1986).

Nem sempre existe uma correlação entre a porcentagem de colonização das raízes por fungos micorrízicos e sua eficiência (Mosse, 1972; Powel, 1977; Kormanik \& McGraw, 1982; Graham et al., 1982; Cardoso, 1986; Pacovsky et al., 1985; 1986a; Pacovsky, 1989a), a qual é dependente dos fatores anteriormente citados. Hamel et al. (1990) observaram que a maior parte do micélio interno não apresentou atividade. Abbott \& Robson (1981) chamam a atenção para o fato de que a falta de relação entre infectividade e eficiência do fungo pode estar relacionada à variação do tempo necessário 
ao estabelecimento da colonização radicular, sobretudo nas culturas anuais. Lambais \& Cardoso (1988) observaram que Gigaspora margarita apresentou maior lentidão ao estabelecer simbiose com Stylosanthes guianensis, em comparação com outras duas espécies de FMAs, o que provavelmente limitou a resposta da planta à micorrização por esta espécie (Lambais \& Cardoso, 1990). A taxa de crescimento do fungo e a longevidade dos arbúsculos, podem ser dependentes tanto do balanço de fatores estimulatórios quanto inibitórios produzidos durante o desenvolvimento da micorriza, o que regula o processo de infecção (Lambais \& Mehdy, 1995). Como o crescimento relativo das plantas micorrizadas e não micorrizadas pode variar no decorrer do ciclo da cultura, conclusões errôneas podem surgir em experimentos de curta duração, com apenas uma época de coleta (Pacovsky \& Fuller, 1988).

Em condições sub-ótimas de $P$, a colonização das raízes é alta, geralmente com grandes beneficios à planta. Já em condições extremas, com níveis muito baixos ou muito altos, a interação pode causar redução no crescimento do hospedeiro, resultando na condição de parasitismo. Em cafeeiro, Colozzi-Filho \& Siqueira (1986) observaram que a magnitude dos efeitos da colonização por Gigaspora margarita foi dependente do $\mathbf{P}$ adicionado, observando-se depressão de crescimento do hospedeiro nas doses mais altas. O mesmo foi constatado por Bethlenfalvay et al. (1982c) e Fernandes et al. (1987), ambos em soja, ao passo que Antunes \& Cardoso (1991) observaram tal comportamento em citros. A constatação de depressão de crescimento em algumas associações pode estar relacionada à sua incompatibilidade funcional, e esteve associada a baixas concentrações de $P$ na planta, indicando que a não compatibilidade envolveu o mecanismo de absorção de $\mathbf{P}$ pelas raizes micorrizadas (Jakobsen, 1995). Em níveis muito baixos de $\mathrm{P}$, a diminuição de crescimento pode ser devida à competição entre os simbiontes (Bethlenfalvay et al., 1983). Crescimento parasítico, com redução de crescimento do hospedeiro, também pode ser observado nas primeiras fases do estabelecimento da associação, quando há grande deslocamento de fotoassimilados deste para o endófito (Stribley et al., 1980; Bethlenfalvay et al., 1982b). Assim, a relação hospedeiro-endófito varia entre parasitismo e mutualismo dependendo dos níveis de $\mathrm{P}$ disponível no solo (Bethlenfalvay et al., 1982a, b, d, 1983). Conforme Bethlenfalvay et al. 
(1982e), se o P disponível não for limitante no início do desenvolvimento da planta, respostas positivas à micorrização poderão não ser observadas. No entanto, à medida que o P é absorvido pela planta, sua disponibilidade no substrato tende a diminuir, podendo tornar-se limitante. Nesta fase, a absorção poderá ser incrementada pelas hifas do FMA, auxiliando no crescimento da planta.

Numa associação tripla, envolvendo FMA-soja-rizóbio, a limitação de P no substrato levou à menor nodulação em conseqüência da competição por carboidratos e $P$ entre os simbiontes (Bethlenfalfay et al., 1982d; 1983). Harris et al. (1985), observaram redução de $50 \%$ do teor de amido nas folhas de soja inoculadas com estes dois simbiontes em relação ao controle, embora tenham apresentado maiores concentrações de $\mathrm{N}$ e P. Pacovsky et al. (1985) também atribuíram o menor teor de $\mathrm{N}$ nas folhas de sorgo, associado a Azospirilium brasiliensis e FMA, à competição por carboidratos entre eles. Em compensação, foram observados por Pacovsky et al. (1986c), aumentos na área foliar de soja em associação tripla, resultando em maior fotossíntese, com aumento da capacidade da planta em suprir a demanda mais intensa por carboidratos em conseqüência do estabelecimento dos simbiontes.

$\mathrm{O}$ mecanismo pelo qual o $\mathrm{P}$ influencia a colonização radicular não é bem conhecido. Minhoni et al. (1993a, b) encontraram que a colonização de raízes de soja foi favorecida em dose baixa de fosfato solúvel, ocorrendo sua inibição nas doses mais elevadas, sendo o mesmo constatado por Lambert et al. (1979), Paula et al. (1990), Siqueira et al. (1984), Fernandes et al. (1987) e Lambais \& Cardoso (1988). Na busca de sua elucidação, diversos autores têm estudado mudanças na fisiologia do hospedeiro e expressão gênica decorrentes da simbiose. Harris et al. (1985) observaram aumentos da ordem de $50 \%$ na taxa de incorporação de $\mathrm{C}^{14}$ quando plantas de soja foram associadas a FMAs e Rizóbio ao mesmo tempo. Pacovsky (1989a) observou mudanças bioquímicas em carboidratos, proteínas, lipídios e aminoácidos em soja colonizada por FMA e sugeriu que estas mudanças podem estar relacionadas à variações na concentração de macronutrientes. A associação com FMAs não altera somente a habilidade do hospedeiro em adquirir nutrientes essenciais, mas também altera o particionamento de metabólitos dentro do mesmo (Pacovsky, 1989b). Conforme Hampp (1995), altos níveis de fósforo 
inorgânico (Pi) limitam o fluxo de carboidratos para as raízes. Em trevo, constatou-se baixa porcentagem de conversão de raízes em micorriza, coincidindo com baixos níveis de carboidratos solúveis nas mesmas quando foram fornecidos altos níveis deste elemento. Outro estudo, também com trevo, mostrou que baixos níveis de P levaram ao aumento da exsudação de carboidratos solúveis pelas raízes o que, segundo o autor, atrairia os fungos e aumentaria a micorrização. Siqueira et al. (1984) sugerem que o nível de colonização das raízes pelos FMAs é controlado pelo metabolismo de carboidratos do hospedeiro, o que é controlado pelo seu estado nutricional em P. Nagahashi et al. (1996) sugeriram que o nível de $\mathbf{P}$ no hospedeiro pode alterar a quantidade ou qualidade dos exsudatos radiculares.

Lambais \& Mehdy (1993) observaram, numa associação entre FMA e feijão, que a presença do fungo levou a uma supressão de enzimas relacionadas à defesa da planta contra patógenos mais intensa quando estas foram cultivadas sob baixa disponibilidade de $P$. Essa diminuição da atividade enzimática coincidiu com a redução do mRNA codificador dessa enzima. Os resultados sugeriram que houve supressão das respostas de defesa durante o desenvolvimento da micorriza, e que a intensidade dessa supressão foi dependente dos níveis de $\mathrm{P}$ sob os quais a planta hospedeira foi cultivada.

A regulação diferencial de vários genes da planta relacionados à defesa durante o desenvolvimento da micorriza sugere que pode existir um mecanismo ativo de reconhecimento que, sob condições ambientais adequadas à simbiose, como a baixa disponibilidade de $\mathrm{P}$, possibilita seu completo estabelecimento, com respostas positivas ao crescimento da planta (Lambais \& Mehdy, 1995).

A natureza mutualística da simbiose baseia-se no fato de que, através da fotossintese, a planta fornece energia e carbono para o fungo (estima-se que $10 \%$ do $\mathrm{C}-\mathrm{C}_{2}$ fixado pela planta é deslocado para o fungo), enquanto este absorve nutrientes minerais e água do solo, transferindo-os para a planta hospedeira (Harris et al., 1985; Siqueira, 1994). Assim, o crescimento do hospedeiro em resposta à associação com os FMAs é determinado por dois processos opostos: um efeito estimulatório devido aos aumentos na absorção de $\mathrm{P}$, acompanhado de um efeito negativo causado pelo dreno de carboidratos que o fungo causa à planta (Stribley et al., 1980). 
Apesar de todas as vantagens decorrentes deste tipo de associação, a possibilidade da sua utilização mais imediata tem se restringido à recuperação de áreas degradadas ou a culturas cujas mudas são produzidas em viveiros. Isto ocorre porque a produção de inoculantes dos FMA é deficiente, pois ainda não se conseguiu cultivá-los em meio artificial. Sob este aspecto, pesquisas comumente vêm buscando condições ideais para a associação que the possibilite expressar todo seu potencial, por meio do manejo das práticas agrícolas (Paula et al., 1990; Silveira, 1992; Hungria et al., 1994).

Conforme citado por Cardoso (1985 e 1986); Antunes \& Cardoso, 1991), vários autores deixam claro que o efeito das micorrizas arbusculares são mais acentuados em condições inadequadas de disponibilidade de $P$, e que as plantas micorrizadas têm acesso às mesmas formas de $\mathrm{P}$ que as não micorrizadas (Nurlaeny et al., 1996), porém tornam-se mais eficientes no tempo e espaço em aproveitar o $P$ lábil do solo (Pacovsky \& Fuller, 1986). A micorrização representa um importante mecanismo de maximização do uso dos fertilizantes fosfatados aplicados aos solos deficientes e com elevada capacidade de fixação, como os predominantes nos trópicos, podendo contribuir para a redução da necessidade de $\mathbf{P}$ das culturas (Siqueira, 1994). Aumentos na absorção de $\mathrm{P}$ é considerado o principal mecanismo pelo qual a micorriza favorece $\mathrm{O}$ desenvolvimento vegetal, com efeitos diretos sobre a produção de massa seca de parte aérea e raízes, nodulação e conseqüente fixação de $\mathrm{N}$, quando a simbiose envolve leguminosas, como a soja (Bethlenfalvay et al., 1982d; Cardoso, 1985; 1986; Harris et al., 1985; Pacovsky et al., 1986c).

Embora a interação positiva entre os FMAs e Rizóbio seja atribuída a uma base nutricional, são sugeridos outros efeitos secundários (Barea \& Azcón-Aguilar, 1983) como: produção de compostos que aumentam a permeabilidade celular, facilitando a infecção dos microssimbiontes, bem como a produção de substâncias reguladoras de crescimento, as quais podem promover mudanças fisiológicas e morfológicas no hospedeiro, favorecendo o estabelecimento da simbiose. Outro fato que merece destaque é a observação de que, em muitos casos, a micorrização tem levado à diminuição nos teores de Mn na planta (Cardoso, 1985; Pacovsky, 1986; Pacovsky et al., 1985, 1986a, b; Fernandes et al., 1987, Pacovsky \& Fuller, 1988), o que é de grande 
importância principalmente em solos ácidos, uma vez que o excesso desse nutriente na planta influencia negativamente a fixação biológica de nitrogênio (Pacovsky et al., 1986b).

Estudando parâmetros cinéticos da absorção de $\mathrm{P}$ por raízes de soja micorrizada e não micorrizada em solução nutritiva, Karunaratne et al. (1986) observaram que as primeiras não apresentaram aumento da afinidade por $\mathrm{P}$ (diminuição do $K_{m}$ - Constante de Michaelis, a qual representa a concentração de substrato que propicia metade da velocidade máxima de absorção $-V_{\text {máx }}$ ) mas apenas um aumento dos valores de $\mathrm{V}_{\text {maxx }}$, indicando apenas o aumento do número de sítios de absorção de $\mathrm{P}$ por unidade de área da raiz micorrizada. Por outro lado, Silveira \& Cardoso (1990), utilizando-se de plantas de feijão, observaram que além do aumento do $V_{\max }$ houve diminuição do $\mathrm{C}_{\min }$ (concentração mínima que possibilita absorção contra um gradiente de concentração) nas plantas micorrizadas indicando que estas ainda conseguem absorver $P$ da solução contra um gradiente de concentração, no qual uma planta não micorrizada não conseguiria. Houve também diminuição do $\mathrm{K}_{\mathrm{m}}$, ou seja, aumento da afinidade das raízes por $\mathrm{P}$, sendo que estes parâmetros variaram com a espécie fúngica empregada. Faquin et al. (1990) observaram que plantas de soja micorrizadas, quando cultivadas a um nível nutricional considerado baixo, exauriram mais rapidamente o $P$ da solução do que as não micorrizadas. Essa diferença diminuiu com o aumento do nível de nutrição, levando a uma inversão das tendências anteriormente observadas. No menor nível de nutrição, as plantas colonizadas apresentaram valores de $\mathrm{K}_{\mathrm{m}}$ e $\mathrm{V}_{\max }, 28$ e $33 \%$, respectivamente maiores e $C_{\min } 62 \%$ menor que as não colonizadas, também concluindo que o maior influxo de $\mathbf{P}$ foi devido ao aumento do número de sítios de absorção e não um aumento da afinidade do mecanismos de absorção pelo $P$.

Aos $40 \mathrm{~d}$ do desenvolvimento da cultura da soja, Paula et al. (1990) não encontraram diferenças significativas na produção de massa seca pela parte aérea quando as plantas foram inoculadas com diferentes combinações de fungos micorrízicos em solo fumigado e com $11 \mathrm{mg} \mathrm{kg}^{-1}$ de $\mathrm{P}$ disponível. $\mathrm{O}$ mesmo foi observado em relação ao tratamento não inoculado que recebeu $P$ na dose de $400 \mathrm{mg} \mathrm{kg}^{-1} \mathrm{e}$ à testemunha absoluta (sem adição de $\mathrm{P}$ e sem inoculação). Contudo, ao final do ciclo da cultura, 
constataram que a adição de $\mathrm{P}$ resultou na produção de massa seca e grãos pela soja equivalente aos tratamentos em condições sub-ótimas de $\mathrm{P}$, mas que foram inoculadas com os FMAs. Aos 80 dias, para três dos inóculos testados (nos quais predominou $G$. etunicatum), a produção de massa seca pela parte aérea relativa à testemunha absoluta foi maior que $90 \%$, ressaltando a alta dependência micorrízica da soja e a maior eficiência e infectividade desta espécie de fungo, o que foi atribuido às características intrínsecas da própria espécie. Para Jakobsen (1995), diferenças na eficiência simbiótica entre os fungos micorrízicos parecem estar muito mais relacionadas ao transporte de $\mathrm{P}$ pelos diferentes fungos do que à quantidade de $\mathrm{C}$ que cada um consome do hospedeiro.

Maiores concentrações de $\mathbf{P}$ têm sido observadas nas fases iniciais do desenvolvimento da cultura da soja, com redução nas demais épocas. Essa redução durante o ciclo, que geralmente é maior nas plantas micorrizadas, está relacionada à translocação desse nutriente para as partes reprodutivas e utilização na produção de grãos (Faquin, 1988).

Trabalho realizado por Cardoso (1985), empregando fosfato natural em combinação ou não com Glomus fasciculatum ou G. fasciculatum + Gigaspora margarita revelou que o fosfato natural e os fungos micorrizicos tiveram efeito positivo sobre o crescimento, absorção de nutrientes e produção da soja, além de aumentar sua nodulação. Maior desenvolvimento vegetal e nodulação foram observados no tratamento que combinava fosfato natural e fungos micorrízicos. Constatou-se ainda, que a micorrização elevou os teores de $\mathrm{Zn}$ e P na parte aérea da soja e causou diminuição nos teores de Mg e Mn. Paula et al. (1990) observaram correlação positiva entre colonização e teor de $P$ na planta aos 60 dias $\left(R=0,86^{* *}\right)$ e entre colonização aos 60 dias e produção de grãos $\left(\mathrm{R}=0,89^{* *}\right)$, sendo que as populações mais infectivas proporcionaram maior absorção de P e produção de grãos. Pacovsky et al. (1986b) e Pacovsky \& Fuller (1988) observaram aumentos na absorção de $\mathrm{Cu}$ em plantas de soja micorrizadas. Contudo, houve diminuição na concentração deste elemento quando as plantas também foram inoculadas com rizóbio. Como este comportamento não esteve relacionado com a absorção de $\mathrm{N}$ e $\mathrm{P}$, os autores sugeriram que a presença do fungo levou a uma absorção iônica seletiva. Aumentos na capacidade de absorção de nutrientes por raízes 
micorrizadas e alterações nos requerimentos minerais em decorrência da simbiose, podem também afetar a absorção e redistribuição de micronutrientes (Pacovsky, 1986; Pacovsky et al., 1986b). Mudanças nos niveis de colonização em função da disponibilidade de P no substrato leva a grandes alterações na absorção, translocação e assimilação de certos elementos. Portanto, comparações de concentração de nutrientes entre plantas em diferentes pontos ao longo da curva de fornecimento de $\mathrm{P}$ podem refletir mecanismos diversos, e não simplesmente efeito da micorrização (Colozzi-Filho \& Siqueira, 1986), da mesma forma que são observadas complexas interações entre a nutrição por $\mathrm{P}$ e absorção de micronutrientes (Lambert et al., 1979).

Minhoni et al. (1993a, b) observaram que a adição de uma fonte de carbono, em conjunto com o fosfato de rocha, não propiciou efeitos significativos sobre as variáveis: crescimento vegetal e acúmulo de $\mathrm{N}$ e P pela soja. Quando comparações foram feitas com relação ao uso de fosfato solúvel, as plantas micorrizadas que receberam fosfato de rocha tiveram crescimento e absorção de nutrientes equivalentes às que receberam maiores doses do fosfato solúvel. A presença do fungo micorrízico, associado ao fornecimento de fosfato natural, tendeu a aumentar, em relação ao tratamento sem micorriza, a massa seca da parte aérea, massa seca e número de nódulos em cerca de três, duzentas e cem vezes, respectivamente. Incrementos expressivos na nodulação de plantas de soja micorrizadas também foram observados por Harris et al. (1985), Cardoso (1985, 1986), Pacovsky et al. (1986c), sempre quando os níveis de P no solo foram limitantes.

Em condições de solo não esterilizado, a inoculação de fungos micorrízicos só seria benéfica às plantas se estes fossem mais eficientes que os nativos ou possuíssem maior infectividade (Abbott \& Robson, 1981). Conforme Cardoso (1986), dependendo do solo estudado, ao se inocular com o mesmo fungo micorrízico uma amostra esterilizada e uma não esterilizada, pode-se observar ou não, efeitos positivos na massa seca da parte aérea e vagens, número e peso de nódulos e conteúdo total de alguns nutrientes vegetais, neste último solo. Em cada condição, a presença de fungos nativos no solo natural contribui para a nutrição mineral das plantas, e o efeito do fungo adicionado pode não ser observado. Os fungos Glomus macrocarpum e Gigaspora heterogama, 
tanto no solo natural, quanto no esterilizado, levaram a aumentos significativos das variáveis avaliadas, com maior destaque para o primeiro.

Ao utilizar um solo de cerrado natural, fumigado ou natural e inoculado com G. macrocarpum que recebeu 0, 15, 30, 60, 120 e $240 \mathrm{mg} \mathrm{kg}^{-1}$ de $\mathrm{P}_{2} \mathrm{O}_{5}$ na forma de superfosfato simples, Siqueira \& Paula (1986) observaram que as plantas de soja colonizadas com este fungo apresentaram concentrações mais elevadas de $\mathbf{P}$ do que as cultivadas em solo fumigado e solo natural (colonizadas pelos fungos nativos), em todas as doses de $\mathrm{P}$. A porcentagem de $\mathrm{P}$ na planta teve um aumento até a dose de $60 \mathrm{mg} \mathrm{kg}^{-1}$ de $\mathrm{P}_{2} \mathrm{O}_{5}$, havendo pouca alteração a partir desta dose. Já o total de $\mathrm{P}$ acumulado aumentou com a dose do nutriente, com maior destaque aos tratamentos inoculados com o fungo micorrízico. No entanto, a presença de G. macrocarpum causou redução nos teores de $\mathrm{K}, \mathrm{Mg}, \mathrm{Zn}$ e $\mathrm{Cu}$, fato este atribuído a um efeito diluição destes nutrientes, com o maior crescimento vegetativo da soja. Também observou-se que o maior acúmulo de $P$ em relação ao solo fumigado ocorreu na inoculação com G. macrocarpum e o menor, no solo natural, evidenciando uma baixa eficiência dos fungos nativos, fato também observado por Paula et al. (1988). O índice de aproveitamento de $P$ foi cerca de duas vezes maior nas plantas colonizadas com G. macrocarpum para todas as doses de $\mathrm{P}, \mathrm{o}$ que foi atribuído à maior capacidade absortiva da planta colonizada. A inoculação deste fungo, juntamente com a aplicação de $30 \mathrm{mg} \mathrm{kg}^{-1}$ de $\mathrm{P}_{2} \mathrm{O}_{5}$, propiciou produção equivalente a que foi obtida quando se aplicaram $240 \mathrm{mg} \mathrm{kg}^{-1}$ de $\mathrm{P}_{2} \mathrm{O}_{5}$ sem inoculação, mostrando que a presença do fungo foi equivalente a $210 \mathrm{mg} \mathrm{kg}^{-1}$ de $\mathrm{P}_{2} \mathrm{O}_{5}$, indicando o potencial de uso deste fungo para a sojicultura brasileira.

Uma vez que tanto a infectividade quanto a eficiência simbiótica de diferentes fungos variam grandemente para as várias combinações fungo-planta e condições ambientais, surge a necessidade de se selecionar fungos mais infectivos e eficientes para as culturas e condições onde se pretende explorar esta simbiose (Paula et al., 1988). Estes mesmos autores, avaliando os efeitos de oito populações de FMAs isolados de diversas regiões, sobre o crescimento, produção e nutrição mineral da soja, obtiveram que, em solo não esterilizado, os inóculos introduzidos não diferiram entre si 
quanto aos parâmetros estudados, como também não foram mais eficientes que os fungos nativos.

Apesar da colonização pelos FMAs apresentar duas fases, a interna e a externa à raiz, esta última não tem recebido atenção adequada, mesmo sendo a parte responsável pela absorção e redistribuição de nutrientes. Assim, são necessários estudos que tornem mais claras as relações entre colonização radicular, produção de hifa externa e resposta do hospedeiro (Sylvia, 1992). Além do mais, têm surgido evidências de que os aumentos de crescimento do hospedeiro na presença do FMA nem sempre estão diretamente ligados ao incremento da nutrição mineral devido à colonização pelo endófito (Harris et al., 1985; Pacovsky et al., 1986a). Sob este aspecto, alguns autores têm voltado suas atenções para o estudo da relação entre o micélio interno e o externo à raiz (Abbott \& Robson, 1985; Bethlenfalvay et al., 1982a; Graham et al., 1982) e seu impacto no crescimento da planta hospedeira (Abbott et al., 1984; Bethlenfalvay et al., 1982c). A falta de informações sobre o micélio externo, geralmente é atribuída à dificuldade de determinar a colonização do solo (Graham et al., 1982; Abbott et al., 1984) e os resultados encontrados são muitas vezes controvertidos devido aos diversos métodos empregados na sua avaliação (Graham et al., 1982; Pacovsky \& Bethlenfalvay, 1982).

Usando um método indireto de quantificação de micélio externo (pesagem do solo aderido à raiz), Graham et al. (1982) obtiveram resultados que sugeriram que diferentes isolados de FMAs podem diferir em sua capacidade de desenvolver hifa externa, independente da capacidade de colonizar o córtex do hospedeiro, o que também foi observado por Abbott \& Robson (1985), os quais utilizaram um método direto de quantificação. Desta forma, não se pode assumir que altos níveis de colonização necessariamente resultam em desenvolvimento do micélio no solo de maneira proporcional, uma vez que estes autores observaram extensiva colonização radicular do hospedeiro pelos FMAs, sem no entanto observarem respostas de crescimento, para alguns isolados, justamente os que apresentaram menor extensão de micélio externo. Sugeriram então, que o estudo do micélio externo pode explicar melhor este comportamento do que quando se baseia apenas nos níveis de colonização. 
O direcionamento da resposta de crescimento da planta pode variar com a proporção de micélio fúngico intra e extrarradicular (Abbott \& Robson, 1981; Bethlenfalvay et al., 1982c). Desta forma, respostas negativas do crescimento do hospedeiro ou parasitismo, podem ser resultado de um grande crescimento intrarradicular do fungo na ausência de micélio extrarradicular suficiente (Bethlenfalvay et al., 1982c).

Para a quantificação do micélio externo, é preciso que este seja extraído da matriz do solo. O método que emprega a extração e contagem do micélio em membrana quadriculada (Miller et al., 1987; Sylvia, 1988), é realizado pela pesagem de uma amostra de solo, adição de um volume conhecido de água ou solução tampão, agitação dessa suspensão, peneiramento, coloração com o corante adequado, filtração a vácuo em membrana de filtração quadriculada e quantificação sob microscópio, contando-se os segmentos do micélio que interceptam as linhas horizontais numa área conhecida da membrana. Considerando-se a umidade do solo original, as diluições durante a extração e o número de interseções nas linhas horizontais da membrana, aplicase a equação de Newman (1966) para se estimar o comprimento de micélio por grama de solo seco. Outros métodos de extração foram utilizados por Schubert et al. (1987) e Cardoso Filho (1994), sendo que este último autor apresentou um método de extração relativamente prático, baseado nos dois métodos citados anteriormente, o qual foi novamente adaptado por Melloni (1996).

Uma limitação do método de contagem do micélio em membrana quadriculada é que as hifas de fungos não micorrízicos não são facilmente distinguiveis daquelas produzidas pelos FMAs, por não haver diferenças morfológicas ou de coloração expressivas entre ambas (Abbott et al., 1984; Abbott \& Robson, 1985; Sylvia, 1992). Para tentar contornar este problema, alguns autores (Abbott et al., 1984; Abbott \& Robson, 1985; Sylvia, 1992; Kabir et al., 1996) assumiram que a quantidade de micélio obtida num tratamento sem FMA pode ser subtraída das amostras tratadas com FMAs, porém são unânimes em concordar que a não consideração de uma possível interação entre estes dois grupos de fungos pode levar a erros e que estudos mais detalhados devem ser realizados. Atualmente, no estudo de micélio extrarradicular, predomina o método de contagem em membrana. O desenvolvimento de métodos baseados em 
estudos de DNA, ácidos graxos específicos ou métodos imunológicos possibilitaria o reconhecimento preciso de hifas de FMA no solo (Frey et al., 1994; Kabir et al., 1996).

Os fatores que afetam a colonização micorrízica também atuam na porção externa da simbiose (Bethlenfalvay \& Ames, 1987), como a disponibilidade de $P$ (Sylvia, 1992; Hampp, 1995; Nagahashi et al., 1996) e a presença de hospedeiros micotróficos (Kabir et al., 1996). Abbott et al. (1984) observaram que a hifa externa foi estimulada a crescer quando pequenas quantidades de $\mathbf{P}$ foram adicionadas, enquanto maiores adições levaram à diminuição de seu crescimento a taxas maiores que as observadas para os decréscimos de colonização radicular. Nagahashi et al. (1996) observaram que exsudatos de raízes crescendo sob altos níveis de $\mathrm{P}$ levaram à menor ramificação das hifas de Gigaspora margarita, em relação àquelas expostas aos exsudatos produzidos por raízes estressadas em P. O mesmo foi observado por Elias \& Safir (1987) com relação ao comprimento de hifa de Glomus fasciculatus.

Melloni (1996) observou, dependendo do hospedeiro, correlação positiva entre o comprimento de micélio extrarradicular total (MET) e adição de $\mathbf{P}$ ao substrato, sendo as mesmas tendências observadas por Crush (1976), Cardoso-Filho (1994), Melloni et al. (1996) e Gomes (1997). Contudo, estes resultados contrariam as observações de Abbott \& Robson (1985), Miller et al. (1987), Miranda et al. (1989) e Miranda \& Harris (1994a,b) cujos dados revelaram decréscimo nas quantidades de MET com o incremento do teor de P na planta.

As estruturas fúngicas, internas e externas à raiz da soja, desenvolvemse a diferentes taxas e são afetadas diretamente pelo desenvolvimento da planta hospedeira (Pacovsky, 1989a). Gomes (1997) não encontrou boa correlação entre o comprimento do MET e a porcentagem de colonização radicular de plantas cítricas. Grandes variações na distribuição de hifas também podem ocorrer devido aos fatores do solo (Abbott \& Robson, 1985), o que geralmente é atribuído a questões adaptativas da espécie frente às condições edáficas a que é submetida (Abbott \& Robson, 1984).

Embora métodos colorimétricos, de contagem direta sob microscópio e indiretos (quitina) tenham sido empregados na quantificação do micélio total externo, métodos que diferenciem entre a hifa viva (ativa) e a não ativa são de grande interesse 
(Bethlenfalvay \& Ames, 1987; Schubert et al., 1987), visto que a absorção de P pelas hifas fúngicas se dá por processo ativo (Sanders et al., 1977).

Vários autores têm proposto o uso de diacetato de fluoresceína (FDA) para a determinação da parte ativa do micélio extrarradicular ou micélio externo ativo (MEA)(Ames et al., 1982; Schubert et al., 1987; Hamel et al., 1990; Sylvia, 1992). O FDA é usado como um indicador da atividade de esterases, as quais são enzimas envolvidas na hidrólise de ésteres de ácidos graxos, reserva de energia para a maioria das células vivas. Este corante sendo apolar, passa rapidamente através da parede celular e membrana plasmática do micélio. Em seguida é hidrolisado pela esterase, permanecendo a fluoresceína, a qual se torna fluorescente quando excitada com luz ultravioleta, emitindo uma luz verde-amarelada.

Schubert et al. (1987) utilizando-se de FDA para a determinação do MEA, observaram que no início da interação, a porcentagem de micélio ativo em relação ao total, foi de aproximadamente $100 \%$, diminuindo para menos de $15 \%$ nas fases finais. Observou, ainda, que a fluorescência das hifas foi irregular, envolvendo apenas porções limitadas, ou seja, no mesmo micélio foram observadas regiões ativas e não ativas, sendo que poucas hifas foram completamente fluorescentes, o que geralmente ocorreu nas fases iniciais do estabelecimento da simbiose. Com estas observações os autores sugeriram que o micélio externo é composto por duas partes: a fluorescente e provavelmente viável, que pode absorver e translocar $P$ e posteriormente, uma parte não fluorescente e provavelmente não viável, que pode apenas fazer a translocação.

Gomes (1997) observou que o comprimento de MEA variou com o hospedeiro e com a espécie de fungo micorrízico estudado, além de ser influenciado negativamente pelo aumento de doses de $\mathbf{P}$ adicionadas ao substrato. Comportamentos semelhantes foram observados por Melloni (1996). 


\section{MATERIAL E MÉTODOS}

\subsection{Instalação do experimento}

O experimento foi instalado e conduzido em casa-de-vegetação nas dependências do Departamento de Ciência do Solo da Escola Superior de Agricultura 'Luiz de Queiroz", Piracicaba, estado de São Paulo, no período de setembro a dezembro de 1996.

O substrato utilizado foi constituído pela mistura $(\mathrm{v} / \mathrm{v})$ de três partes de um solo classificado como Areia Quartzosa, série Paredão Vermelho, distrófico, obtido na camada de 0-20 cm, no município de Piracicaba (seco ao ar, peneirado em peneira de malha de $4 \mathrm{~mm}$ ) e uma parte de areia de rio também peneirada $(<2 \mathrm{~mm})$, lavada por 5 vezes. A mistura teve como finalidade facilitar a remoção das raízes das plantas e o micélio externo.

Após a homogeneização dos constituintes do substrato foi feita a esterilização do mesmo em autoclave por duas horas a $121^{\circ} \mathrm{C}$ ( 1 atm de pressão), com finalidade de inviabilizar propágulos de fungos micorrízicos nativos. Uma amostra composta por 10 sub-amostras foi retirada antes e outra após a autoclavagem e submetidas à análise química para fins de fertilidade no Laboratório de Análises de Solos da ESALQ. Os resultados obtidos estão expressos na Tabela 1.

De acordo com os resultados apresentados na Tabela 1, foi calculada a necessidade de calagem baseando-se na elevação do índice de saturação por bases (V), visando-se sua elevação a $80 \%$ da CTC, bem como a necessidade de adubação recomendada para a cultura da soja no estado de São Paulo (Raij et al., 1985). O substrato, após receber $0,67 \mathrm{~g} \mathrm{~kg}^{-1}$ de calcário dolomítico (PRNT 131\%), foi umedecido a $70 \%$ da capacidade de campo com água destilada e incubado por 15 dias. Após este 
período, foi adicionado a cada quilo do substrato: $0,04 \mathrm{~g}$ de $\mathrm{KCl}\left(50 \% \mathrm{~K}_{2} \mathrm{O}\right)$ e $0,04 \mathrm{~g}$ de gesso $\left(\mathrm{Ca}_{2} \mathrm{SO}_{4} \cdot 2 \mathrm{H}_{2} \mathrm{O}, 18 \% \mathrm{~S}\right)$. Não foi fornecido $\mathrm{N}$ mineral.

Tabela 1. Características químicas antes (1) e após (2) a autoclavagem do substrato utilizado no experimento.

\begin{tabular}{|c|c|c|c|c|c|c|c|c|c|c|c|}
\hline \multirow{2}{*}{\multicolumn{2}{|c|}{$\underset{\mathrm{pH}}{\mathrm{CaCl}_{2}}$}} & \multirow{2}{*}{$\begin{array}{l}\text { M.O. } \\
\mathrm{g} \mathrm{dm}^{-3}\end{array}$} & \multirow{2}{*}{$\frac{\mathrm{PS} \mathrm{S}^{\mathrm{SOO}} \mathrm{SO}_{4}}{\mathrm{mg} \mathrm{dm}^{-3}}$} & $\mathbf{K}^{+}$ & $\mathrm{Ca}^{2+}$ & $\mathrm{Mg}^{2+}$ & $\mathrm{Al}^{3+}$ & $\mathrm{H}+\mathrm{Al}$ & SB & $\mathrm{T}$ & $\mathrm{V} \mathrm{m}$ \\
\hline & & & & \multicolumn{7}{|c|}{$\mathrm{mmol}_{\mathrm{c}} \mathrm{dm}^{-3}$} & $\%$ \\
\hline (1) & 4,2 & 14 & $6 \quad 22,41$ & 0,4 & 5 & 3 & 10 & 31 & 8 & 39 & 2156 \\
\hline \multirow[t]{3}{*}{ (2) } & 4,0 & 15 & 14,25 & 0,4 & 5 & 2 & 11 & 31 & 7 & 38 & $18 \quad 61$ \\
\hline & \multicolumn{11}{|c|}{ micronutrientes $\left(\mathrm{mg} \mathrm{kg}^{-1}\right)$} \\
\hline & \multicolumn{2}{|c|}{ B } & $\mathrm{Cu}$ & \multicolumn{2}{|c|}{$\mathrm{Fe}$} & \multicolumn{2}{|c|}{$\mathrm{Mn}$} & \multicolumn{3}{|c|}{$\mathrm{Zn}$} & $\mathrm{Na}$ \\
\hline (1) & \multicolumn{2}{|c|}{0,06} & 0,64 & \multicolumn{2}{|c|}{90} & \multicolumn{2}{|c|}{3,18} & \multicolumn{2}{|r|}{1,58} & & 4,6 \\
\hline (2) & \multicolumn{2}{|c|}{0,03} & 0,42 & \multicolumn{2}{|c|}{93} & \multicolumn{2}{|c|}{10,92} & \multicolumn{2}{|r|}{1,62} & & 4,6 \\
\hline
\end{tabular}

A unidade experimental foi constituída por vasos de cerâmica com capacidade para $4 \mathrm{~L}$ do substrato, impermeabilizados internamente com "neutrol" desinfestados com "Lysoform", antes de receberem $4 \mathrm{~kg}$ do substrato, o que correspondeu a um volume de $3 \mathrm{~L}$.

$O$ delineamento experimental utilizado foi inteiramente casualizado, em esquema fatorial $3 \times 5 \times 4$, com 3 repetições, sendo 3 os níveis do fator fungos micorrizicos (controle, Glomus intraradices e Gigaspora margarita), 5 os niveis do fator doses de $\mathrm{P}\left(0,25,50,100,200 \mathrm{mg} \mathrm{kg}^{-1}\right.$ de substrato) na forma de superfosfato triplo previamente moído $(<0,5 \mathrm{~mm}$ ) (Tabela 2) e 4 os níveis do fator épocas de avaliação (15, 30,60 e 90 dias após o transplantio), perfazendo um total de 180 parcelas.

Tabela 2. Composição e solubilidade do superfosfato triplo utilizado no experimento (\%).

\begin{tabular}{|c|c|c|c|c|c|c|}
\hline \multirow[b]{2}{*}{ P total } & \multicolumn{3}{|c|}{ solubilidade } & \multirow[b]{2}{*}{$\mathrm{Ca}$ total } & \multirow[b]{2}{*}{ Mg total } & \multirow[b]{2}{*}{$S$ total } \\
\hline & água & CNA+água & ác. cítrico & & & \\
\hline 48,26 & 40,60 & 43,70 & 40,85 & 15,4 & 1,03 & 0,04 \\
\hline
\end{tabular}

$\mathrm{A}$ incorporação das doses de $\mathrm{P}$ foi feita juntamente com o adubo potássico e o gesso. Para isso, juntaram-se os fertilizantes e o substrato necessários para cada vaso em um saco plástico, agitando-o até que a mistura se tornasse homogênea. 
A cultivar de soja utilizada foi a IAC-8. As sementes foram desinfestadas superficialmente com hipoclorito de sódio a $2 \%$ e postas a germinar em bandeja com areia $(<2 \mathrm{~mm})$ lavada e autoclavada. Após três dias, cinco plântulas foram transplantadas para cada vaso. Em seguida, foi fornecido um volume de $5 \mathrm{~mL}$ da mistura de meio de cultura líquido para Bradyrhizobium japonicum, cultivado por 7 dias com as estirpes Semia 587 e Semia 5019, a todos os tratamentos.

A infestação do substrato com os FMAs foi feita três dias antes do transplantio. $O$ inóculo de cada espécie foi constituído por uma suspensão de esporos extraídos por peneiramento úmido (Gerdemann \& Nicolson, 1963) seguido de centrifugação em solução de sacarose para aumentar a pureza, provenientes de vasos de multiplicação em Brachiaria decumbens. $\mathrm{O}$ volume de cada suspensão foi ajustado de modo a possibilitar a obtenção de cerca de 200 esporos ao pipetar $10 \mathrm{~mL}$, os quais foram adicionados e incorporados nos $5 \mathrm{~cm}$ superficiais dos vasos. Por ocasião das pipetagens, os recipientes contendo os esporos foram agitados constantemente para evitar que estes sedimentassem. $O$ tratamento controle (sem FMA) também recebeu o mesmo volume de suspensão, porém proveniente de vasos com Brachiaria, sem FMAs, visando manter a mesma microbiota dos tratamentos que receberam FMAs.

Uma semana após o transplantio, foi feito um desbaste, mantendo-se por vaso apenas duas plântulas mais viçosas e melhor localizadas. No mesmo dia, foram adicionados micronutrientes nas quantidades de: $\mathrm{B}-0,25 \mathrm{mg} \mathrm{kg}^{-1}\left(\mathrm{H}_{3} \mathrm{BO}_{3}\right) ; \mathrm{Cu}-0,75 \mathrm{mg}$ $\mathrm{kg}^{-1}\left(\mathrm{CuSO}_{4} .5 \mathrm{H}_{2} \mathrm{O}\right)$; $\mathrm{Mo}-0,05 \mathrm{mg} \mathrm{kg}{ }^{-1}\left(\mathrm{Na}_{2} \mathrm{MoO}_{4} \cdot 2 \mathrm{H}_{2} \mathrm{O}\right)$ e $\mathrm{Zn}-2,5 \mathrm{mg} \mathrm{kg}{ }^{-1}$ $\left(\mathrm{ZnSO}_{4} \cdot 7 \mathrm{H}_{2} \mathrm{O}\right)$. O Fe foi aplicado na forma de $\mathrm{FeSO}_{4} \cdot 7 \mathrm{H}_{2} \mathrm{O}$, na dose de $2,5 \mathrm{mg} \mathrm{kg}$. Durante o período experimental, as plantas receberam irrigações diárias com água destilada, conforme as necessidades.

Dois controles de ácaro foram necessários nas plantas remanescentes para a última colheita, as quais foram pulverizadas com "Dicofol ${ }^{\circledR 》}$, , na dose de $1 \mathrm{~mL}$ do produto comercial por litro de água. 


\subsection{Análises laboratoriais das variáveis}

\subsubsection{Massa do material seco da parte aérea e vagens}

Em cada época de colheita do experimento a parte aérea das plantas (parte vegetativa e vagens, quando presentes) foi lavada em uma seqüência de água destilada e deionizada, em seguida acondicionadas em sacos de papel e levadas à estufa com circulação forçada de ar a $65^{\circ} \mathrm{C}$ até peso constante para a obtenção da massa do material seco da parte aérea (MSPA). As vagens, quando presentes, foram destacadas previamente e tratadas da mesma maneira, de modo a se obter a massa do material seco de vagens (MSV). Os resultados obtidos de MSPA nas duas épocas finais, quando as vagens estiveram presentes, incluíram a MSV.

\subsubsection{Determinação da concentração de nutrientes e total acumulado}

$O$ material seco de cada parte (vegetativa e vagens) foi moído separadamente em um moinho tipo Willey, provido de peneira de aço inoxidável de 0,42 $\mathrm{mm}$ e submetido às determinações das concentrações dos nutrientes $(\mathrm{N}, \mathrm{P}, \mathrm{K}, \mathrm{Ca}, \mathrm{Mg}, \mathrm{S}$, $\mathrm{Fe}, \mathrm{Cu}, \mathrm{Mn}, \mathrm{Zn}) . \mathrm{ON}$, após obtido o extrato sulfúrico, teve sua concentração determinada pelo método Semi-micro-Kjeldahl, descrito por Malavolta et al. (1989). A obtenção do extrato nítrico-perclórico (Sarruge \& Haag, 1974) foi utilizada para a determinação dos demais nutrientes, sendo que o $\mathrm{P}$ foi determinado por meio da colorimetria do metavanadato, S por turbidimetria do sulfato de Bário (Vitti, 1989) e os demais nutrientes por espectrofotometria de absorção atômica, cujas metodologias também são descritas por Malavolta et al. (1989).

A quantidade de nutrientes acumulada pela parte vegetativa e vagens foi calculada com base no respectivo teor destes nutrientes e na respectiva massa do material seco. A quantidade total de nutrientes acumulada pela parte aérea foi obtida pela soma das duas anteriores. Os valores obtidos para a quantidade total acumulada pela parte 
aérea nas duas primeiras épocas foi exatamente a quantidade total acumulada pela parte vegetativa, visto que nestas épocas as vagens ainda não estavam presentes.

\subsubsection{Número e massa do material seco de nódulos}

Após a remoção das raizes do substrato e lavagem, os nódulos foram destacados e contados. Em seguida, foram acondicionados em recipientes de papel e levados à estufa com circulação forçada de ar a $65^{\circ} \mathrm{C}$ até peso constante para a obtenção da massa do material seco de nódulos (MSN).

\subsubsection{Porcentagem de colonização radicular}

Após a retirada dos nódulos, as raízes das plantas foram mantidas em solução de AFA (em $4 \mathrm{~L}$ de água destilada, acrescentaram-se $500 \mathrm{~mL}$ de formol, $2 \mathrm{~L}$ de álcool etílico e $100 \mathrm{~mL}$ de ácido acético glacial) com a finalidade de conservação, até o momento da coloração.

A clarificação e coloração das raizes foi feita através do método proposto por Phillips \& Hayman (1970), utilizando-se 0,5 g do material fresco. Em seguida, a constatação e a quantificação da porcentagem de colonização radicular pelos FMAs foi feita por meio de observações destas raizes sob microscópio estereoscópio no aumento de 40 vezes pelo método proposto por Giovanneti \& Mosse (1980). Neste método, que utiliza uma placa quadriculada contendo as amostras, acompanham-se as linhas horizontais da placa e contam-se as raízes cujos pontos de intersecção possuem colonização. Simultaneamente contam-se as raizes cujos pontos de interseç̧ão com a linha não possuem colonização, de modo a obter o total de raizes que interceptam as linhas da placa. Do número total (colonizadas e não colonizadas), obtém-se a porcentagem das que possuem colonização, o que representa a porcentagem de colonização radicular. 


\subsubsection{Extração do micélio extrarradicular}

Logo após a desmontagem dos vasos para a retirada das rázes e nódulos, o substrato foi homogeneizado e uma amostra de cerca de $300 \mathrm{~g}$ foi acondicionada em saco plástico devidamente identificado e armazenada em câmara fria a $5^{\circ} \mathrm{C}$ até o momento da extração do micélio extrarradicular. Para este procedimento foi utilizado o método proposto por Cardoso-Filho (1994) e modificado por Melloni (1996), com pequenas adaptações, conforme descrito a seguir:

a) pesaram-se 2 porções de $10 \mathrm{~g}$ da amostra úmida do substrato, sendo uma destinada à metodologia de extração do micélio e a outra para a determinação do seu teor de água, seca em estufa a $105^{\circ} \mathrm{C} / 24 \mathrm{~h}$;

b) Transferiu-se a amostra para béquer de $500 \mathrm{~mL}$ de capacidade, e a ela cerca de $400 \mathrm{~mL}$ de água de torneira sob forte pressão, com a finalidade de romper os aglomerados do substrato;

c) Em seguida, a suspensão foi vertida sobre um conjunto de peneiras de 0,71 e $0,25 \mathrm{~mm}$ montadas sobre um funil, recebendo o peneirado num béquer de $2 \mathrm{~L}$, com um jato forte de água de torneira sobre as peneiras, até o volume de aproximadamente $1450 \mathrm{~mL}$. O jato de água sobre as peneiras tem a finalidade de liberar o micélio agregado nas partículas do substrato;

d) Transferiu-se as suspensão para a jarra de um liquidificador até o volume final de 1,5 L, com o auxilio de uma piceta, lavando-se as paredes do béquer;

e) Completado o volume da jarra, o liquidificador foi acionado por 10 segundos na velocidade mínima. Este tempo foi determinado previamente para este liquidificador e foi o que propiciou melhor distribuição do micélio na membrana de filtração. Em seguida, esperou-se por 2 minutos a sedimentação das partículas de areia fina e silte. Após este tempo, verteu-se a suspensão sobre uma proveta, tomando-se uma alíquota de $500 \mathrm{~mL}$;

f) A alíquota contida na proveta foi vertida sobre uma peneira de $44 \mu \mathrm{m}$ de malha, sendo o retido transferido para um vidro de penicilina, previamente calibrado a um volume de 10 $\mathrm{mL}$, com o auxílio de uma piceta contendo solução tampão fosfato, $\mathrm{pH}$ 7,4 (mistura da 
solução de $\mathrm{KH}_{2} \mathrm{PO}_{4} \quad 0,1 \mathrm{M}$ com uma solução de $\mathrm{NaOH} 0,1 \mathrm{M}$, com o auxílio do peagâmetro até o valor de $\mathrm{pH}$ desejado).

3.2.6 Determinação do comprimento de micélio extrarradicular ativo, pelo uso do método da fluorescência induzida com diacetato de fluoresceína (FDA), e comprimento de micélio extrarradicular total

Uma vez extraído o micélio do substrato, procedeu-se à determinação do comprimento de sua parte ativa e do total, segundo os seguintes procedimentos:

a) Dos $10 \mathrm{~mL}$ obtidos anteriormente, após agitação para ressuspensão do material, foram pipetados $5 \mathrm{~mL}$ e transferidos para outro frasco de penicilina. A estes $5 \mathrm{~mL}$ foi adicionado igual volume da solução com diacetato de fluoresceína preparada de acordo com Schubert (1987) e Sylvia (1992), com pequena modificação (em balão volumétrico de $100 \mathrm{~mL}$, adicionaram-se $5 \mathrm{mg}$ dos cristais de FDA, dissolvendo-os $\mathrm{em} 2 \mathrm{~mL}$ de acetona. Completou-se o volume com a solução tampão fosfato anteriormente descrita). Esperouse por um tempo mínimo de incubação de 5 minutos, à temperatura ambiente, antes de dar prosseguimento;

b) Filtração da suspensão de micélio e FDA a vácuo sobre membrana de triacetato de celulose, quadriculada $(3 \times 3 \mathrm{~mm})$, de $47 \mathrm{~mm}$ de diâmetro e $0,45 \mu \mathrm{m}$ de porosidade, lavando-se as paredes do frasco com auxílio de piceta com a solução tampão fosfato $\mathrm{pH}$ 7,4

c) Após secagem ao ar, a membrana contendo as hifas foi colocada sobre uma lâmina quadrada de $25 \mathrm{~cm}^{2}$, contendo algumas gotas de óleo de amêndoa, com a finalidade de propiciar a transmissão da luz do microscópio através da membrana até as hifas. Sobre a membrana, já acomodada na lâmina, foi colocado um demarcador plástico de $8 \times 8$ quadrículas delimitadas na membrana (64). Cada quadrícula representou um campo a ser avaliado;

d) No microscópio de epifluorescência com luz ultravioleta, acoplou-se um grid reticulado na ocular $(10 \times 10 \mathrm{~mm})$ no aumento de 10 vezes. Assim, em cada um dos 64 campos anteriormente demarcados, foi feita uma única avaliação, contando-se o número 
de vezes que as hifas fluorescentes (ativas) interceptaram as linhas horizontais do grid acoplado à ocular. O aumento da objetiva foi de 10 vezes;

e) Após a leitura de todas as lâminas sob luz ultravioleta (micélio ativo), procedeu-se à contagem das intersecções para a quantificação de micélio total. Para isso, utilizou-se do mesmo procedimento anteriormente descrito, porém sob luz branca do microscópio.

O número de intersecções obtidas anteriormente foi transformado em comprimento de micélio (ativo e total) por grama de substrato seco em estufa através da equação de Newman (1966), a qual é dada pela fórmula:

$$
\mathrm{R}=(\pi \cdot \mathrm{A} \cdot \mathrm{n}) / 2 \cdot \mathrm{H}
$$

onde:

$R=$ comprimento do micélio extrarradicular avaliado nos 64 campos na membrana $(\mathrm{mm})$;

$\mathrm{A}$ = área avaliada na membrana, no aumento considerado (10 vezes) $\left(100 \mathrm{~mm}^{2} .64\right)$;

$\mathrm{n}=$ número de intersecções das hifas nas linhas horizontais do grid da ocular reticulada;

$\mathrm{H}=$ comprimento total das linhas horizontais do grid da ocular reticulada, no aumento considerado (100 mm . 64).

Como as intersecções obtidas foram feitas por amostragem no interior de cada campo da membrana, deve-se utilizar um fator de correção para extrapolar os valores para a área total da membrana $\left(1320,25 \mathrm{~mm}^{2}\right.$ ou $132.025 \mathrm{~mm}^{2}$ no aumento de 100 vezes):

R . $(132.025 / 6.400)=20,629 \cdot \mathbf{R}$

Sabendo-se que foram tomados $5 \mathrm{~mL}$ da suspensão de micélio de um volume inicial de $10 \mathrm{~mL}$, teremos:

$20,629 \cdot R \cdot(10 / 5)=41,258 \cdot R$

A quantidade de micélio até então obtida, refere-se à alíquota de 500 $\mathrm{mL}$ obtida da jarra do liqüidificador. Para o volume inicial, no qual foram diluídos os $10 \mathrm{~g}$ de substrato úmido, teremos:

$41,258 \cdot R(1500 / 500)=123,774 . R$

Levando-se em consideração o teor de água no substrato, obteremos o $R$ total (RT): 


$$
\mathrm{RT}=123,774 \cdot \mathrm{R} /(10-\theta)
$$

onde, $\quad \theta=$ umidade .

Substituindo a eq. 1 na eq. 5 , teremos:

$$
\begin{aligned}
& \mathrm{RT}=\{123,774 \cdot[(\pi \cdot 6400 \cdot \mathrm{n}) /(2.6400)]\} /(10-\theta) \\
& \mathrm{RT}=[194,42 \cdot \mathrm{n} /(10-\theta)] / 1000 \\
& \mathrm{RT}=0,19442 \cdot \mathrm{n} /(10-\theta) \mathrm{m} \text { de micélio/g de solo seco em estufa }
\end{aligned}
$$

\subsubsection{Disponibilidade de $P$ no substrato}

Esta variável também foi avaliada em todas as épocas de colheita. Para isso, quando as parcelas foram desmontadas, e o substrato homogeneizado, foi tomada uma amostra de $100 \mathrm{~g}$, a qual foi deixada secar ao ar e passada por uma por uma peneira de malha de $2 \mathrm{~mm}$. Em seguida, o $\mathrm{P}$ disponível foi determinado pelo método da resina trocadora de íons proposto por Raij \& Quaggio (1983).

\subsubsection{Análise estatística do experimento}

Os resultados obtidos foram submetidos à análise de variância com aplicação do teste F através do software estatístico S.A.S.® (SAS Institute), ao nível de $5 \%$ de probabilidade, através do procedimento GLM. Para romper a relação entre média e variância, os dados de porcentagem de colonização radicular e número de nódulos foram previamente submetidos às transformações $\operatorname{arc} \operatorname{sen}(x / 100)^{1 / 2} \mathrm{e}(\mathrm{x}+0,5)^{1 / 2}$, respectivamente, as quais se mostraram suficientes para o propósito.

A interação entre os fatores envolvidos (quando significativa pelo teste F) foi desdobrada. Para os fatores qualitativos (FMAs) foi aplicado o teste $t$ de Student ao nível de $5 \%$ de probabilidade através do procedimento GLM, enquanto os fatores quantitativos (doses de $\mathrm{P}$ e épocas de colheita) foram submetidos às análises de regressão através dos procedimentos GLM e REG ao nível de 5\% de probabilidade pelo teste $\mathrm{F}$. 


\section{RESULTADOS E DISCUSSÃO}

Os níveis de significância nos quais o efeito dos tratamentos ou a interação entre eles foi significativa pelo teste $F(P>F)$, obtidos do quadro de análise da variância, estão demonstrados no Apêndice 1.

\subsection{Teor de fósforo $(P)$ disponível no substrato}

A disponibilidade de $\mathrm{P}$ no substrato, obtida pelo método da resina trocadora de íons (Raij \& Quaggio, 1983), foi apenas influenciada pelas doses aplicadas deste nutriente, em interação com as épocas de estudo. Assim, pela Figura 1, constatouse diminuição da disponibilidade de $\mathrm{P}$ em decorrência do tempo, especialmente nas maiores doses. Ajustes de regressão indicaram modelos quadráticos e lineares altamente significativos $(\mathbf{P}<0,01)$. Apenas $\mathbf{o}$ tratamento que não recebeu $\mathbf{P}$ não teve sua disponibilidade alterada ao longo das épocas, mantendo um nível de $4 \mathrm{mg} \mathrm{kg}^{-1}$, considerado muito baixo (Raij, 1991).

Esta diminuição da disponibilidade, em sua maior parte, foi decorrência da absorção pela planta. Como exemplo, tomando-se a quantidade total de $\mathbf{P}$ acumulado pela parte aérea das plantas do tratamento controle aos 90 dias, que foi de $236,6 \mathrm{mg}$ por parcela (obtido da Tabela 10 ), observou-se que este valor foi equivalente a cerca de $78 \%$ da redução observada, considerando-se o total disponível na parcela. $O$ restante da redução seria atribuída à quantidade acumulada pelas raizes, e pela biomassa microbiana, as quais não foram determinadas neste experimento. Pelo fato do substrato utilizado ser arenoso, a passagem do $\mathrm{P}$ disponível da forma lábil para a não lábil, em conseqüência da interação do íon fosfato com os óxidos metálicos, como os de Fe e Al (Raij, 1991), pode ter contribuído pouco para a diminuição de sua disponibilidade. 


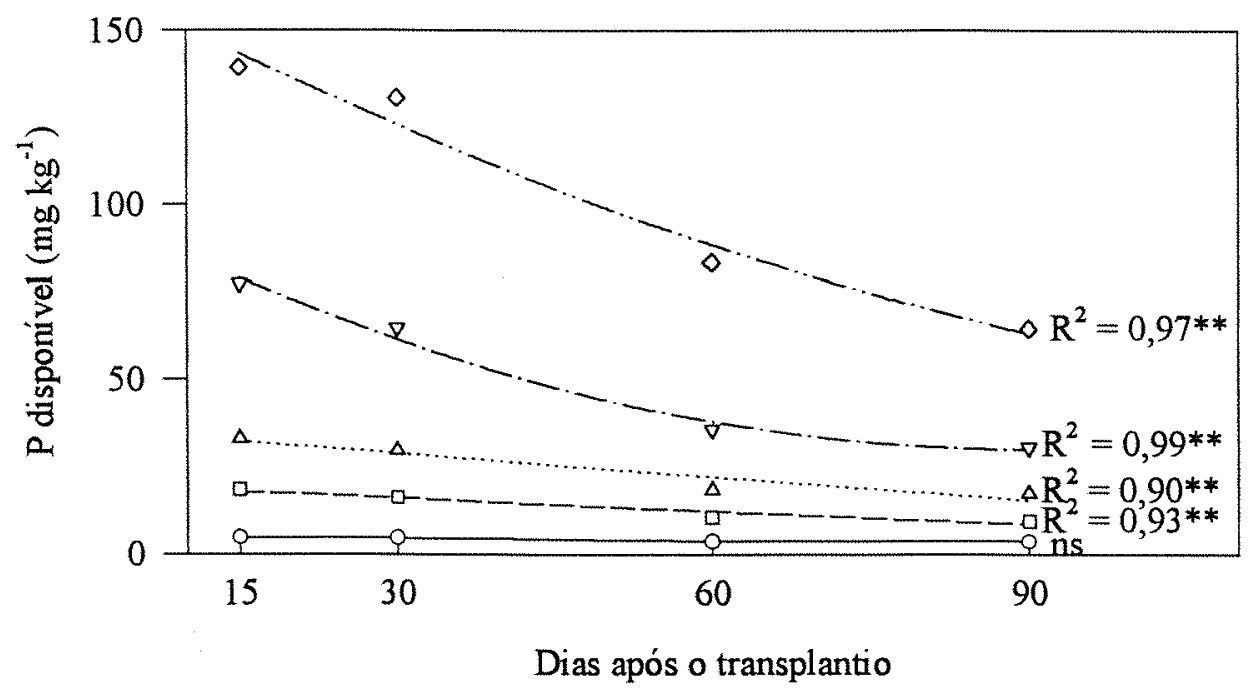

Figura 1. P disponível no substrato em função da idade da planta, para as diferentes doses de $P$ aplicadas: $O=0 ; \square=25 ; \Delta=50 ; \nabla=100$ e $\diamond=200 \mathrm{mg} \mathrm{kg}^{-1}$ de substrato. ${ }^{* *}=$ equação significativa pelo teste $\mathrm{F}(\mathrm{P}<0,01) ; \mathrm{ns}=$ equação não significativa a $\mathrm{P}<0,05$.

Não foram observados efeitos dos FMAs quanto à disponibilidade de $\mathbf{P}$ no substrato. Alguns autores têm observado maior absorção e consequentemente menor disponibilidade deste nutriente ao longo do tempo, quando as plantas estudadas estão associadas a FMAs. Bethlenfalvay et al. (1982b), Pacovsky \& Fuller (1986) e Nurlaeny et al. (1996) observaram que interação FMA e soja, causou maior depleção de P no solo rizosférico em relą̧ão às plantas não inoculadas. Isto provavelmente ocorreu em consequeência da diminuição do $\mathrm{K}_{\mathrm{m}}$ das raízes micorrizadas, conforme observado por Silveira \& Cardoso (1990), ou ainda pelo aumento do número de sítios de absorção por unidade de área de raiz, aumentando o $V_{\text {maxx }}$ (Karunaratne et al., 1986; Faquin, 1988). 


\subsection{Colonização radicular (\%)}

Os resultados de porcentagem de colonização radicular revelaram interação tripla entre os fatores estudados (Apêndice 1). Raizes de plantas que não receberam inóculo também foram submetidas à coloração e exame sob microscópio estereoscópio com aumento de 50 vezes, não sendo observado qualquer sinal de colonização, mesmo na última época de estudo, indicando que a eliminação dos endófitos nativos do substrato por autoclavagem foi eficiente. De forma semelhante, aos 15 dias também não foram observados sinais de início de colonização radicular nos tratamentos que receberam esporos de FMAs, razão pela qual esta época não foi considerada na análise estatística. Bethlenfalvay et al. (1982b) também não observaram colonização radicular aos 14 dias em plantas inoculadas com FMAs.

As primeiras constatações de colonização radicular foram feitas aos 30 dias (Figura 2). Não houve, nesta época, diferenças estatisticamente significativas entre os fungos, em qualquer dose de $P$, uma vez que estavam na fase inicial do estabelecimento da simbiose, com baixas taxas de colonização, não superiores a $4 \%$ e ainda não eram influenciados pelas doses de $P$, o que corrobora com as afirmações de Bethlenfalfay et al. (1982e), Siqueira et al. (1984) e Siqueira (1986) de que a influência de altas doses de $\mathrm{P}$ sobre o grau de colonização radicular se dá após a penetração. Na época seguinte (60 dias), puderam-se observar grandes efeitos das doses de $\mathbf{P}$ sobre um dos fungos em estudo, quando G. intraradices apresentou cerca de $75 \%$ de colonização radicular no tratamento que não recebeu $P$, a qual foi severamente afetada com $O$ incremento das doses, com uma drástica queda na variável estudada quando foram aplicados $50 \mathrm{mg} \mathrm{kg}^{-1}$. Até esta dose, G. intraradices diferiu significativamente de $G i$. margarita, apresentando maiores taxas de colonização radicular. Nas maiores doses (100 e $200 \mathrm{mg} \mathrm{kg}^{-1}$ ), não houve diferenças significativas entre os dois fungos, os quais apresentaram baixos níveis de colonização (não superiores a $5 \%$ ). É interessante notar que nesta época, Gi. margarita foi muito pouco afetado pelas doses de $\mathrm{P}$ (Figura 2), e também pouco eficiente em colonizar o hospedeiro, quando comparado a $G$. intraradices, mesmo nas menores doses de $\mathbf{P}$. 


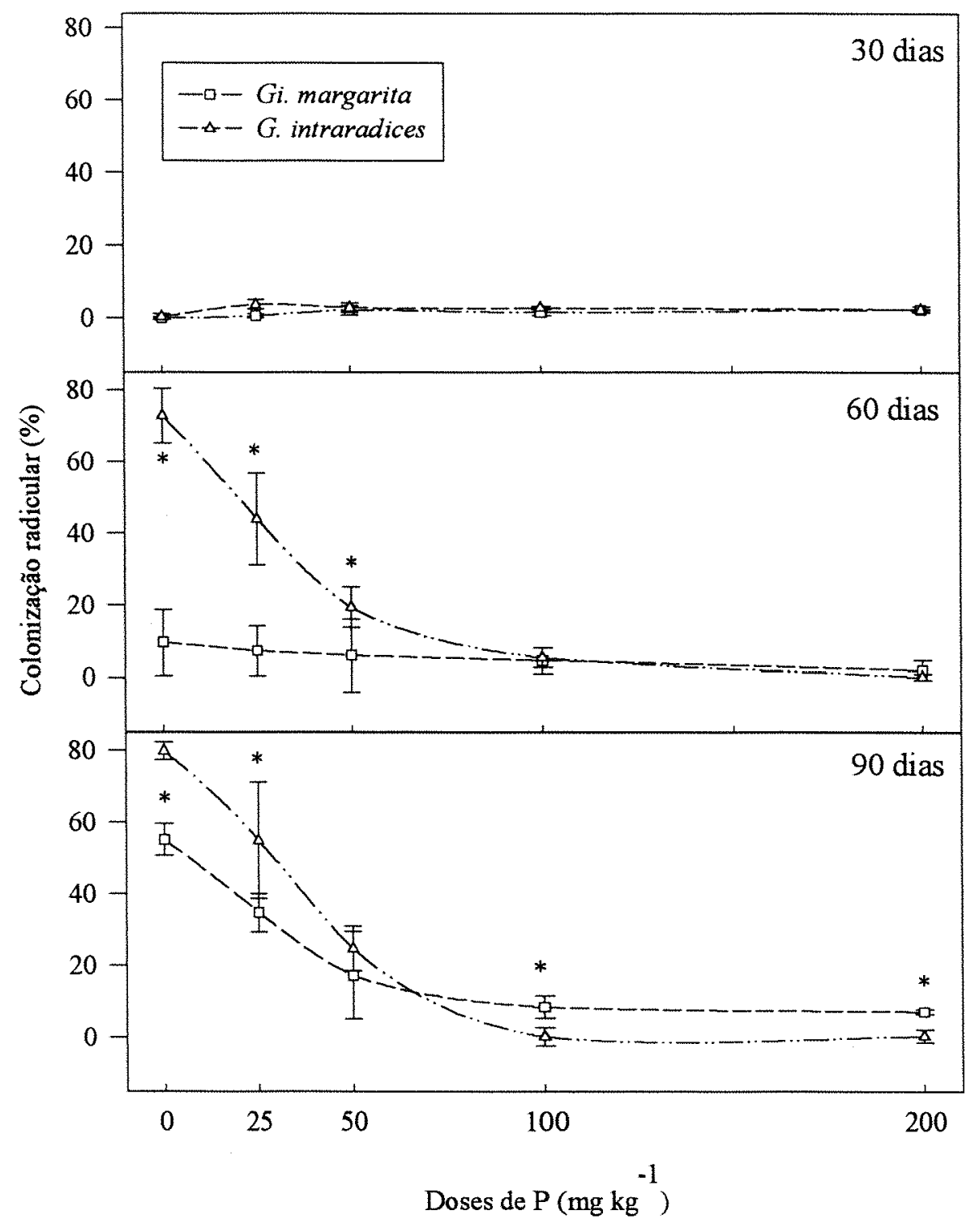

Figura 2. Colonização de raízes de soja por fungos micorrízicos arbusculares, em função de doses de $\mathrm{P}$ e em cada época. ${ }^{*}=$ Diferenças significativas entre fungos na mesma dose, pelo teste $t(\mathrm{P}<0,05)$. Pontos e barras verticais representam média e desvio-padrão de três repetições. 
Aos 90 dias (Figura 2), notou-se pouco incremento de colonização por G. intraradices em relação à época anterior, até a dose de $50 \mathrm{mg} \mathrm{kg}^{-1} \mathrm{de} P$. Nas doses seguintes, a taxa de colonização pareceu não ter sido alterada. O contrário ocorreu para Gi. margarita, que apresentou grande incremento na taxa de colonização radicular nesta época, especialmente nas menores doses de $\mathrm{P}\left(0 \mathrm{e} 25 \mathrm{mg} \mathrm{kg}^{-1}\right)$ (Figura 3). Nesta época, também este fungo foi grandemente afetado pelas doses de P (Figura 2), sendo que na dose de $P 50 \mathrm{mg} \mathrm{kg}^{-1}$, não diferiu significativamente de $G$. intraradices. Nas doses seguintes (100 e $200 \mathrm{mg} \mathrm{kg}^{-1}$ ), apresentou níveis de colonização significativamente maiores (cerca de $15 \%$ ) em relação a $G$. intraradices (cerca de $3 \%$ ), o qual apresentou maior inibição à colonização com o aumento das doses de $\mathrm{P}$, conforme pode-se observar nesta figura. Estas observações indicaram grande sensibilidade dos dois FMAs às altas doses de $\mathrm{P}$, mesmo com níveis de colonização significativamente maiores observados para Gi. margarita nas duas maiores doses de P.

Minhoni et al. (1993b), estudando a inoculação de Glomus macrocarpum em soja, obtiveram no final do ciclo da cultura cerca de 45 e $35 \%$ de colonização radicular no tratamento controle e no que recebeu $P$ solúvel na dose de 70 $\mathrm{mg} \mathrm{kg}{ }^{-1}$, respectivamente, indicando apenas uma tendência de diminuição desta variável com o aumento das doses de P. Faquin (1988) estudando esta mesma simbiose, encontrou taxas de colonização em torno de $55 \%$ aos 90 dias, as quais não foram influenciadas pelas doses de $P$, mesmo na maior delas $\left(90 \mathrm{mg} \mathrm{kg}^{-1}\right.$, equivalente a $33 \mathrm{mg}$ $\mathrm{kg}^{-1}$ de $\mathrm{P}$ disponível pelo método da resina). Contudo, deve-se salientar que naqueles trabalhos foram utilizados solos argilosos, o que restringiu a disponibilidade de $\mathrm{P}$ devido à fixação. Siqueira et al. (1984) utilizando solo arenoso, obtiveram aos 70 dias, grande decréscimo na colonização radicular de soja com o aumento das doses de $\mathrm{P}$, a qual caiu de $60 \%$ na dose 0 para $10 \%$ quando esta foi de $160 \mathrm{mg} \mathrm{kg}^{-1}$, embora não tenha apresentado a quantidade de $\mathrm{P}$ disponível no substrato. Cardoso et al. (1986) utilizando substrato semelhante ao empregado neste experimento, porém com plantas cítricas, observaram que a intensidade da diminuição da colonização radicular devido ao aumento das doses de $\mathrm{P}$ dependeu da espécie do FMA e da sua interação com o hospedeiro. Tendências de diminuição da colonização com aumento das doses de $\mathrm{P}$, sugerindo 
inibição do processo, também foram verificadas por Lambert et al. (1979), Thomson et al. (1986), Lambais \& Cardoso (1988), Antunes \& Cardoso (1991), Colozzi-Filho \& Siqueira (1986). Para este estudo, aos 90 dias a porcentagem de colonização radicular por G. intraradices foi cerca de $80 \%$ na ausência de $\mathbf{P}$ adicionado ao substrato e $30 \%$ na dose $50 \mathrm{mg} \mathrm{kg}^{-1}$. Para Gi. margarita obteve-se cerca de $60 \%$ e $20 \%$ nas mesmas condições, com níveis de colonização estatisticamente superiores em relação a $G$. intraradices nas maiores doses de P. Estas observações, reforçam a idéia de que a maior ou menor sensibilidade do fungo às doses de $\mathrm{P}$, é um fator intrínseco à espécie, refletindo na sua eficiência em colonizar o hospedeiro (Abbott \& Robson, 1981; Abbott \& Robson 1984; Pacovsky et al., 1986a; Lambais \& Cardoso, 1988, 1990; Paula, 1990; Lambais \& Mehdy, 1996), embora o nível de colonização atingida nem sempre esteja relacionada com a eficiência do FMA (Powel, 1977; Graham et al., 1982; Cardoso, 1986). Contudo, a interação deste fator com outros, tais como a espécie do hospedeiro (Abbott \& Robson, 1981; Pacovsky et al., 1986a; Fernandes et al., 1987), tipo de solo (Pacovsky et al., 1985; Cardoso, 1986; Lambais, 1987), dentre outros, deve ser considerada (Powell, 1977), pois cada um deles poderá influenciar a colonização, com reflexos no estabelecimento da simbiose.

A diminuição do nível de colonização radicular com o incremento das doses de $\mathbf{P}$ demonstrou o efeito negativo dessas doses sobre os dois fungos com relação ao estabelecimento da simbiose, o que sugeriu uma interação negativa, na qual o hospedeiro tentou eliminar e/ou restringir o estabelecimento do endófito que não the foi benéfico, através de vários mecanismos. Lambais \& Mehdy $(1993,1995)$ encontraram redução da supressão dos mecanismos de defesa a patógenos de plantas micorrizadas cultivadas em altos níveis de $\mathrm{P}$ disponível. Mudanças fisiológicas e morfológicas do hospedeiro, como a diminuição da permeabilidade da membrana das células radiculares, dificultando a infeç̧ão (Thomson et al., 1986; Miranda et al., 1989), diminuição de exsudatos radiculares com interferência no processo inicial de desenvolvimento micelial dos FMAs (Graham et al., 1981; Miranda \& Harris, 1994a; Jakobsen, 1995); diminuição da esporulação (Miranda \& Harris, 1994b) e inibição do crescimento da hifa externa (Elias \& Safir, 1987; Nagahashi et al., 1996; Tawaraya et al., 1996) também são fatores 
que podem estar ligados à menor taxa de colonização radicular em condições supraótimas de $\mathrm{P}$ disponível.

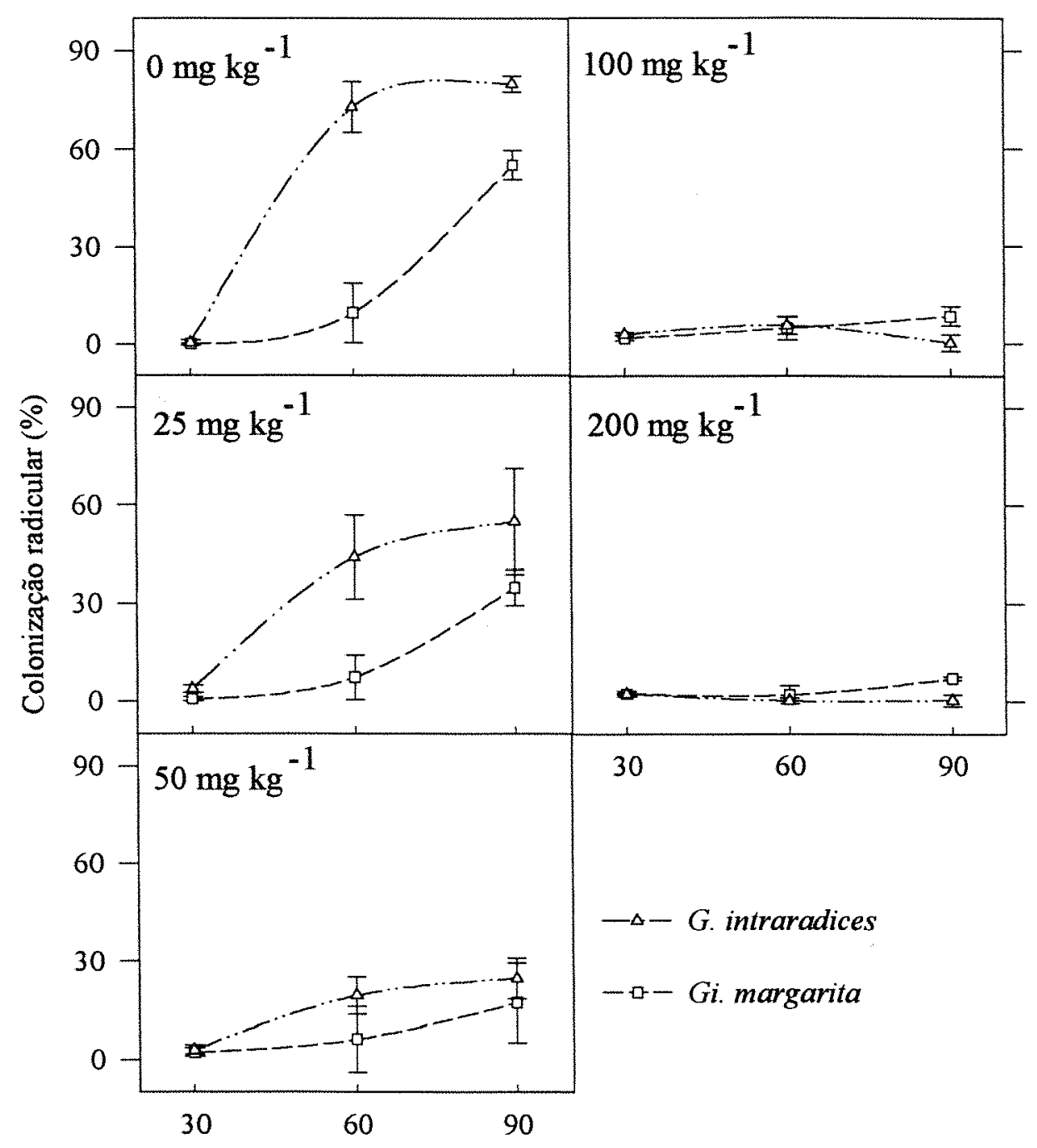

Dias após o transplantio

Figura 3. Colonização de raízes de soja por fungos micorrízicos arbusculares, em função da idade da planta, em cada dose de $\mathrm{P}$ adicionada. Pontos e barras verticais representam média e desvio-padrão de três repetições. Teor inicial de $\mathrm{P}$ no substrato: $4 \mathrm{mg} \mathrm{kg}^{-1}$. 
Estudando-se a dinâmica da colonização pelos fungos micorrízicos em função do tempo para cada dose de P (Figura 3), pôde-se constatar que os dois fungos apresentaram aumentos da taxa de colonização até a terceira dose de $\mathrm{P}$, com ajustes de regressão linear altamente significativos $(P<0,01)$ e com $R^{2}$ superiores a 0,80 (equações não apresentadas). Para as duas últimas doses, o ajuste do modelo não foi significativo, ou seja, o nível de colonização inicial observado aos 30 dias não evoluiu até o final do estudo. Pelo fato de terem sido constatadas colonizações em apenas três épocas, um único ajuste de regressão polinomial possível foi o de primeiro grau, o qual indicou que a taxa de colonização foi linearmente crescente com o tempo. Sabe-se contudo, que este comportamento não é linear, mas sim obedece um modelo de 3 fases: inicialmente crescimento lento, seguido por uma fase exponencial e finalmente uma fase de estabilização, conforme observado por Faquin (1988). Assim, optou-se por representar os dados unindo os pontos nos gráficos por curvas atenuadas e os respectivos desviospadrões (Figura 3). Observando-se as curvas de crescimento nesta figura, constatamos que para o tratamento sem adição de $\mathbf{P}\left(0 \mathrm{mg} \mathrm{kg}^{-1}\right)$ a fase de crescimento lento de $G$. intraradices se deu entre 15 e 30 dias e assim não pôde ser constatada, enquanto $G i$. margarita apresentou esta fase até 60 dias. Para os tratamentos que receberam $P$, estas curvas foram cada vez mais atenuadas com o aumento das doses que causaram inibição da colonização, embora $G$. intraradices tenha se destacado até a dose de $50 \mathrm{mg} \mathrm{kg}^{-1}$. De fato, nas menores doses de P, G. intraradices apresentou grande incremento na taxa de colonização até 60 dias, com incrementos decrescentes após esta época. Por outro lado, Gi. margarita ainda apresentou a fase de crescimento lento até esta época, e a fase exponencial ocorreu apenas no período final, entre 60 e 90 dias, apresentando incrementos crescentes nas três primeiras doses de $P$. Devido à maior lentidão em colonizar as raízes, provavelmente este fungo somente pôde contribuir para o desenvolvimento do hospedeiro quando este já se encontrava na fase final de seu ciclo, não havendo tempo suficiente para que beneficios mais expressivos fossem observados. Frente a esta situação, quando se tratar de culturas anuais, de ciclo curto, seriam interessantes os fungos com capacidade de colonizar rapidamente seu hospedeiro, para 
que os beneficios do estabelecimento da simbiose ocorressem logo no início do desenvolvimento da cultura.

Fase de crescimento lento prolongada de Gi. margarita, semelhante ao que ocorreu neste experimento foi observada por Lambais \& Cardoso (1988). Diferentes espécies ou populações de FMAs apresentam curvas variadas de colonização em função do tempo (Abbott \& Robson, 1985), dependendo das condições edáficas (Abbott \& Robson, 1984). Esta menor capacidade de crescimento inicial apresentada em algumas interações, pode ser atribuída ao menor potencial e distribuição do inóculo no substrato ou à menor capacidade do fungo crescer externamente à raiz e produzir infecções secundárias. Aparentemente, a última possibilidade parece ter sido a que provavelmente ocorreu neste experimento, tendo em vista que o potencial de inóculo e a sua distribuição foram adequados. Comportamento diferencial de colonização em diversas condições edáficas pode ser função da adaptação diferenciada dos FMAs a estas condições (Lambais \& Cardoso, 1988). Além dos fatores citados acima, a interação genética entre o fungo e a planta talvez seja o fator de maior importância no que se refere ao nível de colonização pelos FMAs (Lambais \& Cardoso, 1989).

\subsection{Massa do material seco da parte aérea (MSPA)}

Analisando-se os dados de MSPA, observou-se interação tripla entre os fatores estudados. Ao avaliar o efeito dos FMAs em cada dose de $P$ e em cada época estudada, não foram observadas diferenças estatísticas entre os FMAs e controle sem fungo na fase inicial da cultura ( 15 e 30 dias) em qualquer dose de $P$ para a variável em questão (Tabela 3). Este comportamento também foi observado por Paula et al. (1990). Tais observações foram coerentes, pois neste período, era pouca ou nenhuma a colonização das raizes pelos FMAs (Figuras 2 e 3), e assim não podiam influenciar significativamente a produção de MSPA pelas plantas. Por outro lado, à medida que a simbiose evoluiu, diferenças devido à presença dos fungos micorrízicos foram observadas nas fases seguintes ( 60 e 90 dias) do ciclo da cultura (Tabela 3 ).

Aos 60 dias, não houve diferenças estatísticas entre os FMA e controle sem fungo apenas na dose 0 de $\mathrm{P}$, mesmo para as plantas inoculadas com $G$. intraradices, 
as quais apresentaram tendência de MSPA superior ao controle em $36 \%$. Nesta combinação (60 dias e dose 0 de $\mathrm{P}$ ), o teor de $\mathrm{P}$ disponível no substrato foi de $4 \mathrm{mg} \mathrm{kg}^{-1}$ (Figura 1). Essa tendência de aumento da MSPA no tratamento com G. intraradices explica-se pelo fato de que este fungo já apresentava uma taxa de colonização radicular de cerca de $75 \%$, ao passo que Gi. margarita apresentava apenas cerca de $10 \%$ de colonização. Neste caso, o teor de P no substrato foi limitante mesmo na sua presença, pois não havia ainda atingido sua taxa máxima de colonização (Figura 3).

Tabela 3. Efeito de fungos micorrízicos arbusculares sobre a massa do material seco da parte aérea de plantas de soja $\left(\mathrm{g}\right.$ parcela $\left.{ }^{-1}\right)$ em cada nível do fator época, em interação com cada nível do fator doses de $P$.

\begin{tabular}{|c|c|c|c|c|c|}
\hline \multirow[b]{2}{*}{ Fungos } & \multicolumn{5}{|c|}{ Doses de $\mathrm{P}\left(\mathrm{mg} \mathrm{kg}^{-1}\right)$} \\
\hline & 0 & 25 & 50 & 100 & 200 \\
\hline & & & 15 dias & 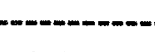 & -.-- \\
\hline Controle & $0,67 a^{(1)}$ & $0,78 \mathrm{a}$ & $0,80 \mathrm{a}$ & $0,90 \mathrm{a}$ & $0,85 \mathrm{a}$ \\
\hline Gi. margarita & $0,73 \mathrm{a}$ & $0,85 \mathrm{a}$ & $1,09 \mathrm{a}$ & $0,93 \mathrm{a}$ & 0,83 a \\
\hline G. intraradices & $0,67 \mathrm{a}$ & $0,86 \mathrm{a}$ & $1,11 \mathrm{a}$ & $0,75 \mathrm{a}$ & $0,70 \mathrm{a}$ \\
\hline Controle & $1,54 \mathrm{a}$ & $3,36 \mathrm{a}$ & $4,40 \mathrm{a}$ & $5,64 \mathrm{a}$ & $4,83 \mathrm{a}$ \\
\hline Gi. margarita & $1,52 \mathrm{a}$ & $3,31 \mathrm{a}$ & $3,88 \mathrm{a}$ & $5,79 \mathrm{a}$ & $4,64 \mathrm{a}$ \\
\hline G. intraradices & $1,67 \mathrm{a}$ & $3,57 \mathrm{a}$ & $4,89 \mathrm{a}$ & $4,68 \mathrm{a}$ & $5,43 \mathrm{a}$ \\
\hline Controle & $3,44 \mathrm{a}$ & $18,42 \mathrm{~b}$ & $34,94 \mathrm{a}$ & $38,23 \mathrm{~b}$ & $36,68 \mathrm{ab}$ \\
\hline Gi. margarita & $3,66 \mathrm{a}$ & $17,84 b$ & $28,08 \mathrm{~b}$ & $32,10 \mathrm{c}$ & $36,96 \mathbf{a}$ \\
\hline G. intraradices & $4,68 \mathrm{a}$ & $22,04 \mathrm{a}$ & $33,04 \mathrm{a}$ & $42,26 \mathrm{a}$ & $33,77 \mathrm{~b}$ \\
\hline Controle & $3,80 \mathrm{~b}$ & $23,13 \mathrm{~b}$ & $48,90 \mathrm{~b}$ & 56,27 a & $49,60 \mathrm{a}$ \\
\hline Gi. margarita & $8,70 \mathrm{a}$ & $24,90 \mathrm{~b}$ & $47,25 \mathrm{~b}$ & $55,67 \mathrm{a}$ & $52,20 \mathrm{a}$ \\
\hline G. intraradices & $7,60 \mathrm{a}$ & $30,80 \mathrm{a}$ & $55,70 \mathrm{a}$ & 55,95 a & $51,85 \mathrm{a}$ \\
\hline
\end{tabular}

(1) Letras iguais, comparadas entre fungos, dentro da mesma dose e época, não diferem entre si pelo teste $t(\mathrm{P}<0,05)$. C.V. $=11,35 \%$

$\mathrm{Na}$ dose de $25 \mathrm{mg} \mathrm{kg}^{-1}$ de $\mathrm{P}$ adicionado ao substrato, equivalente a 15 $\mathrm{mg} \mathrm{kg}^{-1}$ de $\mathrm{P}$ disponível (Figura 1), G. intraradices propiciou incremento de matéria seca $23,5 \%$ e $19,7 \%$ superior a Gi. margarita e ao controle, respectivamente, que por sua vez não diferiram significativamente entre si. Também nesta fase, a porcentagem de 
colonização radicular por G. intraradices foi maior que a alcançada por Gi. margarita, com cerca de $45 \%$ e $10 \%$, respectivamente (Figura 2), novamente permitindo que o primeiro fungo desse maiores contribuições à planta. Nas demais doses de $\mathrm{P}(50,100 \mathrm{e}$ $200 \mathrm{mg} \mathrm{kg}^{-1}$ ), a presença de Gi. margarita levou a produções de MSPA estatisticamente menores (50 e $100 \mathrm{mg} \mathrm{kg}^{-1}$ ) ou iguais $\left(200 \mathrm{mg} \mathrm{kg}^{-1}\right.$ ) quando comparado ao controle (Tabela 3). Neste caso, Gi. margarita ainda estava em fase de estabelecimento da simbiose (fase de crescimento lento), visto que a porcentagem de colonização radicular ainda era baixa em relação à época seguinte (90 dias) (Figura 3). Este fato, leva à suposição de que este fungo teria levado a uma depressão transitória de crescimento, uma vez que ainda não estaria contribuindo significativamente para o desenvolvimento da planta, mas apenas constituía um dreno de carbono da mesma, utilizado na formação de sua biomassa. Estudos de Harris et al. (1985) revelaram que 17 e $8 \%$ dos fotoassimilados totais da planta de soja foram consumidos pelo fungo micorrízico aos 42 dias e no final do ciclo da cultura, respectivamente. Neste estudo, as produções de MSPA aos 60 dias nas doses 50 e $100 \mathrm{mg} \mathrm{kg}^{-1}$ de P foram 19 e $16 \%$, respectivamente, menores em relação à testemunha sem FMA. Conforme Jakobsen (1995), pode-se observar depressão transitória de crescimento nas primeiras fases da colonização em plantas com reservas limitadas de $\mathrm{C}$, principalmente em condições de altos níveis de $\mathrm{P}$. Bethlenfalvay et al. (1982b) também obtiveram inibição inicial de crescimento em soja, o que foi atribuído a uma demanda de carboidratos do hospedeiro pelo endófito, numa fase em que a relação parte aérea/raiz e a capacidade fotossitética eram baixas.

Aos 90 dias (Tabela 3), G. intraradices destacou-se nas doses mais baixas de $\mathrm{P}\left(0,25\right.$ e $\left.50 \mathrm{mg} \mathrm{kg}^{-1}\right)$, propiciando maior acúmulo de matéria seca. Gi. margarita somente levou a diferença significativa superior ao controle, na ausência de $\mathbf{P}$ adicionado ( $\left.0 \mathrm{mg} \mathrm{kg}^{-1}\right)$. É possível que o não efeito de Gi. margarita nas demais doses de $\mathbf{P}$, tenha sido decorrente do fato que este fungo somente atingiu estes níveis de colonização radicular no final do ciclo da cultura, sem tempo hábil para maiores contribuições. Nas demais doses (100 e $200 \mathrm{mg} \mathrm{kg}^{-1}$ ), não houve diferenças estatísticas entre os FMAs e nem entre estes e o controle sem FMA, uma vez que estes níveis de $\mathbf{P}$ foram supra-ótimos e conseqüentemente os níveis de colonização atingidos foram baixos 
(Figura 2). Esta observação evidencia novamente o aumento do crescimento de plantas de soja micorrizadas em condições de baixa disponibilidade de $\mathrm{P}$, fato amplamente constatado por diversos pesquisadores desde longa data (Gerdeman, 1968; Ross \& Harper, 1970; Cardoso, 1985 e 1986; Paula et al., 1990; Minhoni et al., 1993a; Douds, 1994; Nurlaeny et al., 1996). Embora não se possa dizer que haja especificidade entre espécies de plantas e espécies de fungos micorrízicos, pudemos constatar claramente a diferença de eficiência entre os dois FMAs estudados em promover acúmulo de matéria seca pela soja. Neste caso, G. intraradices contribuiu para maior acúmulo de MSPA até a dose de P $50 \mathrm{mg} \mathrm{kg}^{-1}$, enquanto Gi. margarita destacou-se em relação ao controle apenas quando $P$ não foi adicionado ao substrato, o que sugere que a simbiose com este fungo foi menos eficiente em auxiliar o crescimento da planta, pela sua maior sensibilidade às adições de $\mathrm{P}$ ao substrato. Segundo Jakobsen (1995), diferenças na eficiência simbiótica entre fungos micorrízicos parecem estar ligadas muito mais à variação no transporte de $\mathrm{P}$ pelo fungo do que às quantidades de carbono que este consome do hospedeiro. Silveira \& Cardoso (1990) observaram que o FMA mais eficiente em feijão foi aquele que propiciou maior influxo de $\mathbf{P}$ pelo sistema radicular da planta (mais de $100 \%$ em relação ao controle).

A capacidade de fixação de $\mathbf{P}$ pelo solo parece ser um fator muito importante na determinação da resposta do hospedeiro aos FMAs (Pacovsky et al., 1985). Este pode ter sido um dos fatores responsáveis pela baixa resposta das plantas à micorrização obtidas neste experimento, tendo em vista que o substrato utilizado foi arenoso, com baixa capacidade de fixação de P. Cardoso (1986), observou que a eficiência dos fungos micorrízicos em promover beneficios agronômicos à planta variou com o tipo de solo em que foram cultivadas, embora também tenha constatado que Gi. margarita foi o menos eficiente dentre os fungos estudados, não levando geralmente a incrementos de MSPA quando comparado ao controle, o que concorda com os resultados obtidos neste estudo. Por outro lado, resultados de Colozzi-Filho \& Siqueira (1986) demonstraram que esta mesma espécie foi altamente eficiente em promover o crescimento de mudas de cafeeiro em substrato argiloso. É importante salientar que em experimentos conduzidos em vasos, onde a densidade de raízes é freqüentemente alta, a 
contribuição micorrízica ao acúmulo de material seco pela planta, em consequiência de maior absorção de $\mathrm{P}$, pode ser menor do que aconteceria em condições de campo onde não há restrição ao crescimento de raízes, e assim a densidade das mesmas é menor (Nurlaeny et al., 1996). Esta pode ser a razão para os diferentes resultados observados entre experimentos de campo e de casa-de-vegetação sobre micorrização, observando-se diminuição de resposta à colonização em volumes restritos de solo ou com alta densidade de plantas, onde ocorre uma sobreposição da zona de depleção de $\mathrm{P}$ em torno das raízes (Baath \& Hayman, 1984).

Analisando-se o comportamento dos fungos em função das doses de $\mathrm{P}$ (Figura 4), obtivemos ajustes de regressão quadráticos altamente significativos $(P<0,01)$ e com valores de $R^{2}$ superiores a 0,90 , apenas aos 60 e 90 dias. Nas duas primeiras épocas não houve ajuste significativo, indicando que as doses de $\mathrm{P}$ ainda não influenciavam esta variável. Aos 60 dias, observou-se que o modelo obtido para Gi. margarita descreveu valores menores da variável em questão, enquanto G. intraradices apresentou comportamento semelhante ao do controle. Aos 90 dias, todos os tratamentos apresentaram comportamento semelhante.

Tanto aos 60 quanto aos 90 dias, o comportamento do modelo matemático indicou queda na produção de MSPA na maior dose de $\mathrm{P}$, atingindo um ponto de máximo da equação em torno da dose teórica de $150 \mathrm{mg} \mathrm{kg}^{-1}$. Este comportamento pode ter sido conseqüência de um desbalanço nutricional causado pela alta disponibilidade deste elemento. Sabe-se que altas doses de $\mathrm{P}$ podem causar redução na absorção de outros elementos, especialmente micronutrientes como $\mathrm{Zn}, \mathrm{Cu}$ e $\mathrm{Fe}$, ou ainda diminuir a concentração destes, em decorrência da resposta de crescimento da planta ao P (Murphy et al., 1981), os quais poderiam se tornar limitantes em algum processo metabólico da planta, com reflexos negativos sobre a produção de MSPA. Maiores discussões sobre interações entre $P$ e nutrientes e seu reflexo na MSPA encontram-se na discussão dos resultados obtidos para macro e micronutrientes. 


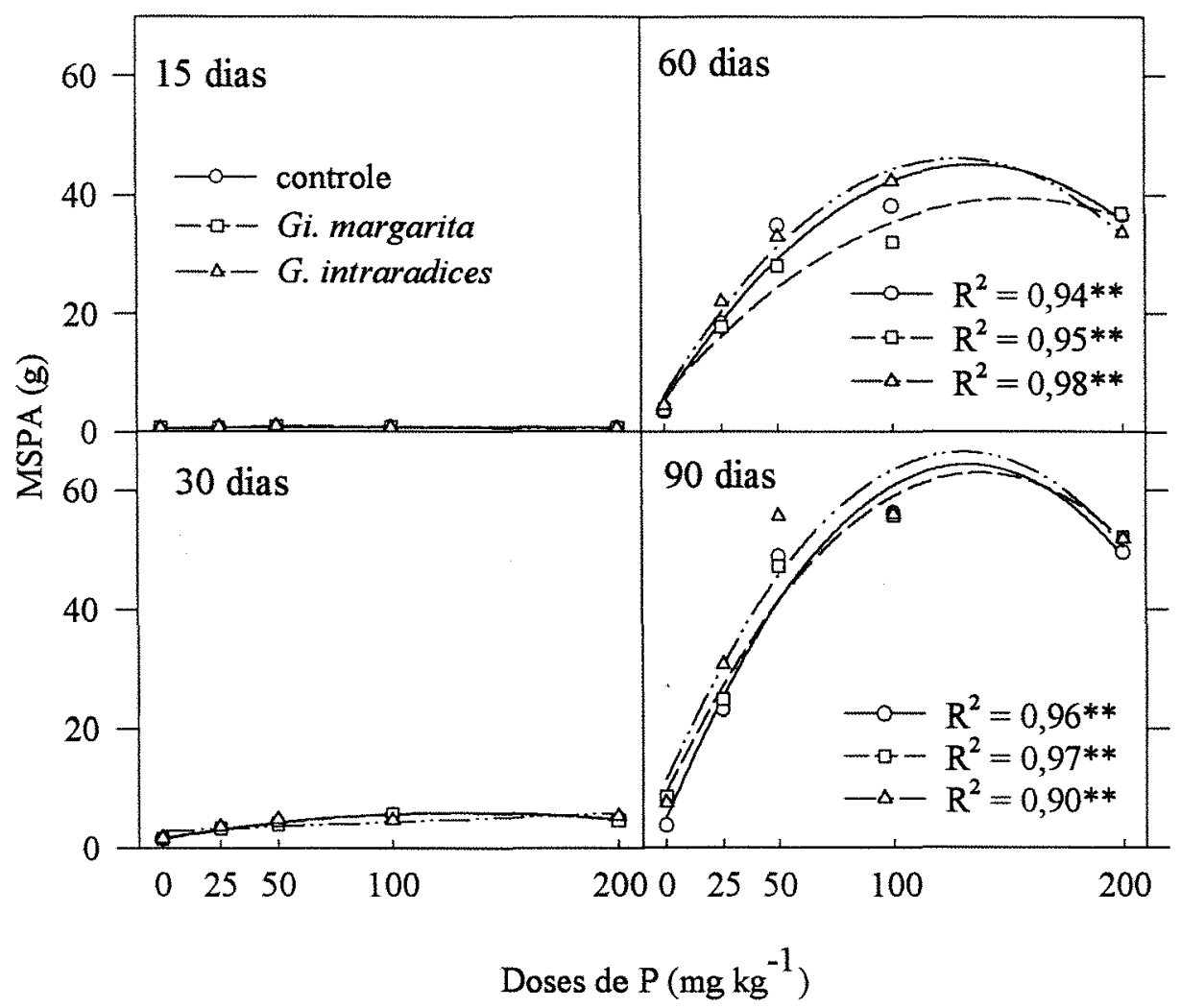

Figura 4. Produção de massa do material seco da parte aérea (MSPA) por plantas de soja (g parcela ${ }^{-1}$ ) micorrizadas e não micorrizadas, em função das doses de $\mathrm{P}$, para cada época de colheita. ${ }^{* *}=$ Equações significativas pelo teste $\mathrm{F}(\mathrm{P}<0,05)$.

\subsection{Massa do material seco de vagens (MSV)}

A análise estatística dos resultados da produção de vagens, obtidos aos 60 e 90 dias, revelou interações duplas entre os fatores Épocas de Colheita e Fungos Micorrizicos e entre Épocas de Colheita e Doses de P. Estudando-se o efeito dos FMAs dentro de cada nível do fator época de colheita, pôde-se constatar efeitos positivos de $G$. intraradices apenas aos 90 dias, com incremento de produção de $16 \%$ sobre o controle sem fungo, que por sua vez não diferiu significativamente de Gi. margarita (Tabela 4). 
Novamente foi constatada maior eficiência do primeiro fungo em relação ao segundo. Como o objetivo final de uma cultura de soja são os grãos, neste caso, poder-se-ia inferir que Gi. margarita não teria qualquer efeito perceptível sobre a produção final.

Tabela 4. Efeito da micorrização sobre a produção de massa do material seco de vagens $\left(\mathrm{g}_{\text {parcela }}{ }^{-1}\right)$ por plantas de soja em duas épocas do ciclo da cultura (média das 5 doses de $\mathbf{P})$.

\begin{tabular}{ccc}
\hline & \multicolumn{3}{c}{ épocas (dias) } \\
\cline { 2 - 3 } Fungos & 60 & 90 \\
\hline Controle & $0,75 \mathrm{a}^{(1)}$ & $12,98 \mathrm{~b}$ \\
Gi. margarita & $0,92 \mathrm{a}$ & $12,69 \mathrm{~b}$ \\
G. intraradices & $0,78 \mathrm{a}$ & $15,07 \mathrm{a}$ \\
\hline
\end{tabular}

(1) Letras iguais, comparadas na vertical e dentro da mesma época, não diferem entre si pelo teste $t$ $(\mathrm{P}<0,01)$. C. $\mathrm{V} .=20 \%$

Efeitos das doses de $\mathrm{P}$ sobre esta variável foram observados apenas aos 90 dias, conforme demonstrado na Figura 5. Nota-se que a dose de $50 \mathrm{mg} \mathrm{kg}^{-1}$ de $\mathrm{P}$ se mostra suficiente para a máxima produção de grãos, uma vez que nas maiores doses não são notados incrementos de produção. Embora pouco evidente, aos 90 dias $G$. intraradices levou à maior produção de massa do material seco de vagens nas doses de 25 e $50 \mathrm{mg} \mathrm{kg}^{-1}$ de $P$. 


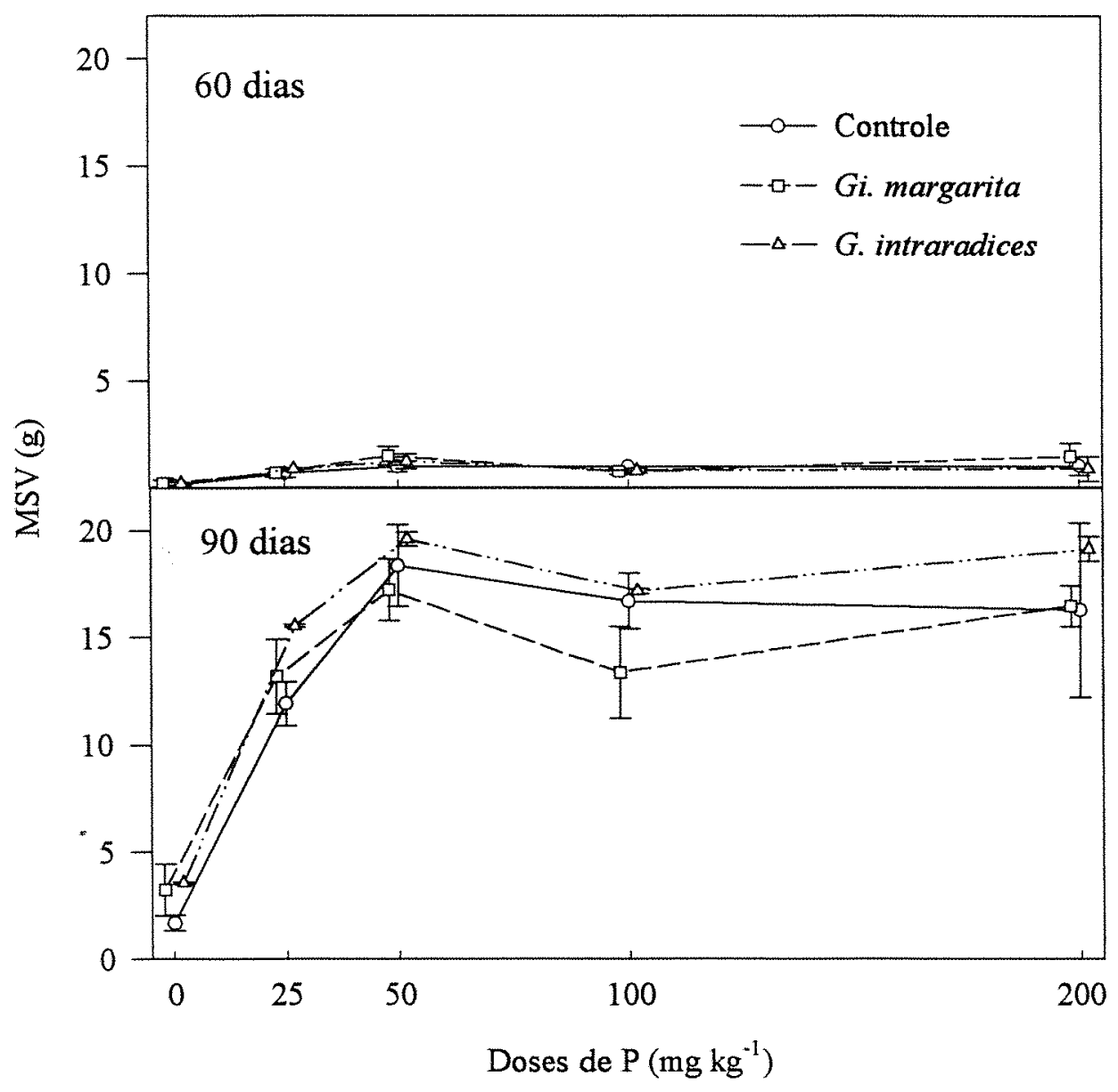

Figura 5. Produção de massa do material seco de vagens (MSV) por plantas de soja (g parcela $^{-1}$ ) em função das doses de P. Pontos e barras verticais representam média e desvio-padrão de três repetições

\subsection{Número e massa do material seco de nódulos (MSN)}

Para massa do material seco de nódulos houve duas interações duplas: uma entre Doses de P e Fungos Micorrízicos e outra entre Épocas de Colheita e Doses de $P$, a qual não será discutida em razão de pouco contribuir para o objetivo do estudo. A primeira interação (Tabela 5), revelou que a presença de G. intraradices propiciou um 
aumento em $200 \%$ sobre esta variável em relação ao controle no tratamento $0 \mathrm{mg} \mathrm{kg}^{-1}$, embora esta diferença não tenha sido estatisticamente significativa. Aumento significativo foi obtido somente na dose de $P 25 \mathrm{mg} \mathrm{kg}^{-1}$. Neste caso, a presença do fungo teria auxiliado no equilíbrio nutricional da planta, especialmente em $P$, o que provavelmente favoreceu a simbiose com o Bradyrhizobium, uma vez que esta interação demanda energia, consumindo ATP. Uma planta com maior suprimento deste nutriente teria melhores condições de atender à demanda energética decorrente do estabelecimento da simbiose durante a formação do nódulo e manutenção dos bacteróides. Devemos considerar o fato de que outros nutrientes também são de grande importância para a fixação biológica de nitrogênio e estes poderiam ser melhor supridos pela presença da micorriza. Além do aspecto nutricional, também podem ser relacionados os não nutricionais, como a produção de hormônios vegetais (Barea \& Azcón-Aguilar, 1983). Incrementos mais expressivos na nodulação de soja micorrizada foram obtidos por Cardoso $(1985,1986)$ e Harris et al. (1995).

Tabela 5. Efeito de FMAs sobre MSN de soja $\left(\mathrm{g} \mathrm{parcela}^{-1}\right)$ em cada dose de $\mathrm{P}$ estudada (média das 4 épocas).

\begin{tabular}{cccccc}
\hline & \multicolumn{5}{c}{ Doses de $\mathrm{P}\left(\mathrm{mg} \mathrm{kg}^{-1}\right)$} \\
\cline { 2 - 6 } Fungos & 0 & 25 & 50 & 100 & 200 \\
\hline Controle & $0,03 \mathrm{a}^{(1)}$ & $0,37 \mathrm{~b}$ & $0,78 \mathrm{a}$ & $1,40 \mathrm{a}$ & $1,18 \mathrm{a}$ \\
Gi. margarita & $0,07 \mathrm{a}$ & $0,40 \mathrm{ab}$ & $0,75 \mathrm{a}$ & $1,15 \mathrm{~b}$ & $1,28 \mathrm{a}$ \\
G. intraradices & $0,09 \mathrm{a}$ & $0,50 \mathrm{a}$ & $0,83 \mathrm{a}$ & $1,19 \mathrm{~b}$ & $1,24 \mathrm{a}$ \\
\hline
\end{tabular}

(1) Letras iguais, comparadas na vertical e dentro da mesma dose, não diferem entre si pelo teste $t$ $(\mathrm{P}<0,05)$. C. $\mathrm{V} .=25,68 \%$.

$\mathrm{Na}$ dose $100 \mathrm{mg} \mathrm{kg}^{-1}$, o comportamento foi inverso, e os dois fungos levaram a um decréscimo na variável estudada. Esta diminuição pode estar relacionada ao fato de que, sob altas doses de $\mathrm{P}$ e associadas aos FMAs, a planta apresenta mudanças quantitativas e qualitativas de seus exsudatos radiculares, com mudanças na comunidade microbiana da micorrizosfera de modo a afetar o estabelecimento do Rizóbio (Barea \& Azcón-Aguilar, 1983). Neste caso, o número de nódulos nesta dose também foi menor na presença dos FMAs (Tabela 6). Outra possibilidade poderia estar relacionada ao 
consumo de carboidratos da planta pelos FMAs, o que teria restringido o desenvolvimento dos nódulos. Estas observações são apenas sugestivas, visto que não foram obtidos resultados conclusivos. Outros experimentos mais específicos deveriam ser instalados a fim de investigar o que os resultados sugeriram. Nas demais doses, não foram observadas diferenças significativas entre os fungos e o controle.

Tabela 6. Efeito de FMAs sobre o número de nódulos de soja em cada dose de $\mathrm{P}$ estudada (média das 4 épocas).

\begin{tabular}{cccccc}
\hline & \multicolumn{5}{c}{ Doses de P $\left(\mathrm{mg} \mathrm{kg}^{-1}\right)$} \\
\cline { 2 - 6 } Fungos & 0 & 25 & 50 & 100 & 200 \\
\hline Controle & $33 \mathrm{a}^{(1)}$ & $150 \mathrm{~b}$ & $250 \mathrm{a}$ & $328 \mathrm{a}$ & $270 \mathrm{a}$ \\
Gi. margarita & $49 \mathrm{a}$ & $157 \mathrm{ab}$ & $238 \mathrm{a}$ & $267 \mathrm{~b}$ & $305 \mathrm{a}$ \\
G. intraradices & $46 \mathrm{a}$ & $194 \mathrm{a}$ & $275 \mathrm{a}$ & $282 \mathrm{~b}$ & $258 \mathrm{a}$ \\
\hline
\end{tabular}

(1) Letras iguais, comparadas na vertical e dentro da mesma dose, não diferem entre si pelo teste $t$ $(P<0,05)$. C.V. $=13,07 \%$.

Observando-se o comportamento das equações de regressão em função das doses de $\mathrm{P}$ (Figura 6-A), pode-se notar que houve incremento da variável estudada até a dose teórica de aproximadamente $150 \mathrm{mg} \mathrm{kg}^{-1}$ nos tratamentos com os FMAs, para posteriormente indicar um decréscimo na dose seguinte, assim como observado para o número de nódulos (Figura 6-B) e MSPA (Figura 4). Já a equação obtida para o tratamento controle indicou um ponto de máximo próximo à dose teórica de $130 \mathrm{mg} \mathrm{kg}^{-1}$.

$\mathrm{A}$ análise da variável número de nódulos (Tabela 6), de forma semelhante à anterior, também demonstrou duas interações duplas: entre Doses de $\mathrm{P}$ e Fungos Micorrízicos e outra entre Épocas de Colheita e Doses de $\mathbf{P}$ (não será discutida pelos mesmos motivos apresentados anteriormente). Por serem duas variáveis intimamente relacionadas, os resultados foram praticamente os mesmos que os observados para MSN. 


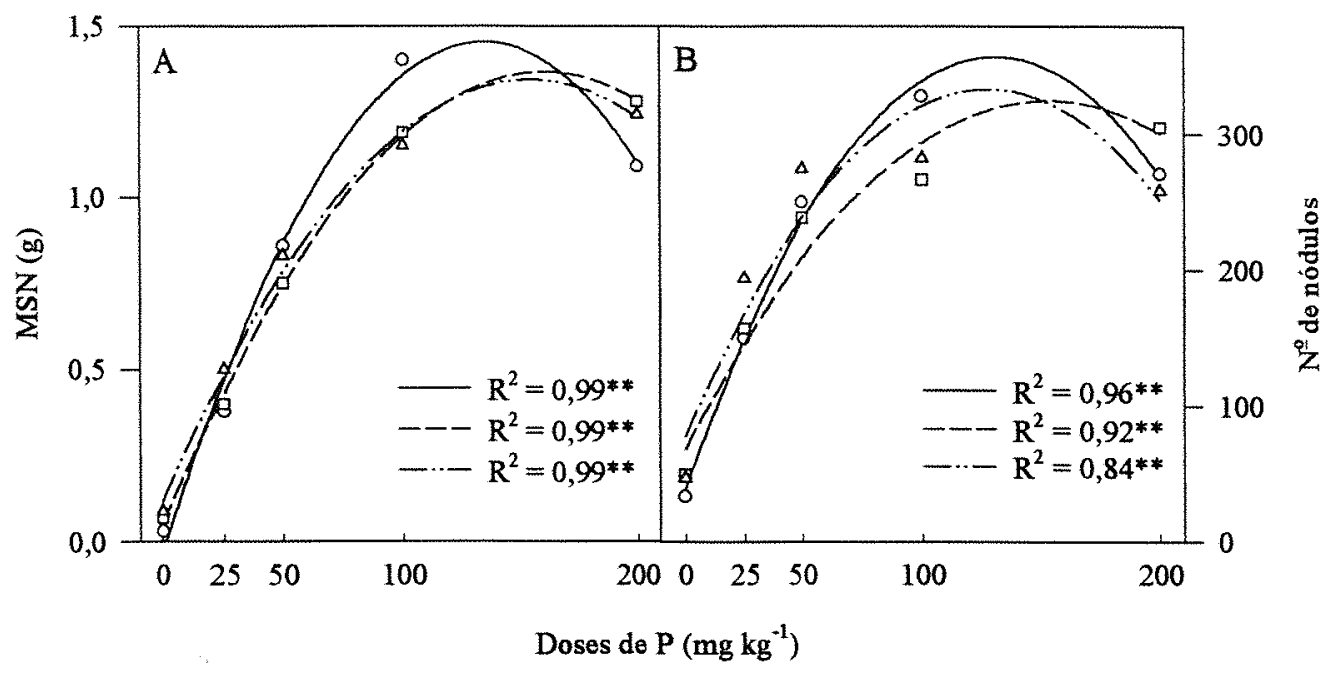

Figura 6. Massa do material seco de nódulos (MSN) (g parcela ${ }^{-1}$ ) e Número de nódulos (por parcela) de plantas de soja colonizadas $(\square=G i$. margarita; $\Delta=G$. intraradices $)$ ou não $(\mathrm{O}=$ Controle $)$ por FMAs em função das doses de $\mathrm{P}$ (média das 4 épocas). $* *$ = equação significativa pelo teste $\mathrm{F}(\mathrm{P}<0,001)$.

De forma semelhante à MSN, $G$. intraradices propiciou maior número de nódulos na dose de $\mathrm{P} 25 \mathrm{mg} \mathrm{kg}^{-1}$, enquanto na dose $100 \mathrm{mg} \mathrm{kg}^{-1}$, menor número de nódulos foi observado em relação ao controle para os dois fungos. Os ajustes das equações de regressão em função das doses de $\mathrm{P}$ (Figura 6B), demonstraram incremento da variável avaliada até próximo à dose teórica de $130 \mathrm{mg} \mathrm{kg}^{-1}$, na qual se obtiveram os pontos de máximo das equações, com conseqüente decréscimo à medida que se tendeu para a última dose. Este comportamento novamente acompanhou as tendências observadas para as variáveis anteriormente discutidas.

\subsection{Comprimento de micélio extrarradicular ativo (MEA)}

Os resultados de MEA no substrato, obtido pelo método que utiliza FDA (Schubert, 1987; Sylvia, 1992), apresentaram interação tripla entre os fatores envolvidos. O tratamento controle (sem FMA) também foi avaliado quanto a esta 
variável, no qual foi constatado MEA, devido à existência de fungos sapróbios. Estes fungos teriam sido introduzidos durante a instalação do experimento, ocasião em que se adicionou um extrato proveniente de vasos de multiplicação testemunha, visando-se manter todos os tratamentos com a mesma comunidade microbiana, exceto no que se referiu aos FMAs. Em decorrência, propágulos de outros fungos não micorrizicos foram adicionados ao substrato, os quais produziram hifas que nem sempre puderam ser diferenciadas visualmente daquelas originadas pelos FMAs. Esta dificuldade de distinção foi relatada por Abbott et al. (1984), Abbott \& Robson (1985) e Sylvia (1988, 1992). A entrada de fungos sapróbios no substrato de estudo pode ter ocorrido adicionalmente por outras vias, tais como poeira, respingos d'água, ventilação e outros, também sugeridas por Melloni (1996). Kough et al. (1983), Wilson et al. (1983), Frey et al. (1994), sugeriram o uso de técnicas de imunofluorescência, juntamente com anticorpos específicos para cada FMA como uma maneira confiável de estimativa de MEA do fungo em estudo.

Conforme pode ser visto na Tabela 7 , a análise estatística dos resultados de MEA, em interação com cada nível do fator Doses de $\mathrm{P}$ e cada nível do fator Época, não apresentou diferenças significativas entre os FMAs e controle apenas aos 15 dias. Nesta época, como citado anteriormente, não se constataram locais de infeç̧ão radicular pelos FMAs nos seus respectivos tratamentos. O MEA obtido foi menor que $0,2 \mathrm{~m} \mathrm{~g}^{-1}$ de substrato, sugerindo que sua origem provavelmente fosse proveniente dos esporos em germinação.

Aos $30 \mathrm{~d}$ (Tabela 7), especialmente nas menores doses de $\mathrm{P}(0$ e $25 \mathrm{mg}$ $\mathrm{kg}^{-1}$ ), observaram-se maiores quantidades de MEA produzidos pelos FMAs em relação ao controle. Ainda nesta época, Gi. margarita produziu significativamente mais MEA em relação a $G$. intraradices no tratamento que não recebeu $P$. Na dose de $P 50 \mathrm{mg} \mathrm{kg}^{-1}$ e nas seguintes, não foram observadas diferenças de produção de MEA entre os fungos estudados e entre estes e o controle. Com 60 dias (Tabela 7), G. intraradices assumiu posição de destaque quanto à produção de MEA nas doses de $P 0$ e $25 \mathrm{mg} \mathrm{kg}^{-1} \mathrm{em}$ relação ao controle e Gi. margarita, os quais não diferiram entre si. Nas demais doses, a 
produção de MEA não diferiu entre o controle e os tratamentos com fungo, os quais por sua vez, também não diferiram entre si.

Tabela 7. Produção de micélio externo ativo (MEA) $\left(\mathrm{m} \mathrm{g}^{-1}\right)$ pelos FMAs ou controle, em substrato cultivado com soja em cada nível do fator Época, em interação com cada nível do fator Doses de P.

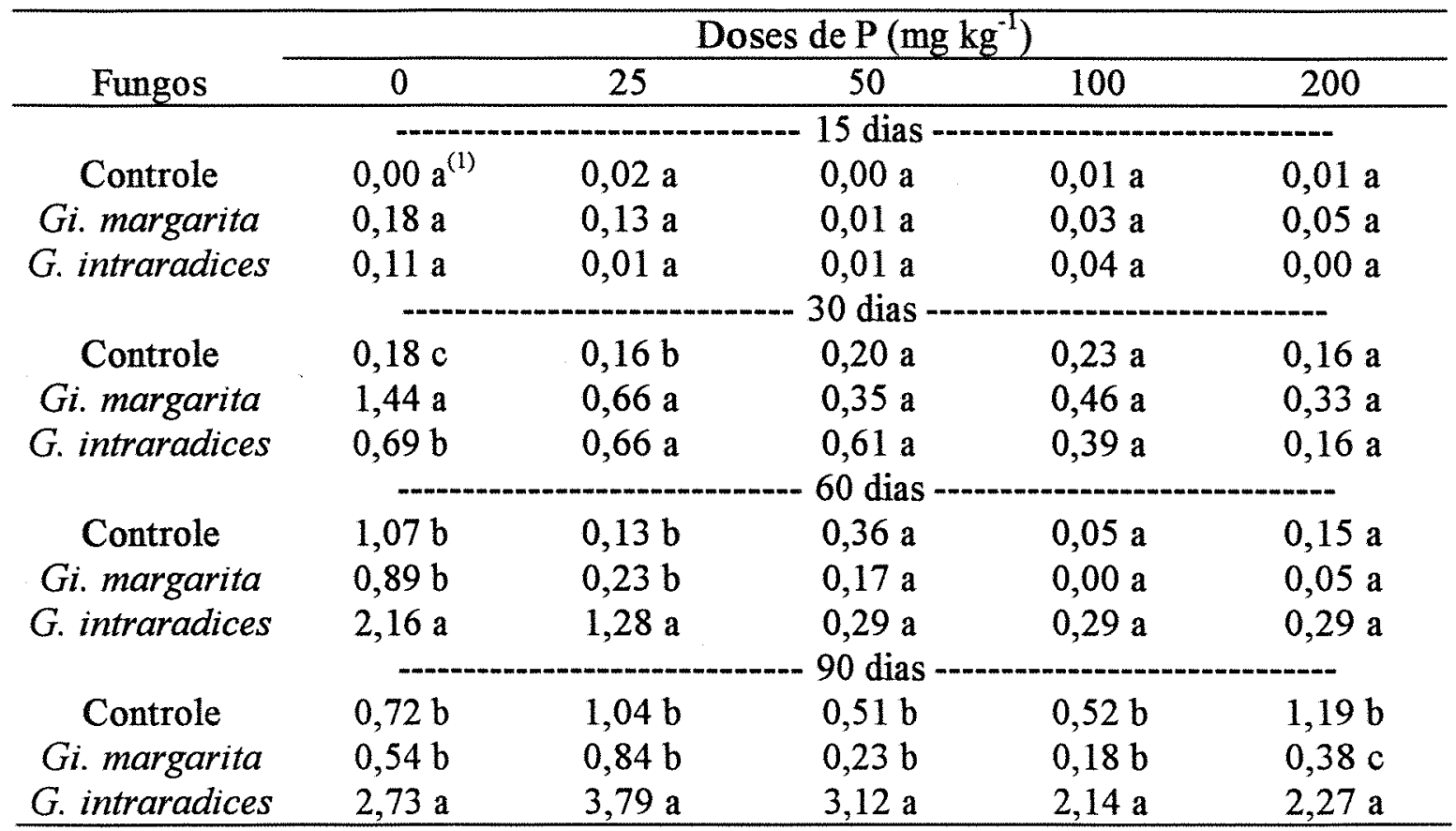

(1) Letras iguais, comparadas na vertical, dentro da mesma dose e época, não diferem entre si pelo teste $t$ $(\mathrm{P}<0,05)$. C.V. $=52,52 \%$

$\mathrm{Na}$ última colheita (90 dias), G. intraradices destacou-se quanto a produção de MEA em todas as doses estudadas, diferindo significativamente do controle e de Gi. margarita. $\quad \mathrm{Na}$ dose de $200 \mathrm{mg} \mathrm{kg}^{-1}$ de $\mathrm{P}$, este último fungo apresentou comprimento de MEA inferior ao controle. Conforme discutido por Silveira (1992), a micorrizosfera difere profundamente da rizosfera de plantas não micorrizadas. Assim, ainda não se conhecem bem as interações entre os fungos sapróbios e os micorrizicos, motivo pelo qual não foi feita a subtração do MEA obtido nos tratamentos sem FMAs dos tratamentos com FMAs. 
Análises de regressão para produção de MEA pelos FMAs e controle, em função das doses de $\mathrm{P}$ em cada época, indicaram ausência de efeito das doses de $\mathrm{P}$ sobre esta variável aos 15 dias, pois não houve ajuste significativo dos modelos estudados (Figura 7). Nas demais épocas, obtiveram-se ajustes significativos para os FMAs, indicando efeitos negativos das doses de $\mathbf{P}$ sobre a atividade de micélio externo, com produção de MEA inversamente proporcional. Comportamentos semelhantes foram obtidos por Melloni (1996) e Gomes (1997).

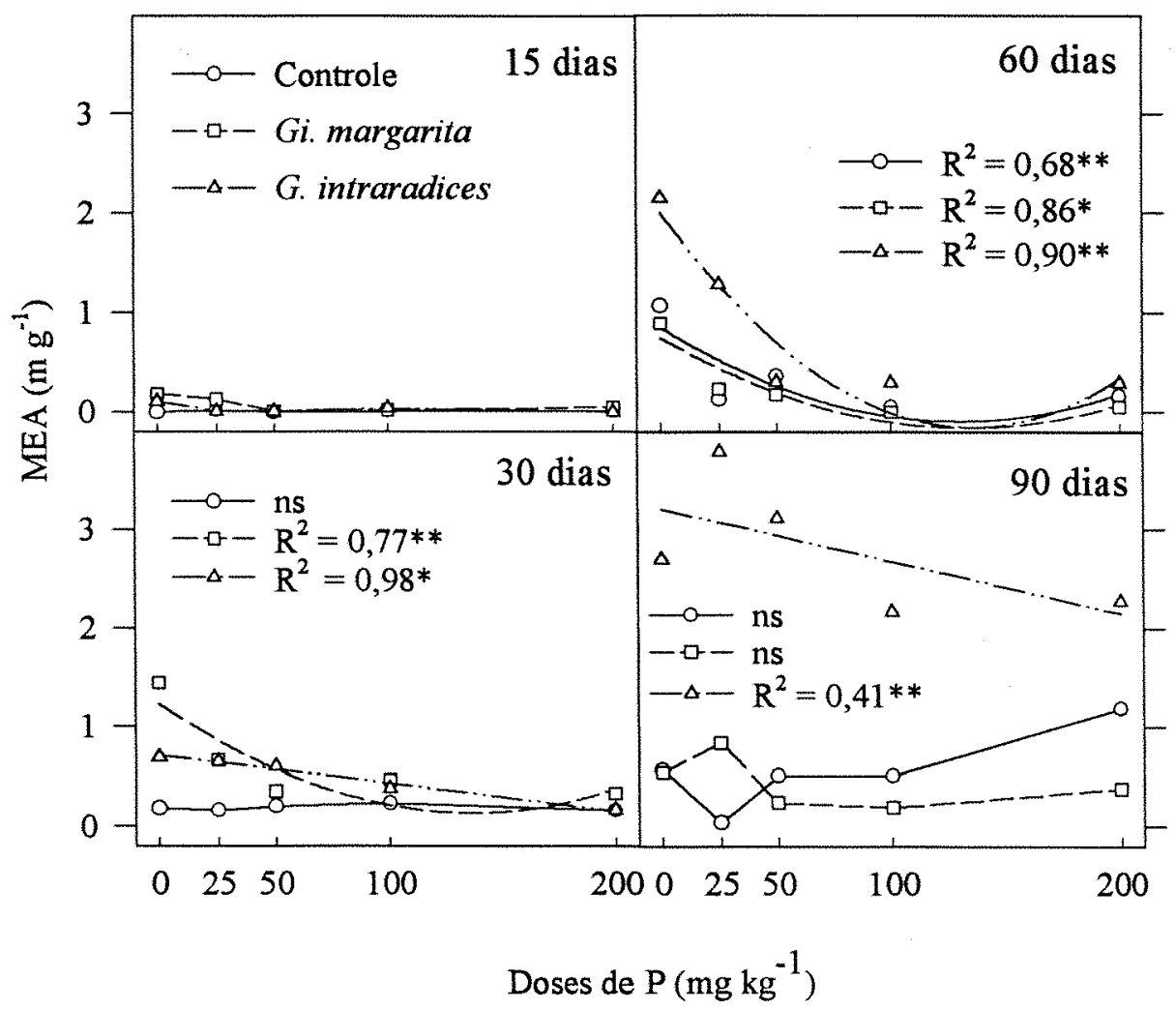

Figura 7. Comprimento de micélio ativo (MEA) em substrato cultivado com soja colonizada ou não por FMAs, em função das doses de $\mathrm{P}^{*}$ = Equação significativa a $\mathrm{P}<0,05 ; * *=$ significativa a $\mathrm{P}<0,01 ;$ ns $=$ não significativa pelo teste F. 
Como pode ser constatado nesta figura, foram obtidos modelos estatisticamente significativos e com altos valores de coeficiente de determinação para os FMAs aos 30 e 60 dias, o que demonstra a grande influência negativa do aumento das doses de $\mathrm{P}$ sobre esta variável (Figura 7), de maneira análoga à colonização radicular anteriormente discutida (Figura 2). Ficou bem evidente que o incremento das doses de $\mathbf{P}$ diminuiu a variável MEA. Por outro lado, no tratamento controle, o MEA somente foi afetado pelas doses de $\mathrm{P}$ aos 60 dias, o que vem reforçar a afirmação de que o MEA quantificado nestes tratamentos foi originário de fungos sapróbios, os quais estiveram menos sujeitos aos efeitos inibitórios diretos das doses de $\mathbf{P}$. Aos 90 dias, as doses de $\mathbf{P}$ não influenciaram o comprimento de MEA de Gi. margarita, que foi semelhante ao controle. Observando-se a Figura 7 e a Tabela 7, nota-se de Gi. margarita apresentou uma tendência de maior crescimento inicial (30 dias) nas doses 0 e $25 \mathrm{mg} \mathrm{kg}^{-1}$ de $P$, sendo superado por $G$. intraradices nas épocas seguintes. G. intraradices, mesmo influenciado negativamente pelo aumento das doses de $P$, apresentou os maiores valores de MEA aos 90 dias (Figura 7), o que provavelmente refletiu nos maiores valores obtidos para MSPA nesta época nas doses 25 e $50 \mathrm{mg} \mathrm{kg}^{-1}$ (Tabela 3). No tratamento sem adição de $\mathbf{P}\left(0 \mathrm{mg} \mathrm{kg}^{-1}\right)$ (90 dias), Gi. margarita foi tão eficiente quanto $G$. intraradices em promover aumentos da MSPA, embora seu MEA estivesse a níveis semelhantes aos do controle. Como Gi. margarita apresentou maior MEA inicial nesta dose, é provável que seu efeito positivo somente tenha se refletido na MSPA na última colheita.

Contrastando com os resultados de porcentagem de colonização radicular, para os quais Gi. margarita demonstrou níveis estatisticamente superiores ao G. intraradices sob altos níveis de $\mathrm{P}$ (doses $100 \mathrm{e} 200 \mathrm{mg} \mathrm{kg}^{-1}$ ) (Figura 2), a produção de MEA por este fungo, com exceção aos 30 dias, foi mais sensível ao $\mathrm{P}$ que $G$. intraradices. Gi. margarita apresentou maior desenvolvimento inicial de MEA, sobretudo na ausência da adição de P (Figura 7, 30 dias). Contudo, provavelmente devido à falta de adaptação ao substrato (Abbott \& Robson, 1985), este fungo foi superado por $G$. intraradices e passou a apresentar valores estatisticamente iguais ao controle sem FMA (Tabela 7). A concentração de $\mathrm{P}$ no hospedeiro parece influenciar a 
quantidade e/ou qualidade dos exsudatos radiculares, os quais poderão afetar o crescimento da hifa do FMA (Tawaraya et al., 1996). Fatores fisicos, químicos e biológicos do substrato também podem afetar a integridade da hifa e comprometer a habilidade do FMA em translocar nutrientes (Sylvia, 1988).

O comportamento do comprimento de MEA em função das épocas, em cada dose de $\mathbf{P}$, mostrou que $G$. intraradices sempre apresentou relação positiva e significativa com as épocas, em todas as doses de $\mathrm{P}$, mesmo quando o comprimento diminuiu com o aumento dessas doses (Figura 8). Os modelos ajustados para este fungo foram altamente significativos $(P<0,01)$ e apresentaram coeficientes de determinação $\left(R^{2}\right)$ superiores a 0,90. Gi. margarita, ao contrário, somente foi influenciado pelas épocas na dose 0 de $P$, na qual apresentou tendência de queda em função do tempo, e na dose 25 $\mathrm{mg} \mathrm{kg}{ }^{-1}$, com comportamento semelhante ao do controle, contudo os ajustes de regressão obtidos apenas foram significativos a $P<0,05$ e apresentaram $R^{2}$ baixos.

Estas observações vêm enfatizar a baixa eficiência de Gi. margarita em auxiliar positivamente a simbiose, quando $P$ foi adicionado ao substrato. Aparentemente este fungo apresentou dificuldades de adaptação às condições a que foi submetido, o que foi agravado pela adição de $P$. Como a parte responsável pela absorção e transporte de nutrientes e água é o micélio ativo (Schubert et al., 1987), este fungo pouco teria a contribuir, visto que praticamente não apresentou micélio ativo, com valores que não diferiram do controle na maioria das vezes.

Schubert et al. (1987), Sylvia (1988) e Hamel et al. (1990) observaram que em geral, a porcentagem de MEA em relação ao total é alta no início do estabelecimento da simbiose, diminuindo conforme sua evolução. Neste estudo, foi observado um comportamento oposto, principalmente para $G$. intraradices, o qual demonstrou aumento do MEA na última época estudada (Figura 8). Isto também pode ter sido conseqüência de uma falta de adaptação inicial ao meio, que posteriormente foi superada por G. intraradices, mas não por Gi. margarita. 


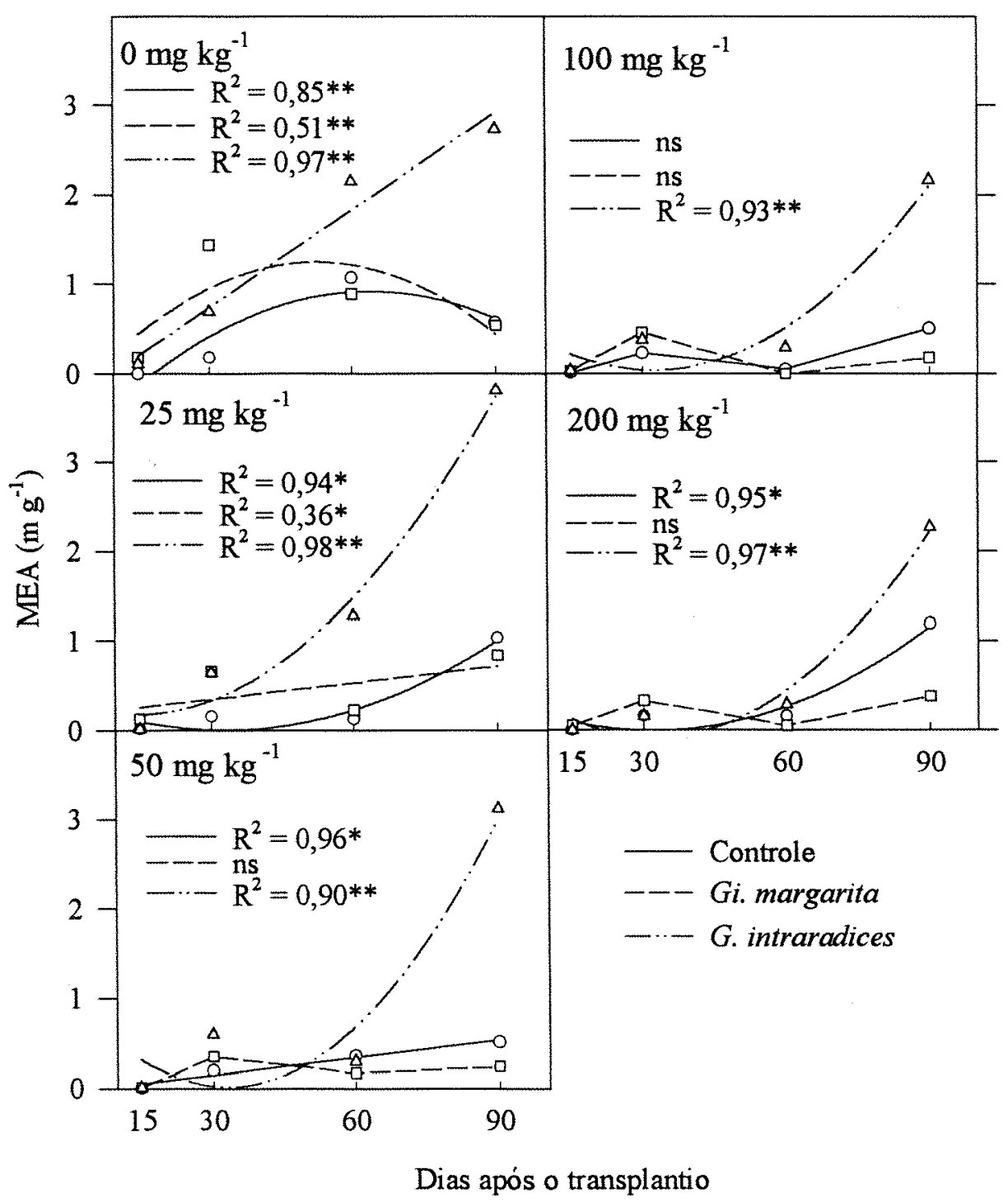

Figura 8. Comprimento de micélio ativo (MEA) em substrato cultivado com soja colonizada ou não por FMAs, em função da idade da planta. * = Equação significativa a $\mathrm{P}<0,05 ; * *=$ significativa a $\mathrm{P}<0,01 ; \mathrm{ns}=$ não significativa pelo teste F. 
Em geral podemos dizer que o MEA sofreu diminuição com o aumento das doses de P (Figura 7) e aumentou com o tempo (Figura 8), com maior destaque sendo observado para G. intraradices. Como a absorção de nutrientes pela hifa do fungo ocorre por um processo ativo, o aumento do MEA e conseqüente da superficie disponivel para absorção, melhoraria o estado nutricional do hospedeiro, principalmente nas doses mais baixas de P. Entretanto, a planta teve pouco tempo para se beneficiar da interação, tendo em vista já ter concluído mais de $75 \%$ do seu ciclo.

\subsection{Comprimento de micélio extrarradicular total (MET)}

De acordo com Sylvia (1992), a maioria dos autores propõem subtrair a quantidade de MET encontrada nos substratos controle, daquela encontrada nos substratos que receberam FMAs. Desta forma, teoricamente ter-se-ia como resultado apenas o micélio produzido por estes fungos biotróficos obrigatórios. Contudo, este autor não considera a ocorrência de interações entre os diversos fungos (biotróficos obrigatórios e sapróbios) ou ainda a competição entre eles, o que poderia alterar a proporção de cada um, em cada situação. Neste estudo, tal subtração não foi realizada, tendo em vista que, em algumas situações, houve maior comprimento de MET no tratamento controle, supostamente pelos mesmos motivos apresentados para MEA. Deve-se novamente ressaltar a dificuldade de diferenciação visual entre hifas de FMAs e hifas dos fungos sapróbios (Abbott et al., 1984; Abbott \& Robson, 1985; Sylvia 1988, 1992).

A análise dos resultados desta variável revelou apenas interações duplas entre Épocas e Fungos e entre Épocas e Doses de P. Conforme mostrado na Tabela 8, observou-se que nas duas primeiras épocas, Gi. margarita apresentou comprimento de MET significativamente superior a $G$. intraradices e ao controle. Esta observação poderia justificar em parte as constatações de decréscimo na produção de MSPA de plantas colonizadas por este fungo aos 60 dias (Tabela 3). Desta forma, o endófito teria consumido mais carboidratos da planta para a formação de sua biomassa, o que pode ter refletido na produção de MSPA naquela fase, ressaltando ainda mais a suposição de que este fungo apresentou um maior dreno de carbono para a planta hospedeira, causando 
redução transitória de seu crescimento, fato também observado por outros pesquisadores (Stribley et al., 1980; Bethlenfalvay et al., 1982b).

$\mathrm{Na}$ fase seguinte (60 dias), G. intraradices apresentou valores significativamente maiores de MET, o que coincidiu com sua maior porcentagem de colonização radicular (Figura 2), especialmente nas menores doses de P. Aos 90 dias, os resultados apresentados não diferiram entre si.

Tabela 8. Comprimento de micélio externo total (MET) ( $\mathrm{m} \mathrm{g}^{-1}$ de substrato) produzido em cada época de colheita (média das doses de $\mathrm{P}$ ).

\begin{tabular}{ccccc}
\hline & \multicolumn{4}{c}{ épocas (dias) } \\
\cline { 2 - 5 } Fungos & 15 & 30 & 60 & 90 \\
\hline Controle & $1,99 \mathrm{c}(1)$ & $4,57 \mathrm{~b}$ & $6,65 \mathrm{~b}$ & $8,06 \mathrm{a}$ \\
Gi. margarita & $5,56 \mathrm{a}$ & $8,14 \mathrm{a}$ & $6,60 \mathrm{~b}$ & $8,13 \mathrm{a}$ \\
G. intraradices & $3,39 \mathrm{~b}$ & $5,61 \mathrm{~b}$ & $8,09 \mathrm{a}$ & $7,47 \mathrm{a}$ \\
\hline (1) Letras iguais, comparadas na vertical e dentro da mesma época, não diferem entre si pelo teste $t$ \\
$(\mathrm{P}<0,01)$. C.V. $=24,66 \%$
\end{tabular}

Analisando-se o comportamento dos fungos em função das épocas (Figura 9), obteve-se ajuste de regressão altamente significativo para $G$. intraradices, o qual demonstrou aumento do comprimento de MET até pouco mais de 60 dias, para em seguida evidenciar um decréscimo. Bethlenfalvay et al. (1982c), em experimento envolvendo $G$. fasciculatum e soja, observaram diminuição de $29 \%$ no peso de micélio externo após 70 dias do desenvolvimento desta cultura, o que coincidiu com as altas taxas de crescimento de vagens observadas na mesma época. Esta observação indicou que, assim como os órgãos vegetativos, o endófito passou a receber menos carboidratos, visto que estes foram destinados ao desenvolvimento das partes reprodutivas da planta (flores, vagens e sementes). Observaram também que, após esta fase, a quantidade de micélio interno continuou a aumentar, enquanto o micélio externo diminuiu, sugerindo que este comportamento poderia ser decorrente da reabsorção da hifa externa e a continuação da produção de vesículas no córtex da raiz às custas de outras estruturas do fungo. Schubert et al. (1987) também observaram aumento e posterior decréscimo de MET ao longo do ciclo da planta hospedeira, sem que isto estivesse relacionado ao 
desenvolvimento de estruturas reprodutivas ou à senescência da mesma, indicando que este decréscimo poderia ser conseqüência da degradação da parede celular dos fungos por outros microrganismos, o que também foi sugerido por Hamel et al. (1990).

Neste estudo, porém, observou-se estabilização na taxa de colonização radicular por G. intraradices (Figura 3) a partir dos 60 dias, mas um grande aumento da MSV entre 60 e 90 dias (Figura 5), permitindo sugerir que a diminuição de MET desse fungo (Figura 9) esteve associada à necessidade da planta em direcionar seu fluxo energético para o desenvolvimento das estruturas reprodutivas, havendo maior concordância com os resultados de Bethlenfalfay et al. (1982c). Por outro lado, o ajuste obtido para Gi. margarita, apesar de altamente significativo, apresentou baixo coeficiente de determinação, indicando baixa relação do MET deste fungo em função do tempo (Figura 9). Para o tratamento controle, o ajuste obtido foi altamente significativo com alto coeficiente de determinação, demonstrando apenas aumento dos valores obtidos até a época final, uma vez que o ponto de máximo da equação de regressão ajustada está fora do intervalo de tempo estudado (Figura 9). 


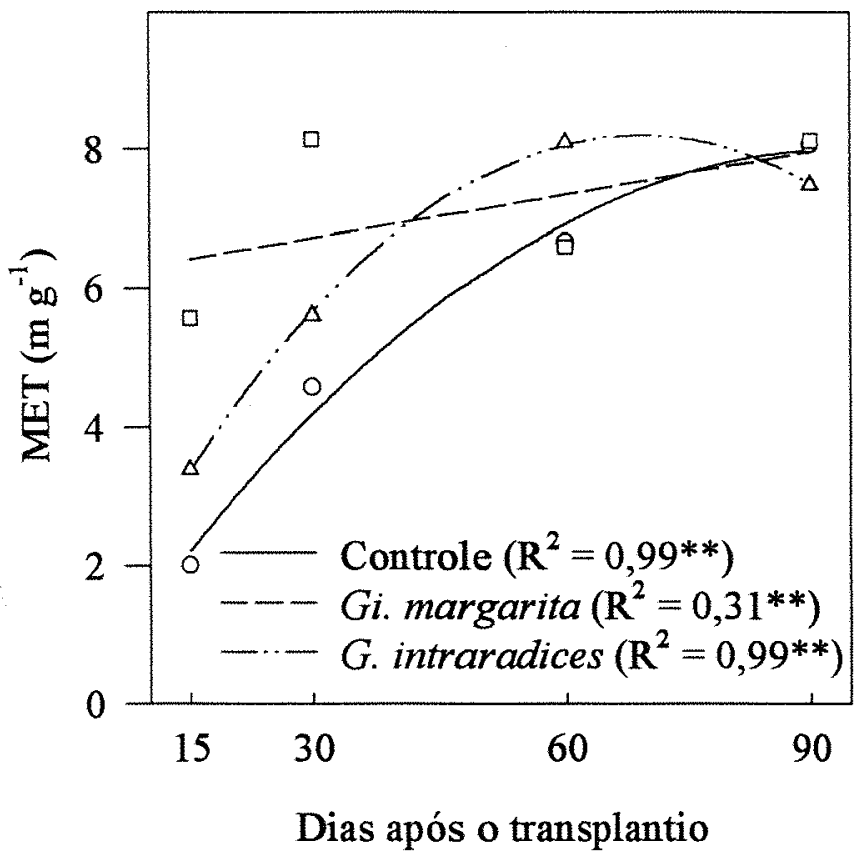

Figura 9. Comprimento de micélio externo total (MET) em substrato cultivado com soja inoculada ou não com FMAs, em função da idade da planta (média das 5 doses). ${ }^{* *}=$ Equação significativa a $\mathrm{P}<0,01$ pelo teste $\mathrm{F}$.

Mesmo tendo ocorrido apenas interação dupla entre MET e tempo, os resultados também foram apresentados em cada nível do fator dose (Figura 10) e em cada nível do fator época (Figura 11). Apesar da não significância estatística, os resultados demonstraram que, de maneira geral, houve tendência de aumento do MET ao longo do tempo (Figura 10), enquanto o aumento das doses de P tendeu a diminuir o MET (Figura 11), especialmente aos 60 dias.

Decréscimos do MET causados pelo aumento das doses de P (Figura 11) também foram observados por Miranda \& Harris (1994a) e Abbott et al. (1984), estando relacionado à diminuição da porcentagem de colonização radicular, de forma semelhante aos resultados obtidos neste experimento (Figura 2). É interessante notar que 
em apenas uma das épocas ficou bem evidente a diminuição do MET com o aumento das doses de $\mathbf{P}$ (60 dias, Figura 11), ao passo que para as demais épocas este comportamento não ficou bem claro. Esta observação ressalta a importância de se avaliar a produção de MET, bem como as outras variáveis relacionadas, em diversas fases do ciclo da planta hospedeira, visto que o estabelecimento da simbiose com o FMA é um processo dinâmico, no qual as mais variadas condições do hospedeiro influenciarão o simbionte $\mathrm{e}$ vice-versa, tanto no que se refere à disponibilidade de $\mathrm{P}$ quanto à adaptação do FMA às condições do meio.

Uma interessante questão levantada por Abbott \& Robson (1985), Sylvia (1988) e Hamel et al. (1990) foi sobre qual seria a longevidade da hifa no solo. Em seus estudos, enquanto observaram grande incremento da colonização radicular, não foi constatado aumento do micélio externo no mesmo período. Uma explicação para o fato seria a rápida reciclagem da hifa externa ou sua degradação por microrganismos do solo. Neste experimento, houve em geral, aumentos do MET com o tempo, embora decréscimos também tenham sido observados em algumas épocas, como para Gi. margarita aos 60 dias e para G. intraradices aos 90 dias (Figuras 9 e 10).

Segundo Abbott \& Robson (1985), a capacidade do FMA colonizar o hospedeiro e produzir micélio externo devem ser consideradas na seleção de fungos mais eficientes. Por outro lado, Schubert et al. (1987), salienta que há pouca relação entre MET e absorção de nutrientes e por isso deve-se dar mais importância à distribuição espacial dos dois componentes do micélio no solo, considerando também a parte ativa. 


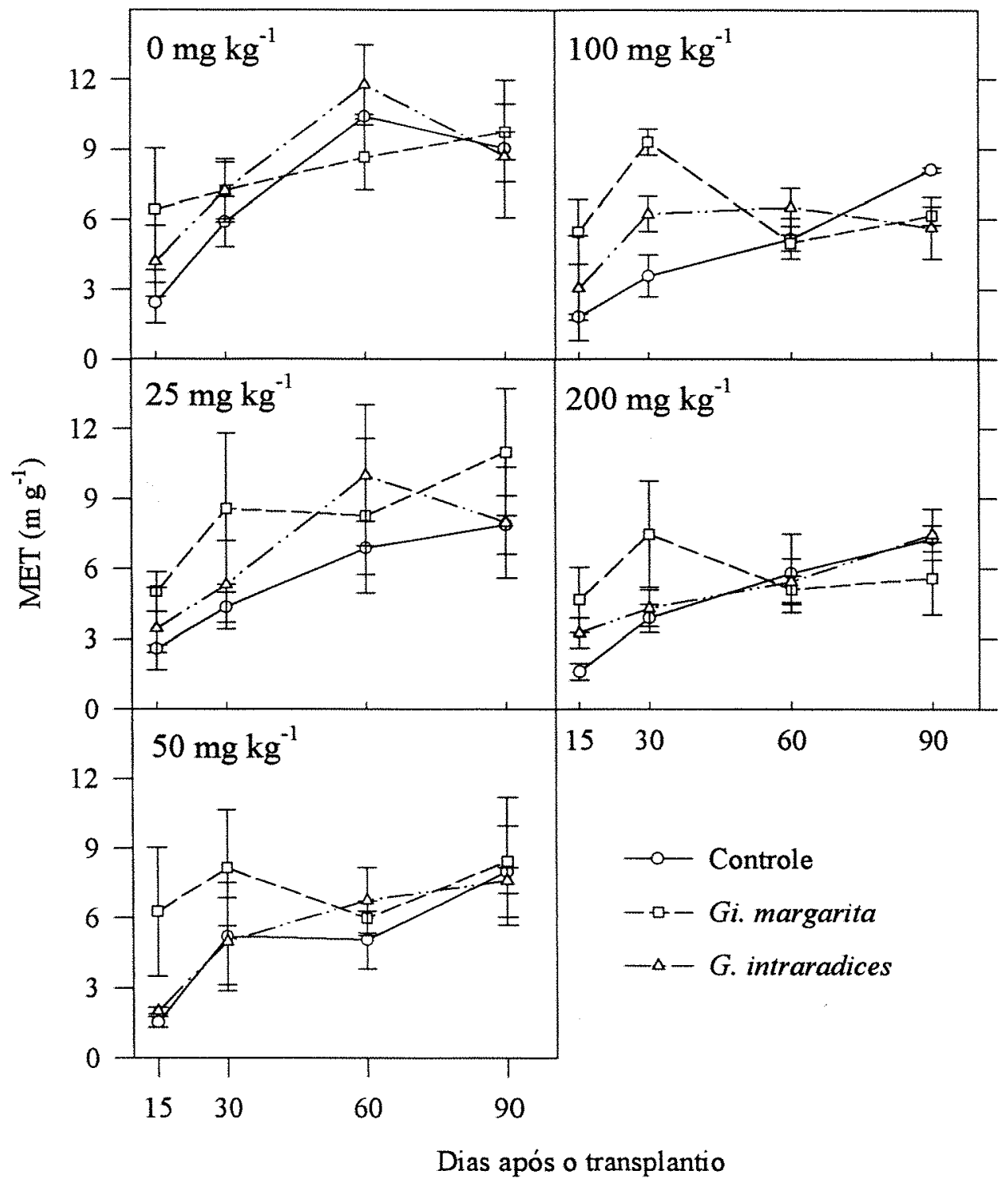

Figura 10. Comprimento de micélio externo total (MET) em substrato cultivado com soja colonizada ou não por FMAs, em função das épocas de amostragem. Pontos e barras verticais representam média e desvio-padrão de três repetições. 


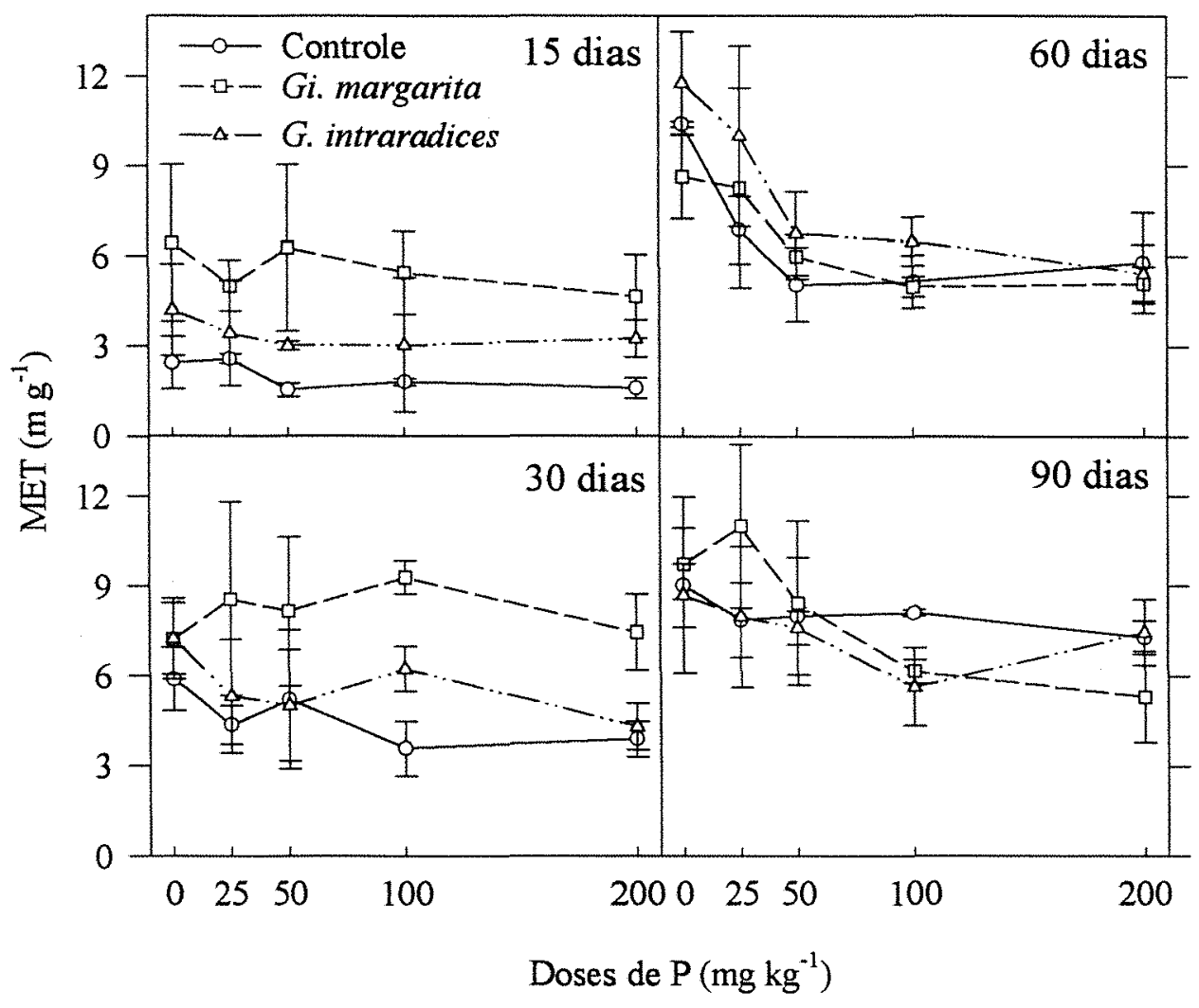

Figura 11. Comprimento de micélio externo total (MET) em substrato cultivado com soja colonizada ou não por FMAs, em função das doses de P. Pontos e barras verticais representam média e desvio-padrão de três repetições.

\subsection{Macronutrientes}

Os efeitos das doses de $\mathrm{P}$ sobre os macronutrientes totais acumulados na parte aérea e produção de MSPA aos 90 dias estão ilustrados na Figura 12. Observou-se que para todas estas variáveis, com exceção do $\mathrm{P}$, ocorreu tendência de queda dos valores quando a dose de $P$ tende para $200 \mathrm{mg} \mathrm{kg}^{-1}$. 


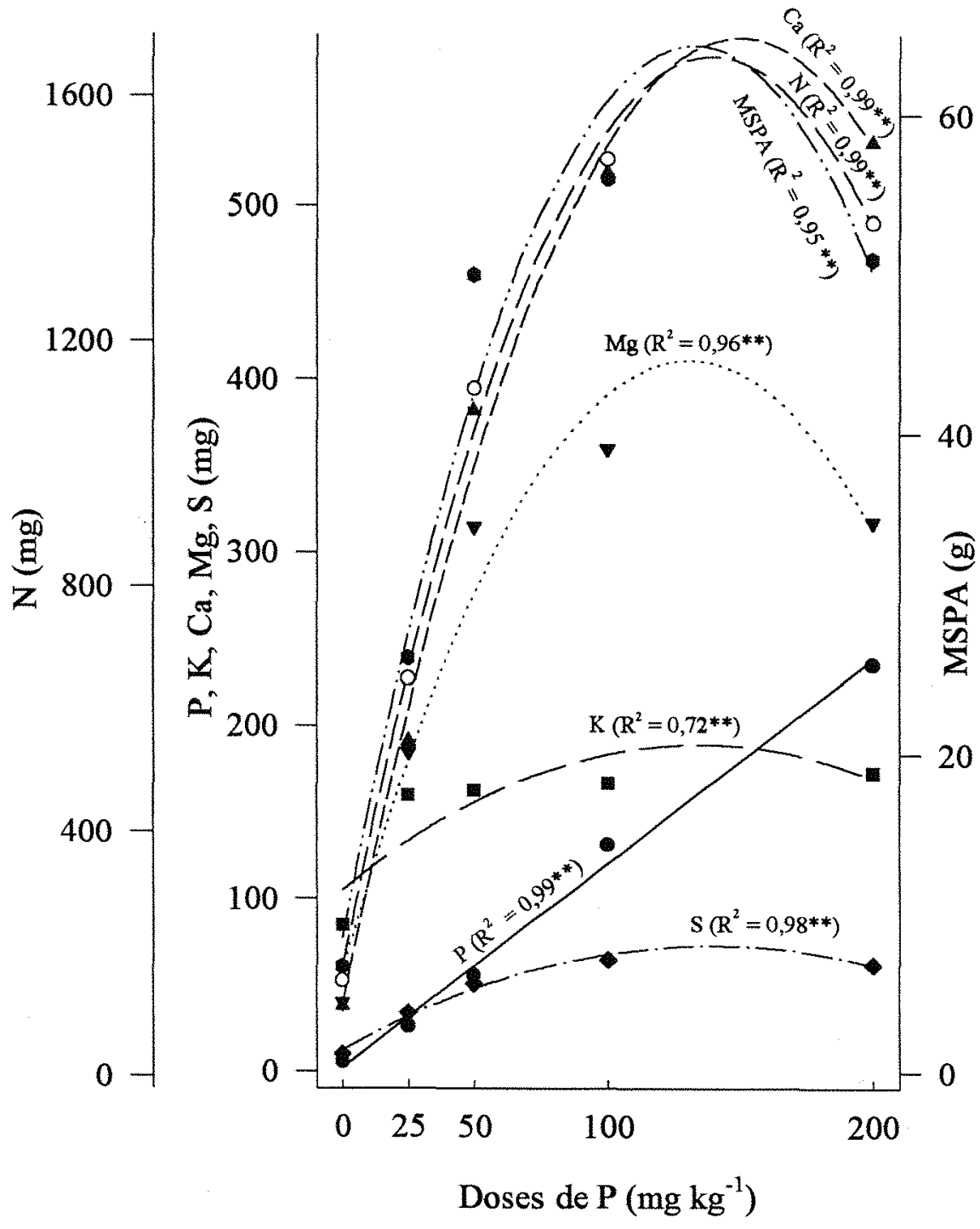

Figura 12. Efeito das doses de $P$ sobre a produção de MSPA e acúmulo de macronutrientes por plantas de soja aos 90 dias após o transplantio (média dos tratamentos com FMAs e controle). ${ }^{* *}=$ Equação significativa a $\mathbf{P}<0,01$ pelo teste F. 
Esta figura ilustra claramente aumento na quantidade de $\mathbf{P}$ acumulado, mesmo na maior dose adicionada, contrastando com a queda dos valores das outras variáveis. Este comportamento provavelmente foi decorrente de inibição competitiva pelos sítios de absorção de nutrientes na maior dose de $\mathrm{P}$, ou ainda devido às altas quantidades de $\mathrm{P}$ acumuladas, causando desbalanços nutricionais com conseqüente queda na produção de MSPA. Segundo Murphy et al. (1981) também pode haver absorção de luxo para $\mathrm{P}$ e que o aumento da absorção deste nutriente pode estar associada à menor absorção dos demais, especialmente micronutrientes.

A seguir, serão discutidos os efeitos dos FMAs sobre cada um dos nutrientes avaliados.

\subsubsection{Nitrogênio}

Para esta variável houve interação tripla entre os fatores estudados. O desdobramento da interação revelou que efeitos decorrentes da presença dos FMAs sobre o total de $\mathrm{N}$ absorvido e acumulado pela parte aérea das plantas somente foram constatados aos 60 e 90 dias (Tabela 9), de forma semelhante ao que aconteceu com os resultados de MSPA.

$\mathrm{O}$ efeito positivo de $G$. intraradices em relação ao controle, sobre o $\mathrm{N}$ total acumulado aos 60 dias, apenas na dose $25 \mathrm{mg} \mathrm{kg}^{-1}$, também pode ser atribuído ao estabelecimento mais rápido deste fungo, e conseqüente colaboração à planta em termos nutricionais, o que permitiu que a formação da simbiose com o rizóbio fosse mais eficiente. Nas demais doses, a ausência de efeitos desse fungo poderia ser atribuída à limitação de $\mathrm{P}$ na dose $0 \mathrm{mg} \mathrm{kg}^{-1}$ mesmo na presença do fungo, apesar da tendência de aumento e suficiência nas demais doses. Ainda nesta época, Gi. margarita apresentou efeitos negativos quanto a esta variável nas duas últimas doses em relação ao controle. Novamente para esta variável, os dados sugerem que a presença deste fungo levou a uma competição, provavelmente por carboidratos, com as bactérias fixadoras de $\mathrm{N}$ que as tornou menos eficientes, resultando em menores quantidades de $\mathrm{N}$ obtidas.

$\mathrm{Na}$ última época estudada, efeitos positivos devido à presença de $G$. intraradices foram evidentes nas três primeiras doses $\left(0,25\right.$ e $\left.50 \mathrm{mg} \mathrm{kg}^{-1}\right)$. Gi. margarita 
somente apresentou valores superiores aos do controle nas doses extremas. A presença deste fungo na ausência de $\mathbf{P}$ adicionado provavelmente contribuiu para melhor nutrição da planta e conseguinte acúmulo de matéria seca, resultando na maior quantidade de $\mathrm{N}$ acumulado. Na maior dose, embora apresentando baixa colonização, a presença dos dois fungos levou a maiores valores desta variável em relação ao controle.

Tabela 9. Efeito de FMAs sobre o total de $\mathrm{N}$ acumulado (mg parcela ${ }^{-1}$ ) pela parte aérea de plantas de soja, em cada nível do fator Época, em interação com os níveis do fator Doses de P.

\begin{tabular}{|c|c|c|c|c|c|}
\hline \multirow[b]{2}{*}{ Fungos } & \multicolumn{5}{|c|}{ Doses de $\mathrm{P}\left(\mathrm{mg} \mathrm{kg}^{-1}\right)$} \\
\hline & 0 & 25 & 50 & 100 & 200 \\
\hline & \multicolumn{5}{|c|}{ - 15 dias $-1 \ldots$} \\
\hline Controle & $27 a^{(1)}$ & $39 a$ & $35 \mathrm{a}$ & 32 a & $43 \mathrm{a}$ \\
\hline Gi. margarita & 34 a & 34 a & $42 \mathrm{a}$ & 37 a & $36 \mathrm{a}$ \\
\hline G. intraradices & $32 \mathrm{a}$ & $36 \mathrm{a}$ & $48 \mathrm{a}$ & $35 \mathrm{a}$ & $31 \mathrm{a}$ \\
\hline Controle & $63 a$ & $82 a$ & $115 \mathrm{a}$ & $153 \mathrm{a}$ & $170 \mathbf{a}$ \\
\hline Gi. margarita & $64 \mathrm{a}$ & $86 a$ & $104 a$ & $182 \mathrm{a}$ & $128 \mathrm{a}$ \\
\hline G. intraradices & $66 a$ & $90 a$ & $142 \mathrm{a}$ & $150 \mathrm{a}$ & $171 \mathrm{a}$ \\
\hline Controle & $75 \mathrm{a}$ & $337 \mathrm{~b}$ & $749 \mathrm{a}$ & $1052 \mathrm{a}$ & $1120 \mathrm{a}$ \\
\hline Gi. margarita & $63 a$ & $313 \mathrm{~b}$ & $693 a$ & $804 b$ & $1076 \mathrm{ab}$ \\
\hline G. intraradices & $92 a$ & $453 \mathrm{a}$ & $696 a$ & $1016 a$ & $1026 \mathrm{~b}$ \\
\hline & & & 90 dias & & $-\cdots$ \\
\hline Controle & $95 \mathrm{~b}$ & $601 \mathrm{~b}$ & $1033 \mathrm{~b}$ & $1566 \mathrm{a}$ & $1252 \mathrm{c}$ \\
\hline Gi. margarita & $213 a$ & $636 \mathrm{~b}$ & $1030 \mathrm{~b}$ & $1467 \mathrm{~b}$ & $1414 b$ \\
\hline G. intraradices & $166 a b$ & $713 \mathrm{a}$ & $1306 \mathrm{a}$ & $1458 \mathrm{~b}$ & $1519 \mathrm{a}$ \\
\hline
\end{tabular}

\subsubsection{Fósforo}

Para esta variável também houve interação tripla entre os fatores. Os efeitos dos fungos micorrízicos nesta interação são mostrados na Tabela 10. Pela observação desses resultados, podemos constatar a baixa eficiência destes fungos em promover absorção e acúmulo de $\mathrm{P}$ pelas plantas de soja, nas condições em que este experimento foi conduzido. Incremento no acúmulo de $\mathrm{P}$ só foi observado para $G$. 
intraradices aos 90 dias na dose $50 \mathrm{mg} \mathrm{kg}^{-1}$. As demais diferenças significativas provocadas pelos FMAs em relação ao controle foram no sentido de redução desta variável, sobretudo nas doses mais altas de $P$.

Observou-se, nas duas últimas épocas estudadas, especialmente nas doses mais baixas de $P$, apenas uma tendência de maiores valores na presença dos FMAs, embora estas diferenças não sejam significativas ao nível de significância considerado.

Tabela 10. Efeito de FMAs sobre o total de $\mathbf{P}$ absorvido e acumulado (mg parcela ${ }^{-1}$ ) pela parte aérea de plantas de soja, em cada nivel do fator Época, em interação com os níveis do fator Doses de $P$.

\begin{tabular}{|c|c|c|c|c|c|}
\hline \multirow[b]{2}{*}{ Fungos } & \multicolumn{5}{|c|}{ Doses de $\mathrm{P}\left(\mathrm{mg} \mathrm{kg}^{-1}\right)$} \\
\hline & 0 & 25 & 50 & 100 & 200 \\
\hline & & & 15 dias & & $-\ldots$ \\
\hline Controle & $1,10 a^{(1)}$ & $1,45 \mathrm{a}$ & $1,99 \mathrm{a}$ & $3,96 \mathrm{a}$ & $6,31 \mathrm{a}$ \\
\hline Gi. margarita & $1,10 \mathrm{a}$ & $1,55 \mathrm{a}$ & $2,25 \mathrm{a}$ & $4,00 \mathrm{a}$ & $6,30 \mathrm{a}$ \\
\hline G. intraradices & $0,89 \mathrm{a}$ & $1,46 \mathrm{a}$ & $2,68 \mathrm{a}$ & $4,40 \mathrm{a}$ & $6,15 \mathrm{a}$ \\
\hline Controle & $123 \mathrm{a}$ & $340 \mathrm{a}$ & 30 dias & 23849 & $2870 \mathrm{a}$ \\
\hline Gi. margarita & $1,47 \mathrm{a}$ & $3,95 \mathrm{a}$ & $7,52 \mathrm{a}$ & $22,20 \mathrm{a}$ & $28,85 \mathrm{a}$ \\
\hline G. intraradices & $1,28 \mathrm{a}$ & $4,30 \mathrm{a}$ & $8,26 \mathrm{a}$ & $20,02 \mathrm{a}$ & $32,75 \mathrm{a}$ \\
\hline & & & 60 dias & & 180839 \\
\hline Controle & $1,60 \mathrm{a}$ & 14,02 a & $39,38 \mathrm{a}$ & $122,55 \mathrm{a}$ & $180,83 \mathrm{a}$ \\
\hline Gi. margarita & $1,91 \mathrm{a}$ & 13,75 a & $29,90 \mathrm{a}$ & 84,77 b & 174,1 a \\
\hline G. intraradices & $3,07 \mathbf{a}$ & 19,93 a & $35,10 \mathrm{a}$ & $112,13 \mathrm{a}$ & $148,93 \mathrm{~b}$ \\
\hline Controle & $2,57 \mathrm{a}$ & $21,69 \mathrm{a}$ & $43,69 \mathrm{~b}$ & $147,87 \mathrm{a}$ & $236,60 \mathrm{a}$ \\
\hline Gi. margarita & $7,43 \mathrm{a}$ & $25,02 \mathrm{a}$ & $49,92 \mathrm{~b}$ & $118,73 \mathrm{~b}$ & $241,47 \mathrm{a}$ \\
\hline G. intraradices & $6,97 \mathrm{a}$ & $32,02 \mathrm{a}$ & $74,21 \mathrm{a}$ & $127,20 \mathrm{~b}$ & 229,93 a \\
\hline
\end{tabular}

(1) Letras iguais, comparadas na vertical, dentro da mesma dose e época, não diferem entre si pelo teste $t$ $(\mathrm{P}<0,05)$. C.V. $=20,92 \%$

Como o cálculo para a obtenção da quantidade total de $\mathrm{P}$ acumulado pelas plantas foi feito multiplicando-se o teor obtido pela MSPA, é provável que as diferenças estatísticas obtidas sejam causadas apenas pelo efeito dos valores de MSPA, justamente mais altos nos mesmos tratamentos que apresentam maiores quantidades de $\mathrm{P}$ (Tabela 10). As análises estatísticas dos resultados de concentração de $P$ tanto para 
MSPA, quanto para vagens, não apresentaram diferenças significativas entre os tratamentos, nem tampouco tendências de maiores concentrações nos tratamentos em que os FMAs estiveram presentes (dados não apresentados). Estes resultados sugerem que a contribuição dos fungos, especialmente $G$. intraradices, em termos aumento de absorção de $\mathbf{P}$ não foi afetada em sua concentração, pois uma maior absorção de $\mathbf{P}$ poderia estar causando maior desenvolvimento vegetativo e conseqüente diluição deste elemento, não possibilitando que diferenças fossem detectadas. Entretanto, tendências de maiores quantidades totais acumuladas de $\mathbf{P}$ na presença de $G$. intraradices e nas baixas doses de $\mathrm{P}$ foram observadas ao 60 e 90 dias, enquanto Gi. margarita só demonstrou esta tendência na ausência de $\mathrm{P}$ adicionado.

\subsubsection{Potássio}

Os efeitos da presença dos FMAs sobre o total absorvido deste nutriente (Tabela 11) também esteve associado à produção de material seco pela parte aérea, de forma semelhante ao observado para $P$, uma vez que os resultados referentes à concentração, tanto na parte vegetativa, quanto nas vagens não foram influenciados diretamente pelos fungos (dados não apresentados).

Observa-se, que os efeitos da presença dos FMAs tornam-se mais evidentes no final do ciclo da cultura, justamente quando seus efeitos sobre a produção da MSPA também foram mais evidentes (Tabela 3). Efeitos de FMAs sobre a concentração deste elemento no tecido vegetal somente têm sido observados quando, em decorrência da melhor nutrição da planta por outros nutrientes, ocorre maior desenvolvimento da mesma e em conseqüência um efeito diluição do $\mathrm{K}$, diminuindo sua concentração, embora a quantidade total possa ser maior que nas plantas não micorrizadas. Por ser um elemento altamente móvel em nossos solos, nos quais predominam argilas 1:1, sua absorção é feita predominantemente por fluxo de massa pelas próprias raízes, não dependendo do complexo de hifas dos FMAs para ter sua absorção aumentada. 
Tabela 11. Efeito de FMAs sobre o total de $\mathrm{K}$ acumulado (mg parcela $\left.{ }^{-1}\right)$ pela parte aérea de plantas de soja, em cada nível do fator Época, em interação com os níveis do fator Doses de P.

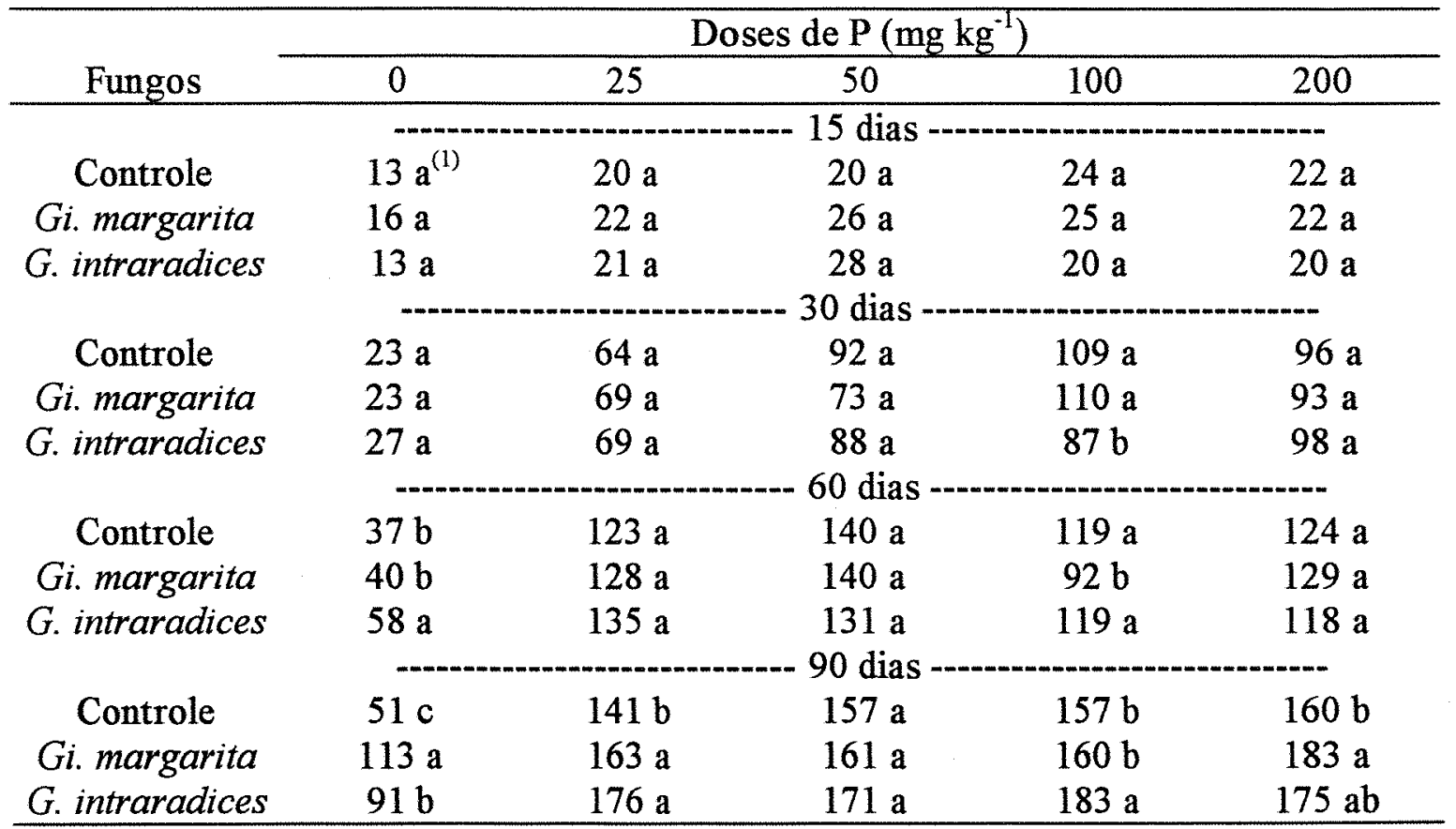

(1) Letras iguais, comparadas na vertical, dentro da mesma dose e época, não diferem entre si pelo teste $t$ $(\mathrm{P}<0,05)$. C.V. $=12,73 \%$

\subsubsection{Cálcio}

Os resultados desta variável apresentaram interações duplas entre FMAs e Doses de P, como mostrado na Tabela 12.

Tabela 12. Efeito de FMAs sobre o Ca total acumulado (mg parcela ${ }^{-1}$ ) na parte aérea de plantas de soja, em cada nível do fator Doses de $\mathrm{P}$ (média das 4 épocas).

\begin{tabular}{cccccc}
\hline & \multicolumn{5}{c}{ Doses de $\mathrm{P}\left(\mathrm{mg} \mathrm{kg}^{-1}\right)$} \\
\cline { 2 - 6 } Fungos & 0 & 25 & 50 & 100 & 200 \\
\hline Controle & $14 \mathrm{a}^{(1)}$ & $98 \mathrm{a}$ & $182 \mathrm{ab}$ & $276 \mathrm{a}$ & $274 \mathrm{a}$ \\
Gi. margarita & $25 \mathrm{a}$ & $110 \mathrm{a}$ & $162 \mathrm{~b}$ & $227 \mathrm{~b}$ & $273 \mathrm{a}$ \\
G. intraradices & $25 \mathrm{a}$ & $96 \mathrm{a}$ & $198 \mathrm{a}$ & $245 \mathrm{~b}$ & $252 \mathrm{a}$ \\
\hline
\end{tabular}

(1) Letras iguais, comparadas na vertical e dentro da mesma dose, não diferem entre si pelo teste $\mathrm{T}$ $(P<0,05)$. C. $V .=20,75 \%$. 
Diferenças significativas foram observadas quanto à presença dos FMAs apenas nas doses 50 e $100 \mathrm{mg} \mathrm{kg}^{-1}$. Na primeira delas, houve diferença apenas entre os fungos, com maior destaque para $G$. intraradices, o que coincidiu com maiores produções de MSPA das plantas associadas a esse fungo (Tabela 3). Na dose seguinte $\left(100 \mathrm{mg} \mathrm{kg}^{-1}\right)$, a presença dos fungos levou a menores valores desta variável. Tal diminuição também foi observada em termos de concentração na presença dos fungos em relação à testemunha, somente nesta dose (dados não mostrados). Nesta mesma dose foi observada menor nodulação (MSN e número) na presença dos FMAs (Tabelas 4 e 5).

\subsubsection{Magnésio}

Esta variável apresentou interação tripla entre os fatores envolvidos. A Tabela 13 ilustra o efeito da presença dos FMAs em cada nível dos fatores estudados.

Tabela 13. Efeito de FMAs sobre o $\mathrm{Mg}$ total acumulado (mg parcela ${ }^{-1}$ ) pela parte aérea de plantas de soja, em cada nível do fator Época, em interação com os niveis do fator Doses de $\mathbf{P}$.

\begin{tabular}{|c|c|c|c|c|c|}
\hline \multirow[b]{2}{*}{ Fungos } & \multicolumn{5}{|c|}{ Doses de $\mathrm{P}\left(\mathrm{mg} \mathrm{kg}^{-1}\right)$} \\
\hline & 0 & 25 & 50 & 100 & 200 \\
\hline & \multicolumn{5}{|c|}{15 dias -} \\
\hline Controle & $5 a^{(1)}$ & $6 \mathrm{a}$ & $6 \mathrm{a}$ & $7 \mathrm{a}$ & $7 \mathrm{a}$ \\
\hline Gi. margarita & $4 \mathrm{a}$ & $6 \mathrm{a}$ & 8 a & 8 a & $6 \mathrm{a}$ \\
\hline G. intraradices & $5 \mathrm{a}$ & $6 \mathrm{a}$ & $8 \mathrm{a}$ & $5 \mathrm{a}$ & $5 \mathrm{a}$ \\
\hline & 19 & & 30 dias & $\varepsilon$ & -- \\
\hline Controle & $12 \mathrm{a}$ & $22 a$ & $38 \mathrm{a}$ & 53 a & $39 a$ \\
\hline Gi. margarita & $12 \mathrm{a}$ & $26 a$ & $33 a$ & $55 \mathrm{a}$ & $42 \mathrm{a}$ \\
\hline G. intraradices & $13 a$ & $28 \mathrm{a}$ & $41 \mathrm{a}$ & $43 a$ & $52 \mathrm{a}$ \\
\hline & -- & & 60 dias & 007 & - \\
\hline Controle & $21 \mathrm{a}$ & $97 a$ & $213 \mathrm{a}$ & $275 \mathrm{a}$ & $285 a$ \\
\hline Gi. margarita & $25 \mathrm{a}$ & $102 \mathrm{a}$ & $172 \mathrm{~b}$ & $221 b$ & $275 \mathrm{a}$ \\
\hline G. intraradices & $27 a$ & $116 \mathrm{a}$ & $194 a b$ & $279 a$ & $245 \mathrm{~b}$ \\
\hline & $25 \mathrm{~h}$ & 181 & 90 dias & 270 & -- \\
\hline $\begin{array}{l}\text { Controle } \\
\text { Gi margarita }\end{array}$ & 250 & $181 \mathrm{a}$ & $308 \mathrm{~b}$ & 379 a & $351 \mathrm{a}$ \\
\hline G. intraradices & $40 \mathrm{ab}$ & $183 \mathrm{a}$ & $\begin{array}{l}290 \mathrm{a} \\
347 \mathrm{a}\end{array}$ & $\begin{array}{c}350 \text { ab } \\
346 \mathrm{~b}\end{array}$ & $\begin{array}{l}3130 \\
289 b\end{array}$ \\
\hline
\end{tabular}

(1) Letras iguais, comparadas na vertical, dentro da mesma dose e época, não diferem entre si pelo teste $t$ $(\mathrm{P}<0,05)$. C.V. $=15,96 \%$ 
Como observado na Tabela 13, a presença dos fungos aos 60 dias, em combinação com as três últimas doses, de modo geral ocasionou diminuição na quantidade total de $\mathrm{Mg}$ absorvido, sendo que nas duas primeiras doses, apenas se observaram tendências de maiores quantidades na presença dos FMAs, no entanto, sem diferirem estatisticamente entre si. Aos 90 dias, maior acúmulo foi observado na presença de Gi. margarita na dose $0 \mathrm{mg} \mathrm{kg}^{-1} \mathrm{e}$ G. intraradices na dose $50 \mathrm{mg} \mathrm{kg}^{-1}$. Nas maiores doses, a presença dos fungos levou à diminuição desta variável. Estes resultados concordam com Cardoso $(1985,1986)$.

\subsubsection{Enxofre}

Esta variável não foi influenciada pela presença dos FMAs, mas somente pelas doses de $\mathrm{P}$ e pelas épocas estudadas. Com relação ao efeito das épocas, houve sempre aumento linear da variável, até a dose $100 \mathrm{mg} \mathrm{kg}^{-1}$. Na maior dose, o aumento da variável passou a ser quadrático. Todas as equações de regressão obtidas foram altamente significativas $(P<0,001)$ e apresentaram valores de $R^{2}$ superiores a 0,94 . $\mathrm{O}$ efeito das doses de $\mathrm{P}$ sobre $\mathrm{o}$ acúmulo de $\mathrm{S}$ não foi constatado aos 15 dias, uma vez que as plantas ainda eram muito jovens. Aos 30 dias pôde ser observado efeito linear positivo altamente significativo $(P<0,002)$ com $R^{2}$ de 0,78 . Para as duas épocas finais foram obtidos modelos quadráticos também altamente significativos $(\mathrm{P}<0,001)$ e valores de $\mathrm{R}^{2}$ superiores a 0,98 (dados não apresentados).

\subsection{Micronutrientes metálicos $(\mathrm{Cu}, \mathrm{Fe}, \mathrm{Mn}, \mathrm{Zn})$}

De forma semelhante aos macronutrientes, os micronutrientes metálicos também tiveram seu acúmulo influenciado pelas doses de $P$. Houve redução na quantidade total acumulada quando se tendeu para a dose de $200 \mathrm{mg} \mathrm{kg}^{-1}$, a qual novamente apresentou efeitos negativos sobre o acúmulo de nutrientes. Neste caso, além da inibição competitiva, a alta quantidade de $\mathrm{P}$ no substrato pode ter levado à complexação dos nutrientes metálicos, resultando em formas menos solúveis (Murphy et al., 1981). Uma vez que o aumento das doses de $\mathrm{P}$ também causou redução da 
colonização radicular pelos FMAs, a complexação dos micronutrientes não pôde ser compensada pelo aumento da absorção proveniente da rede micelial, resultando em menores quantidades absorvidas (Figura 13).

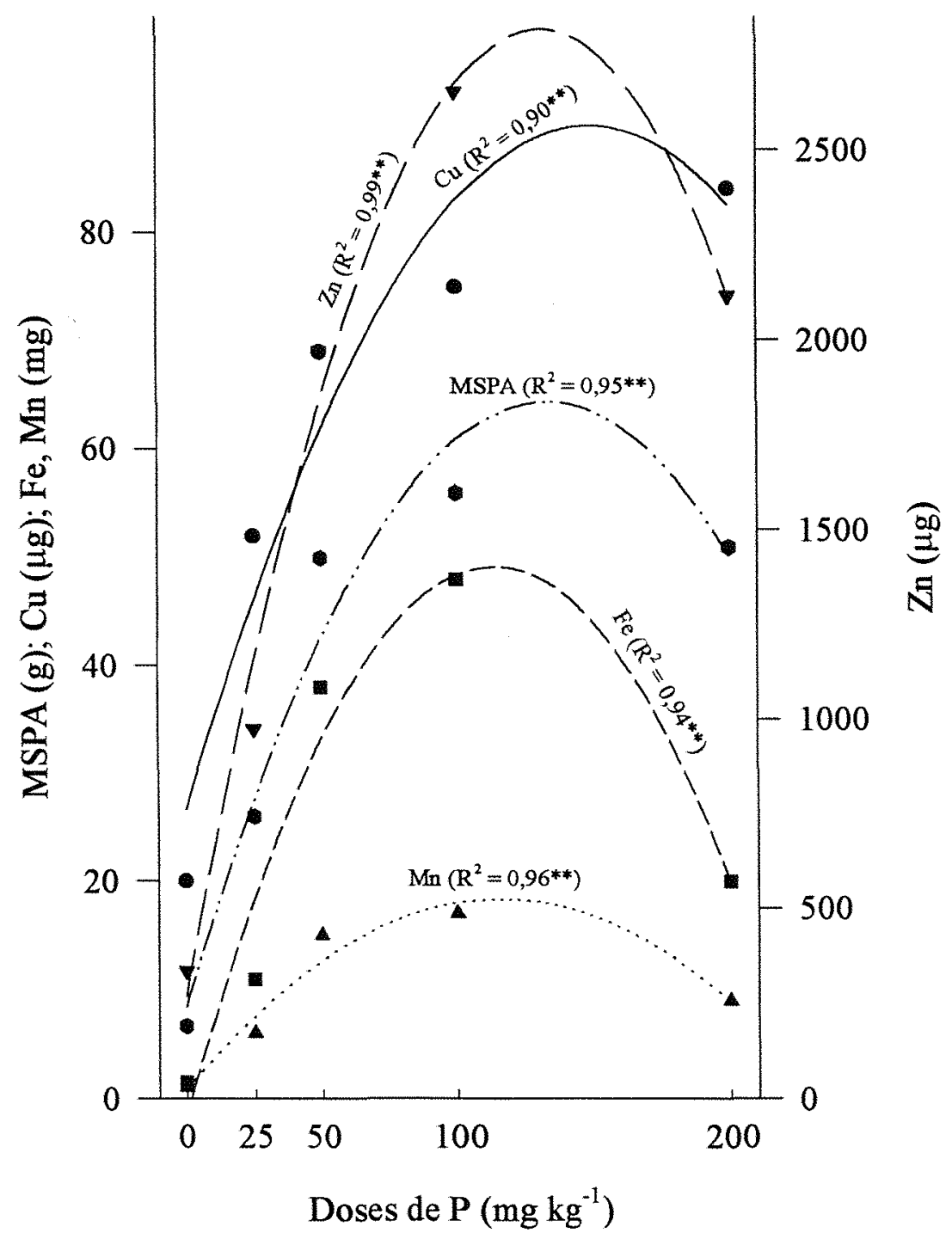

Figura 13. Efeito das doses de $\mathbf{P}$ sobre o acúmulo de alguns micronutrientes pela parte aérea de plantas de soja aos 90 dias após o transplantio (média dos tratamentos com FMAs e controle). ${ }^{* *}=$ Equações significativas a $\mathrm{P}<0,001$ pelo teste $\mathrm{F}$. 
Dentre os micronutrientes analisados, apenas o $\mathrm{Cu}$ e o $\mathrm{Zn}$ foram influenciados de modo significativo pelos FMAs quanto ao total acumulado pela parte aérea e os resultados para estes nutrientes são apresentados nas Tabelas 14 e 15, respectivamente. Como pode ser observado no caso do $\mathrm{Cu}$, os efeitos da presença dos FMAs foram notados apenas aos 60 dias. Ao contrário do que tem sido encontrado por outros resultados de pesquisa, a presença destes FMAs, nesta época, levou ao menor acúmulo deste nutriente. É provável que nesta época, o $\mathrm{Cu}$ estivesse sendo deslocado para a formação das estruturas fúngicas, visto que estes ainda encontravam-se em fase de crescimento.

Tabela 14. Efeito de FMAs sobre o $\mathrm{Cu}$ total acumulado $\left(\mu \mathrm{g}_{\text {parcela }}{ }^{-1}\right)$ pela parte aérea de plantas de soja, em cada nível do fator Época, em interação com os níveis do fator Doses de $\mathbf{P}$.

\begin{tabular}{|c|c|c|c|c|c|}
\hline \multirow[b]{2}{*}{ Fungos } & \multicolumn{5}{|c|}{ Doses de $\mathrm{P}\left(\mathrm{mg} \mathrm{kg}^{-1}\right)$} \\
\hline & 0 & 25 & 50 & 100 & 200 \\
\hline & \multicolumn{5}{|c|}{ - 15 dias } \\
\hline Controle & $8 a^{(1)}$ & $10 \mathrm{a}$ & $11 \mathrm{a}$ & $12 \mathrm{a}$ & $16 \mathrm{a}$ \\
\hline Gi. margarita & $9 \mathrm{a}$ & $13 \mathrm{a}$ & $12 \mathrm{a}$ & $10 \mathrm{a}$ & $11 \mathrm{a}$ \\
\hline G. intraradices & $5 \mathrm{a}$ & 5 a & 8 a & 5 a & $10 \mathrm{a}$ \\
\hline Controle & $6 a$ & $14 a$ & $34 \mathrm{a}$ & $26 \mathrm{a}$ & $41 \mathrm{a}$ \\
\hline Gi. margarita & $14 \mathrm{a}$ & $38 \mathrm{a}$ & $36 a$ & $33 a$ & $32 \mathrm{a}$ \\
\hline G. intraradices & $12 \mathrm{a}$ & $34 \mathrm{a}$ & $34 a$ & $37 a$ & $50 \mathrm{a}$ \\
\hline & & & 60 dia & & \\
\hline Controle & 13 a & $85 a$ & $94 \mathrm{a}$ & $140 \mathrm{a}$ & $86 a$ \\
\hline Gi. margarita & $18 \mathrm{a}$ & $47 b$ & $30 \mathrm{~b}$ & $32 \mathrm{c}$ & $80 \mathrm{a}$ \\
\hline G. intraradices & $17 \mathrm{a}$ & $54 \mathrm{~b}$ & $54 \mathrm{~b}$ & $84 b$ & $41 \mathrm{~b}$ \\
\hline & 10 & 66 & 90 dia & - & $-\overline{10}$ \\
\hline Controle & $18 \mathrm{a}$ & $66 \mathrm{a}$ & $69 a$ & $73 a$ & $70 \mathrm{a}$ \\
\hline Gi. margarita & $18 \mathrm{a}$ & $48 \mathrm{a}$ & $74 \mathrm{a}$ & $68 a$ & $88 \mathrm{a}$ \\
\hline G. intraradices & $23 a$ & $41 \mathrm{a}$ & $68 \mathrm{a}$ & $83 a$ & $95 \mathrm{a}$ \\
\hline
\end{tabular}

(1) Letras iguais, comparadas na vertical, dentro da mesma dose e época, não diferem entre si pelo teste $t$ $(\mathrm{P}<0,05)$. C.V. $=15,96 \%$ 
Quanto ao $\mathrm{Zn}$ acumulado, a Tabela 15 mostra que os efeitos da presença dos FMAs somente foram notados aos 90 dias, nas três maiores doses de $\mathrm{P}$. Na ausência de $\mathrm{P}$ adicionado, houve tendência de aumento quando ambos FMAs estiveram presentes. Dependendo da dose de $\mathrm{P}$ empregada, houve, aos 90 dias, redução na variável estudada na presença de um ou do outro fungo, ou de ambos. Aumento significativo nas quantidades absorvidas de $\mathrm{Zn}$ devido a presença dos FMAs não foi observado, provavelmente devido à formação de compostos insolúveis na presença de $\mathrm{P}$, levando a resultados contrários.

Tabela 15. Efeito de FMAs sobre o $\mathrm{Zn}$ total acumulado $\left(\mu \mathrm{g}\right.$ parcela $\left.{ }^{-1}\right)$ pela parte aérea de plantas de soja, em cada nível do fator Época, em interação com os níveis do fator Doses de $P$.

\begin{tabular}{|c|c|c|c|c|c|}
\hline \multirow[b]{2}{*}{ Fungos } & \multicolumn{5}{|c|}{ Doses de $\mathrm{P}\left(\mathrm{mg} \mathrm{kg}^{-1}\right)$} \\
\hline & 0 & 25 & 50 & 100 & 200 \\
\hline & & & 15 dias & & --- \\
\hline Controle & $33 \mathrm{a}^{(1)}$ & $31 \mathrm{a}$ & $38 \mathrm{a}$ & $39 a$ & $49 a$ \\
\hline Gi. margarita & $26 \mathrm{a}$ & 29 a & $46 \mathrm{a}$ & $52 \mathrm{a}$ & $40 \mathrm{a}$ \\
\hline G. intraradices & 29 a & $36 \mathrm{a}$ & $50 \mathrm{a}$ & $36 \mathrm{a}$ & $49 \mathrm{a}$ \\
\hline Controle & $72 \mathrm{a}$ & $123 \mathrm{a}$ & $167 \mathrm{a}$ & 218 a & $208 \mathrm{a}$ \\
\hline Gi. margarita & $72 \mathrm{a}$ & $136 \mathrm{a}$ & $168 \mathrm{a}$ & $274 a$ & $223 \mathrm{a}$ \\
\hline G. intraradices & $78 \mathrm{a}$ & $135 \mathrm{a}$ & $215 \mathrm{a}$ & $227 \mathrm{a}$ & $273 \mathrm{a}$ \\
\hline Controle & $143 \mathrm{a}$ & $566 \mathrm{a}$ & 1062 a & $1298 \mathrm{a}$ & $1504 \mathrm{a}$ \\
\hline Gi. margarita & $167 \mathrm{a}$ & $549 \mathrm{a}$ & $816 \mathrm{a}$ & $1216 \mathrm{a}$ & $1357 \mathrm{a}$ \\
\hline G. intraradices & $273 a$ & $651 \mathrm{a}$ & $704 \mathrm{a}$ & 1337 a & $1550 \mathrm{a}$ \\
\hline Controle & $183 \mathrm{a}$ & $1018 \mathrm{a}$ & $2185 \mathrm{a}$ & 3378 a & $2355 \mathrm{a}$ \\
\hline Gi. margarita & $426 \mathrm{a}$ & $925 \mathrm{a}$ & $1645 \mathrm{~b}$ & $2361 \mathrm{~b}$ & $2244 a$ \\
\hline G. intraradices & 402 a & $980 \mathrm{a}$ & $2082 \mathrm{a}$ & $2222 b$ & $1748 \mathrm{~b}$ \\
\hline
\end{tabular}

(1) Letras iguais, comparadas na vertical, dentro da mesma dose e época, não diferem entre si pelo teste $t$ $(\mathrm{P}<0,05)$. C. $\mathrm{V} .=32,84 \%$

Conforme Olsen (1972), existe um comportamento antagônico entre o $\mathrm{Zn}$ e $\mathrm{P}$, devido ao fato destes elementos interagirem entre si na planta. A presença de elevadas doses de $\mathrm{P}$ levaria à redução da disponibilidade de $\mathrm{Zn}$ pela formação de 
compostos insolúveis como $\mathrm{Zn}_{3}\left(\mathrm{PO}_{4}\right)_{2}$, resultando em menores taxas de translocação deste elemento das raizes para a parte aérea. Outra conseqüência seria o aparecimento de distúrbios metabólicos nas células, devido ao desequilibrio entre $\mathrm{Zn}$ e $\mathrm{P}$ causado pela interferência deste último na função metabólica do $\mathrm{Zn}$.

A concentração de ferro e manganês nas vagens foi afetada pela presença dos FMAs, dependendo da dose de $P$ associada (Figura 14). Observou-se que a presença dos fungos levou à menor concentração destes elementos nas vagens, quando estiveram associados às menores doses de $P$, quando se obtiveram maiores taxas de colonização radicular (Figura 2). À medida que houve aumento das doses de P, com redução da colonização, as concentrações destes elementos aumentaram, para posteriormente haver diminuição com o aumento das doses. Conforme Murphy et al. (1981), têm-se observado deficiência de $\mathrm{Fe}$ em soja em decorrência da alta disponibilidade de $\mathrm{P}$. Neste experimento, nas menores doses de $\mathrm{P}$, o controle sem fungo apresentou as maiores concentrações destes elementos, com diminuição linear com o aumento das doses. Na maior dose, o decréscimo de concentração ocorreu tanto na presença quanto na ausência dos FMAs, demonstrando ser um efeito atribuível ao $P$. Estes resultados sugerem um efeito protetor dos FMAs quanto a altos níveis destes elementos, especialmente quando se obtém altas taxas de colonização na presença de baixas doses de $P$.

Vários autores citados por Murphy et al. (1981), observaram que em condições de alta disponibilidade de $\mathrm{P}$, a severidade da toxicidade de $\mathrm{Mn}$ é atenuada.

Diminuição da concentração de Mn em tecidos de soja na presença de FMAs também foram obtidos por Cardoso (1985, 1986). Pacovsky \& Fuller (1988), Pacovsky (1986), Pacovsky et al. (1986b) observaram além de diminuições nos teores de Mn, também diminuições nos teores de Fe. Conforme Pacovsky (1986), mudanças de $\mathrm{pH}$ na micorrizosfera pode alterar o estado de oxidação do $\mathrm{Mn}$ o que pode alterar sua absorção. Contudo estes mecanismos ainda não estão bem elucidados. 


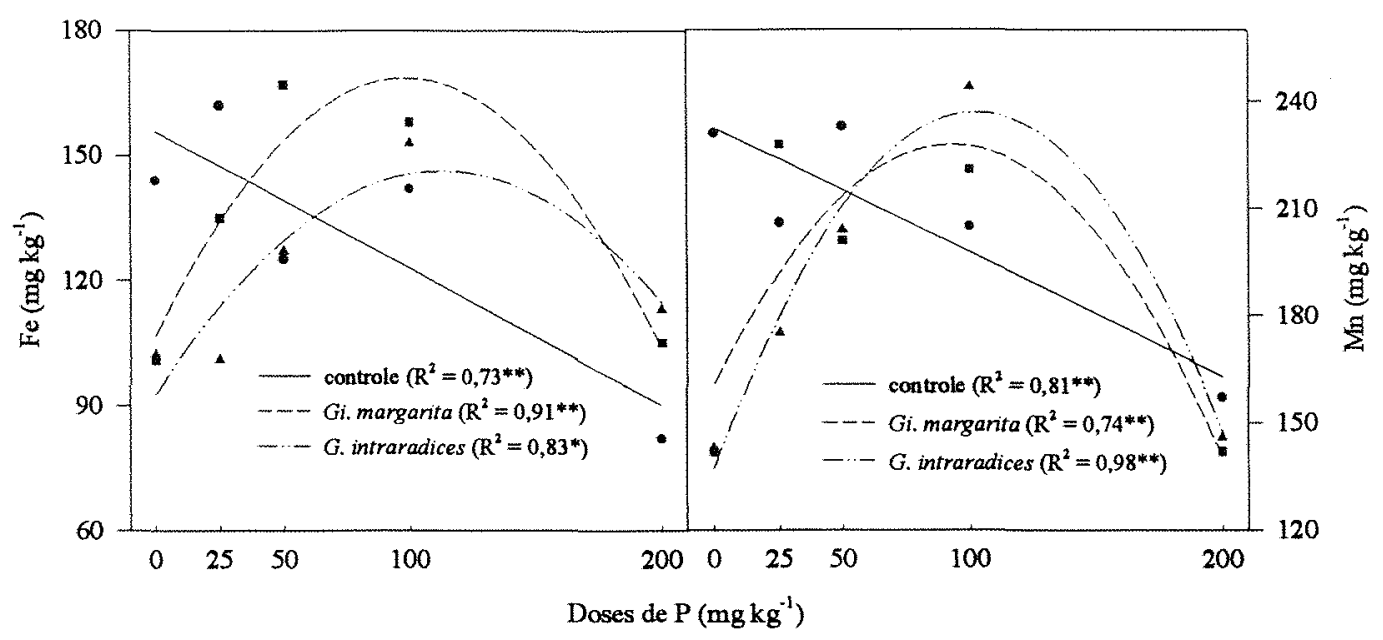

Figura 14. Concentração de Fe e Mn nas vagens de soja, na presença e na ausência de FMAs, aos 90 dias, em função das doses de $\mathrm{P} .{ }^{*}=$ Equação significativa a $\mathbf{P}<0,05 ; * *=$ significativa a $\mathbf{P}<0,01$ pelo teste $\mathrm{F}$. 


\section{CONCLUSÕES}

Conforme os dados obtidos, nas condições em que este experimento foi realizado, concluiu-se que:

1. O fungo Gigaspora margarita foi menos eficiente na colonização do hospedeiro por apresentar fase de crescimento lento mais prolongada;

2. $O$ incremento das doses de $P$ influenciou negativamente a colonização da soja pelos FMAs;

3. A inibição da colonização radicular pelo incremento das doses de $P$ não ocorre nas fases iniciais da interação;

4. Incremento das doses de P causou decréscimos do micélio externo ativo para ambos FMAs;

5. O micélio externo ativo produzido por Glomus intraradices aumentou com o tempo, numa proporção maior que a apresentada por Gigaspora margarita;

6. A maior ou menor eficiência de cada FMA em auxiliar a absorção de nutrientes pela soja foi dependente das doses de $\mathrm{P}$;

7. A presença dos FMAs pode auxiliar na proteção contra níveis tóxicos de $\mathrm{Mn}$ e $\mathrm{Fe}$, quando altos níveis de colonização radicular são atingidos. 


\section{REFERÊNCIAS BIBLIOGRÁFICAS}

ABBOTT, L.K; ROBSON, A.D. Infectivity and effectiveness of vesicular arbuiscular mycorrhizal fungi: effect of inoculation type. Australian Journal of Agricultural Research, v.32, p.631-639, 1981.

ABBOTT, L.K; ROBSON, A.D.; The effect of VA mycorrhizae on plant growth. In: POWELL, C.L.; BAGYARAJ, D.J. (Ed.) V A mycorrhiza. Boca Raton: CRC Press, 1984. p. 113-130.

ABBOTT, L.K; ROBSON, A.D. Formation of external hyphae in soil by four species of vesicular-arbuscular mycorrhizal fungi. New Phytologist, v. 99, p. 245-255, 1985.

ABBOTT, L.K; ROBSON, A.D.; DE BOER, G. The effect of phosphorus on the formation of hyphae in soil by the vesicular-arbuscular mycorrhizal fungus, Glomus fasciculatum. New Phytologist, v. 97, p. 437-446, 1984.

AMES, R.N.; INGHAM, E.R.; REID, C.P.P. Ultraviolet-induced autofuorescence of arbuscular mycorrhizal root infections: an alternative to clearing and staining methods for assessing infections. Canadian Journal of Microbiology, v. 28, p. 351-355, 1982.

ANTUNES, V.; CARDOSO, E.J.B.N. Growth and nutrient status of citrus plants as influencied by mycorrhiza and phosphorus application. Plant and Soil, v. 131, p. 1119, 1991. 
BAATH, E.; HAYMAN, D.S. Effect of soil volume and plant density on mycorrhizal infection and growth response. Plant and Soil, v. 77, p. 373-376, 1984.

BAREA, J.M.; AZCÓN-AGUILAR, C. Mycorrhizas and their significances in nodulating nitrogen-fixing plants. Advances in Agronomy, v. 36, p. 1-54, 1983.

BETHLENFALVAY, G.J.; AMES, R.N. Comparison of two methods for quantifying extraradical mycelium of vesicular-arbuscular mycorrhizal fungi. Soil Science Society of America Journal, v. 51, p. 834-837, 1987.

BETHLENFALVAY, G.J.; BAYNE, H.G.; PACOVSKY, R.S. Parasitic and mutualistic associations between a mycorrhizal fungus and soybean: the effect of phosphorus on host plant-endophyte interactions. Physiologia Plantarum, v. 57, p. 543-548, 1983.

BETHLENFALVAY, G.J.; BROWN, M.S.; PACOVSKY, R.S. Parasitic and mutualistic associations between a mycorrhizal fungus and soybean: development of the endophyte. Ecology and Epidemiology, v. 72, n. 7, p. 894-897, 1982a.

BETHLENFALVAY, G.J.; BROWN, M.S.; PACOVSKY, R.S. Parasitic and mutualistic associations between a mycorrhizal fungus and soybean: development of the host plant. Ecology and Epidemiology, v. 72, n. 7, p. 889-893, 1982b.

BETHLENFALVAY, G.J.; BROWN, M.S.; PACOVSKY, R.S. Relationships between host and endophyte development in mycorrhizal soybeans. New Phytologist, v.90, p. $537-543,1982 \mathrm{c}$.

BETHLENFALVAY, G.J.; PACOVSKY, R.S.; BAYNE, H.G.; STAFFORD, E. Interactions between nitrogen fixation, mycorrhizal colonization, and host-plant growth in the Phaseolus-Rhizobium-Glomus symbiosis. Plant Physiology, v. 70, p. 446-450, 1982d.

BETHLENFALVAY, G.J.; PACOVSKY, R.S.; BROWN, M.S; FULlER, G. Mycotrophic growth and mutualistic development of host plant and fungal endophyte in an endomycorrhizal symbiosis. Plant and Soil, v. 68, n. 9, p. 43-54, 1982e. 
BONFANTE-FASOLO, P. Anatomy and morfology of VA mycorrhizae. In: POWEL, C.L; BAGYARAJ, D.J. (Ed.) VA mycorrhiza. Boca Raton: CRC Press, 1984. p. 5-33.

CALDEIRA, S.F.; CHAVES, G.M.; ZAMBOLIM, L. Observações de micorriza vesicular-arbuscular em diferentes espécies de plantas. Revista Ceres, v. 30, n.167, p. 19-24, 1983.

CARDOSO, E.J.B.N. Efeito de micorriza vesículo-arbuscular e fosrato-de-rocha na simbiose soja-Rhizobium. Revista Brasileira de Ciência do Solo, v. 9, p. 125-130, 1985.

CARDOSO, E.J.B.N. Eficiência de fungos micorrízicos vesículo-arbusculares em soja, com Rhizobium japonicum e fosfato de rocha, em função do tipo de solo. Revista Brasileira de Ciência do Solo, v.10, p. 17-23, 1986.

CARDOSO, E.J.B.N.; ANTUNES, V.; SILVEIRA, A.P.D.; OLIVEIRA, M.H.A. Eficiência de fungos micorrízicos vesículo-arbusculares em porta-enxertos de citrus. Revista Brasileira de Ciência do Solo, v. 10, p. 25-30, 1986.

CARDOSO-FILHO, J.A. Quantificação do micélio extramatricial de Glomus etunicatum e da sua atividade, em simbiose com milho. Piracicaba, 1994. 121 p. Dissertação (Mestrado) - Escola Superior de Agricultura "Luiz de Queiroz", Universidade de São Paulo.

CARLING, D.E.; BROWN, M.F. Relative effect of vesicular-arbuscular mycorrhizal fungi on the growth and yield of soybeans. Soil Science Society of America Journal, v. 44, p. 528-532, 1980.

CARLING, D.E.; BROWN, M.F. Anatomy and phisiology of vesicular-arbuscular and nonmycorrhizal roots. Phytopathology, v. 72, p. 1108-1114, 1982. 
COLOZZI-FILHO, A.; SIQUEIRA, J.O. Micorrizas vesículo-arbusculares em mudas de cafeeiro. I. Efeitos de Gigaspora margarita e adubação fosfatada no crescimento e nutrição. Revista Brasileira de Ciência do Solo, v. 10, p. 199-205, 1986.

COOPER, K.M.; TINKER, P.B. Translocation and transfer of nutrients in vesiculararbuscular mycorrhizas. II. Uptake and translocation of phosphorus, zinc and sulphur. New Phytologist, v. 81, p. 43-52, 1978.

CRUSH, J.R. Endomycorrhizas and legume growth in some soils of the Mackenzie Basin, Canterbury, New Zealand. New Zealand Journal of Agricultural Research, v. 19, p. $473-476,1976$.

DOUDS Jr., D.D. Relationship between hyphal and arbuscular colonization and sporulation in a mycorrhiza of Paspalum notatum Flugge. New Phytologist, v. 126, p. 233-237, 1994.

ELIAS, K.S.; SAFIR, G.R. Hyphal elongation of Glomus fasciculatus in response to root exudates. Applied and Environmental Microbiology, v. 53, n.8, p. 19531933, 1987.

FAQUIN, V. Cinética da absorção de fosfato, nutrição mineral, crescimento e produção da soja sob influência de micorriza vesículo-arbuscular (MVA). Piracicaba, 1988. 136 p. Tese (Doutorado) - Escola Superior de Agricultura "Luiz de Queiroz", Universidade de São Paulo.

FAQUIN, V.; MALAVOLTA, E; MURAOKA, T. Cinética da absorção de fosfato em soja sob influência de micorriza vesículo-arbuscular. Revista Brasileira de Ciência do Solo, v. 14, p. 41-48, 1990.

FERNANDES, A.B.; SIQUEIRA, J.O.; MENEZES, M.A.L.; GUEDES, G.A.A. Efeito diferenciado do fósforo sobre o estabelecimento e efetividade da simbiose endomicorrízica em milho e soja. Revista Brasileira de Ciência do Solo, v. 11, p.101-108, 1987. 
FREY, B.; VILARIÑO, A.; SCHÜEPP, H.; ARINES, J. Chitin and ergosterol content of extraradical and intraradical mycelium of the vesicular-arbuscular mycorrhizal fungus Glomus intraradices. Soil Biology and Biochemistry, v. 26, n. 6, p. 711$717,1994$.

GERDEMANN, J.W. Vesicular-arbuscular mycorrhiza an plant growth. Annual Review of Phytopathology, v. 6, p. 397-418, 1968.

GERDEMANN, J.W.; NICOLSON, T.H. Spores of mycorryzal endogone extracted from soil by wet sieving end decanting. Transactions of British Mycological Society, v. 46, p. 235-244, 1963.

GILDON, A.; TINKER,PB. Interactions of vesicular-arbuscular mycorrhizal infections and heavy metals in plant. II. The effects of infection on uptake of cooper. New Phytologist, v. 5, p. 263-268, 1983.

GIOVANNETI, M; MOSSE, B. An evaluation of techiniques for measuring vesicular arbuscular mycorrhizal infecion in roots. New Phytologist, v. 84, p.489-500, 1980.

GOMES, V.F.F. Desenvolvimento de fungos micorrízicos-arbusculares em três espécies de porta-enxertos cítricos sob níveis de fósforo. Piracicaba, 1997. 89 p. Tese (Doutorado) - Escola Superior de Agricultura "Luiz de Queiroz", Universidade de São Paulo.

GRAHAM, J.H.; LINDERMAN, R.G.; MENGE, J.A. Development of external hyphae by different isolates of mycorrhizal Glomus spp. in relation to root colonization and growth of troyer citrange. New Phytologist, v. 91, p. 183-189, 1982.

HAMEL, C.; FYLES, H.; SMITH, D.L. Measurement of development of endomycorrhizal mycelium using three different vital stains. New Phytologist, v. 115, p. 297-302, 1990. 
HAMPP, R.; SCHAEFFER, C. Mycorrhiza-carbohydrate and energy metabolism. In: VARMA, A.; HOCK, B. (Ed.). Mycorrhiza: structure, function, molecular biology and biotechnology. Berlin: Springer-Verlag, 1995. p. 267-296.

HARLEY, J.L.; SMITH, S.E. Mycorrhizal symbiosis. New York, Academic Press, 1983. $483 \mathrm{p}$.

HARRIS, D.; PACOVSKY, R.S.; PAUL; E.A. Carbon economy of soybean-RhizobiumGlomus associations. New Phytologist, v. 101, p. 427-440, 1985.

HAYMAN, D.S. Plant growth responses to vesicular-arbuscular mycorrhiza. New Phytologist, v. 73, p. 71-80, 1974.

HUNGRIA, M.; ANDRADE, D.S.; COLOZZI-FILHO, A.; BALOTA, E.L.; SANTOS J.C.F. Ecologia microbiana em solos sob cultivo na região sul do Brasil. In: SIMPÓSIO BRASILEIRO SOBRE MICROBIOLOGIA DO SOLO, 3,; REUNIÃO DE LABORATÓRIOS PARA RECOMENDAÇÃO DE ESTIRPES DE RHIZOBIUM E BRADYRHIZOBIUM, 6., Londrina, 1994. Anais. Londrina: IAPAR, 1994. p.234-270.

JAKOBSEN, I. Transport of phosphorus an carbon in VA mycorrhizas. In: VARMA, A.; HOCK, B. (Ed.). Mycorrhiza: structure, function, molecular biology and biotechnology. Berlin: Springer-Verlag, 1995. p. 297-324.

KABIR, Z.; O'HALLORAN, I.P.; HAMEL, C. The proliferation of fungal hyphae in soils supporting mycorrhizal and non mycorryizal plants. Mycorrhiza, v. 6, p. 477$480,1996$.

KARUNARATNE, S.; BAKER, J.H.; BARKER, A.V. Phosphorus uptake by mycorrhizal and nomycorrhizal root of soybean. Journal of Plant Nutrition, v. 9, n. 10, p. 1303-1313, 1986. 
KOIDE, R.T.; SCHREINER, R.P. Regulation fo vesicular-arbuscular mycorrhizal symbiosis. Annual Review of Plant Physiology and Plant Molecular Biology, v.43, p. 557-581, 1992.

KORMANIK, P.P.; McGRAW, A.C. Quantification of vesicular-arbuscular mycorrhizae in plant roots. In: SCHENCK, N.C (Ed.). Methods and principles of mycorrhizal research. Saint Paul: The American Phytopathological Society, 1982. p. 37-45.

KOUGH, J.; MALAJCZUK, N.; LINDERMAN, R.G. Use of indirect immunofluorescent techinque to study the vesicular-arbuscular fungus Glomus epigaeum and other Glomus species. New phytologist, v. 94, p. 57-62, 1983.

LAMBAIS, M.R Condições edáficas que afetam o micotrofismo de Stylosanthes guianensis (Aubl) Sw. Piracicaba, 1987. 102 p. Dissertação (Mestrado) - Escola Superior de Agricultura 'Luiz de Queiroz”, Universidade de São Paulo.

LAMBAIS , M.R.; CARDOSO, E.J.B.N. Avaliação da germinação de esporos de fungos micorrízicos vesículo-arbusculares e da colonização micorrizica de Stylosanthes guianansis em solo ácido e distrófico. Revista Brasileira de Ciência do Solo, v. 12, p. 249-255, 1988.

LAMBAIS , M.R.; CARDOSO, E.J.B.N. Germinação de esporos e crescimento do tubo germinativo de fungos micorrízicos vesículo-arbusculares em diferentes concentrações de alumínio. Revista Brasileira de Ciência do Solo, v. 13, p. 151-154, 1989.

LAMBAIS , M.R.; CARDOSO, E.J.B.N. Response of Stylosanthes guianensis to endomycorrhizal fungi inoculation as affected by lime and phosphorus applications. Plant and Soil, v. 129, p 283-289, 1990.

LAMBAIS, M.R.; MEHDY, M.C. Suppression of endochitinase, $\beta-1,3$-endoglucanase, and chalcone isomerase expression in bean vesicular-arbuscular mycorrhizal roots under different soil phosphate conditions. Molecular Plant-Microbe Interactions, v. 6, n. 1, p. $75-83,1993$. 
LAMBAIS, M.R.; MEHDY, M.C. Differential expression of defense-related genes in arbuscular mycorrhiza. Canadian Journal of Botany, v. 73, suppl. 1, p. S553-S540, 1995.

LAMBAIS, M.R.; MEHDY, M.C. Soybean roots infected by Glomus intraradices strains differing in infectivity exhibit differencial chitinase and $\beta$-1,3-glucanase expression. New Phytologist, v. 134, p. 531-538, 1996.

LAMBERT, D.H.; BAKER, D.E.; COLE-JR, H. The role of mycorrhizae in the interactions of phosphorus with zinc, copper and other elements. Soil Science Society of America Journal, v. 43, p. 976-980, 1979.

MALAVOLTA, E. Elementos de nutrição mineral de plantas. São Paulo: Ceres, 1980. $251 \mathrm{p}$.

MALAVOLTA, E.; VITTI, G.C.; OLIVEIRA, S.A. Avaliação do estado nutricional das plantas: princípios e aplicações. Piracicaba: Associação Brasileira para Pesquisa da Potassa e do Fosfato, 1989. 201 p.

MARX, D.H.; BRYAN, W.C. Growth and ectomicorrhizal development of loblolly pine seedlings in fumigated soil infested with the fungal symbiont Pidoliyhud tinctorius. Forest Science, v. 21, p. 245-254, 1975.

MELLONI, R. Quantificação de micélio extrarradicular de fungos micorrízicos arbusculares em plantas cítricas. Piracicaba, 1996. 83 p. Dissertação (Mestrado) Escola Superior de Agricultura 'Luiz de Queiroz", Universidade de São Paulo.

MELLONI, R.; NOGUEIRA, M.A; FREIRE, V.F.; CARDOSO, E.J.B.N. Efeito de doses de fósforo e fungos micorrízicos arbusculares no crescimento de mudas de limão cravo (Citrus limonia L. Osbeck). In: CONGRESSO LATINO AMERICANO DE CIÊNCIA DO SOLO, 13., Águas de Lindóia, 1996. Solo-suelo 96: trabalhos. Piracicaba: SBCS/SLCS, 1996. 
MILLER, R.M.; JARSTFER, A.G.; PILLAI, J.K. Biomass allocation in an Agropyron smithii-Glomus symbiosis. American Journal of Botany, v. 74, n.1, p. 114-122, 1987.

MINHONI, M.T.A.; CARDOSO, E.J.B.N.; EIRA, A.F.; Efeitos da adição de fosfato de rocha, bagaço de cana-de-açúcar, fosfato solúvel e fungo micorrízico no crescimento e na absorção de nutrientes por plantas de soja. Revista Brasileira de Ciência do Solo, v.17, p. 173-178, 1993a.

MINHONI, M.T.A.; CARDOSO, E.J.B.N.; EIRA, A.F.; Efeitos da interação de fosfato de rocha, matéria orgânica e fungo micorrízico no crescimento e na absorção de nutrientes pela soja. Revista Brasileira de Ciência do Solo, v.17, p. 165-171, 1993b.

MIRANDA, J.C.C.; HARRIS, P.J. The effect of soil phosphorus on the external mycelium growth of arbuscular mycorrhizal fungi during the early stages of mycorrhiza formation. Plant and Soil, v. 166, p. 271-280, 1994a.

MIRANDA, J.C.C.; HARRIS, P.J. Effects of soil phosphorus on spore germination and hyphal growth of arbuscular mycorrhizal fungi. New Phytologist, v. 128, p. 103-108, 1994b.

MIRANDA, J.C.C.; HARRIS, P.J.; WILD, A. Effects of soil and plant phosphorus concentrations on vesicular-arbuscular mycorrhiza in sorghum plants. New Phytologist, v. 112, p. 405-410, 1989.

MORTON, J.N.; BENNY, G.L. Revised classification of arbuscular mycorrhizal fungi (Zygomycetes): a new order Glomales, two new suborders, Glomineae and Gigasporinae, and two new families, Acaulosporaceae and Gigasporaceae, with an emendation of Glomaceae. Myxotaxon, n.37, p. 471-491, 1990. 
MOSSE, B. The influence of soil type and Endogone strain on the growth of mycorrhizal plants in phosphate deficient soils. Review of Ecological Biology Society, v.9, p. 529-537, 1972.

MOSSE. B. Specificity of vesicular-arbuscular mycorrhizas. In: SANDERS, F.E.; MOSSE, B.; TINKER, P.B. (Ed.). Endomycorrhizas. New York: Academic Press, 1975. p. $469-484$.

MURPHY, L.S.; ELLIS JR, R; ADRIANO, D.C. Phosphorus-micronutrient interaction effects on crop production. Jounal of Plant Nutrition, v. 3, n. 1-4, p. 593-613, 1981.

NAGAHASHI, G.; DOUDS JR, D.D.; ABNEY, G.D. Phosphorus amendment inhibits hyphal branching of the VAM fungus Gigaspora margarita directly and indirectly through its effect on root exudation. Mycorrhiza, v. 6, p. 403-408, 1996.

NEWMAN, E.I. A method for estimating the total length of root in a sample. Journal of Applied Ecology, v. 3, p. 139-145, 1966.

NURLAENY, N.; MARSCHNER, H.; GEORGE, E. Effects of liming and mycorrhizal colonization on soil phosphate uptake by maize (Zea mays L.) and soybean (Glycine $\max$ L.) grown in two tropical acid soils. Plant and Soil, v. 181, p. 275-285, 1996.

OJALA, J.C.; JARRELL, W.M.; MENGE, J.A; JOHNSON, E.L.V. Comparison of soil phosphorus extractants as predictors of mycorrhizal dependency. Soil Science Society of America Journal, v. 47, p. 958-962, 1983.

OLSEN, S.R. Micronutrients interactions. In: MORTVED, J.J. (Ed.). Micronutrients in agriculture. Madison: Soil Science Society of America, 1972. p. 243-264.

PACOVSKY, R.S. Micronutrient uptake and distribution in mycorrhizal or phosphorusfertilized soybeans. Plant and Soil, v. 95, p. 379-388, 1986. 
PACOVSKY, R.S. Carbohydrate, proteins and amino-acidis status of Glycine-GlomusBradyrhizobium symbioses. Physiologia Plantarum, v. 75, p. 346-354, 1989a.

PACOVSKY, R.S. Metabolic differences in Zea-Glomus-Azospirillum symbioses. Soil Biology and Biochemistry, v. 21, n. 7, p. 953-960, 1989 b.

PACOVSKY, R.S.; BETHLENFALVAY, G.J. Measurement of the extraradical mycelium of a vesicular-arbuscular mycorrhizal fungus in soil by chitin determination. Plant and Soil, v. 68, p. 143-147, 1982.

PACOVSKY, R.S.; FULLER, G. Development of two endomycorrhizal symbioses on soybean and comparison with phosphorus fertilization. Plant and Soil, v. 95, p. 361-377, 1986.

PACOVSKY, R.S.; BETHLENFALVAY, G.J.; PAUL, E.A. Comparison between Pfertilized and mycorrhizal plants. Crop Science, v. 26, p. 151-156, 1986a.

PACOVSKY, R.S.; FULLER, G. Mineral and lipid composition fo Glycine-GlomusBradyrhizobium symbioses. Physiologia Plantarum, v. 72, p.733-746, 1988.

PACOVSKY, R.S; FULLER, G.; PAUL, E.A.; Influence of soil on the interactions between endomycorrhizae and Azospirillum in sorghum. Soil Biology and Biochemistry, v. 17, n. 4, p. 525-531, 1985.

PACOVSKY, R.S.; PAUL, E.A.; BETHLENFALVAY, G.J. Response of mycorrhizal and P-fertilized soybeans to nodulation by Bradyrhizobium or ammonium nitrate. Crop Science, v. 26, p. 145-150, 1986b.

PACOVSKY, R.S.; FULLER, G.; STAFFORD. A.E.; PAUL, E.A. Nutrient and growth interactions in soybeans colonized with Glomus fasciculatum and Rhizobium japonicum. Plant and Soil, v. 92, p. 37-45, 1986c. 
PAULA, M.A.; SIQUEIRA, J.O.; HOSHIKA, E. Crescimento, nutrição e produção de soja inoculada com populações de fungos micorrízicos vesículo-arbusculares. Revista Brasileira de Ciência do Solo, v.14, p. 151-156, 1990.

PAULA, M.A.; SIQUEIRA, J.O; OLIVEIRA, L.H.; OLIVEIRA, E. Efetividade simbiótica relativa em soja de populações de fungos endomicorrízicos nativos e de isolados de Glomus macrocarpum e Gigaspora margarita. Revista Brasileira de Ciência do Solo, v. 12, p.25-31, 1988.

PHILLIPS, J.M.; HAYMAN, D.S. Improved procedures for clearing roots and staining parasitic and vesicular-arbuscular mycorrhizal fungi for rapid assesment of infection. Transactions of the British Mycological Society, v.55, n. 1, p. 158-160, 1970.

POWELL, C.L. Mycorrhizas in hill-country soils. II. Effect of several mycorrhizal fungi on clover growth in sterilized soils. New Zealand Journal of Agricultural Research, v.20, p. 59-62, 1977.

RAIJ, B.van. Fertilidade do solo e adubação. Piracicaba: Ceres; Potafos, 1991. $343 p$.

RAIJ, B. van; QUAGGIO, J.A. Métodos de análise de solo para fins de fertilidade. Campinas: Instituto Agronômico, 1983. 31p. (IAC. Boletim Técnico, 81).

RAIJ, B.van; SILVA, N.M.; BATAGLIA, O.C.; QUAGGIO, J.A.; HIROCE, R.; CANTARELLA, H.; BELLINAZZI Jr., R. DECHEN, A.R.; TRANI, P.E. Recomendações de adubação e calagem para o Estado de São Paulo. Campinas: Instituto Agronômico, 1985. 107 p. (IAC. Boletim Técnico, 100).

RHODES, L.H; GERDEMANN, J.N. Phosphate uptake zones by mycorrhizal and nonmycorrhizal onions. New Phytologist, v. 73, n. 3, p. 555-561, 1975.

ROSS, J.P.; HARPER, J.A. Effect of Endogone mycorrhiza on soybean yields. Phytopathology, v. 60, p. 1552-1556, 1970. 
SAIF, S.R The influence of stage of host development on vesicular-arbuscular mycorrhizae and endogonaceous spore population in field-grown vegetable crops. I. Summer-grown crops. New Phytologist, v. 79, p. 341-348, 1977.

SANDERS, F.E.; TINKER, P.B.; BLACK, R.L.B.; PALMERLEY, S.M. The development of endomycorrhizal root sytems. I. Spread of infection and growthpromoting effects with four species of vesicular-arbuscular endophyte. New Phytologist, v. 78, p. 257-268, 1977.

SARRUGE, J.R.; HAAG, H.P. Análises químicas em plantas. Piracicaba: ESALQ, 1974. $56 \mathrm{p}$.

SCHUBERT, A.; MARZACHÍ, C.; MAZZITELLI, M.; CRAVERO, M.C.; BONFANTE-FASOLO, P. Development of total and viable extraradical mycelium in the vesicular-arbuscular mycorrhizal fungos Glomus clarum Nicol \& Schenck. New Phytologist, v. 107, p. 183-190, 1987.

SILVEIRA, A.P.D. Micorrizas. In: CARDOSO, E.J.B.N; TSAI, S.M.; NEVES, M.C.P. (Ed.) Microbiologia do solo. Campinas: Sociedade Brasileira de Ciência do Solo, 1992. p. 257-282.

SILVEIRA, A.P.D.; CARDOSO, E.J.B.N. Kinetics of phosphorus uptake, growth and mineral nutrition of mycorrhizal and non-mycorrhizal bean (Phaseolus vulgaris L.). In: NORTH AMERICAN CONFERENCE ON MUCORRHIZAE, 8. Wyoming, 1990. $8^{\text {th }}$ NACOM: innovation and hierarchial integration. Wyoming: Jackson, 1990. p. 264.

SIQUEIRA, J.O. Micorrizas: forma e função. In: REUNIÃO BRASILEIRA SOBRE MICORRIZAS, 1., Lavras, 1986. Anais. , p.5-32.

SIQUEIRA, J.O.; COLOZZI-FILHO, A. Micorrizas vesículo-arbusculares em mudas de cafeeiro. II. Efeito do fósforo no estabelecimento e funcionamento da simbiose. Revista Brasileira de Ciência do Solo, v. 10, p. 207-211, 1986. 
SIQUEIRA, J.O.; PAULA, M.A. Efeito de micorrizas vesículo-arbusculares na nutrição e aproveitamento de fósforo pela soja em solo sob cerrado. Revista Brasileira de Ciência do Solo, v. 10, p. 97-102, 1986.

SIQUEIRA, J.O.; HUBBELL, D.H.; VALLE, R.R. Effects of P on formation of the VAM symbiosis. Pesquisa Agropecuária Brasileira, v. 19, n. 12, p. 1465-1474, 1984.

SIQUEIRA, J.O.; MOREIRA, F.M.S.; GRISI, B.M.; HUNGRIA, M. ARAUJO, R.S. Microrganismos e processos biológicos do solo: perspectiva ambiental. Brasília: EMBRAPA; CNPAF, CNPSo, 1994. 142p

SMITH, S. E.; GIANINAZZI-PEARSON, V. Physiological interactions between symbionts in vesicular-arbuscular mycorrhizal plants. Annual Review on Plant Physiology and Plant Molecular Biology, v. 39, p. 221-244, 1988.

STRIBLEY, D.P.; TINKER, P.B.; RAYNER, J.H. Relation of internal phosphorus concentration and plant weight in plants infected by vesicular-arbuscular mycorrhizas. New Phytologist, v. 86, n. 3, p. 261-266, 1980.

SUTTON, J.C. Development of vesicular-arbuscular mycorrhizae in crop plant. Canadian Journal of Botany, v.51, p. 2487-2493, 1973.

SYLVIA, D.M. Activity of external hyphae of vesicular-arbuscular mycorrhizal fungi. Soil Biology and Biochemistry, v.20, n. 1, p. 39-43, 1988.

SYLVIA, D.M. Quantification of external hyphae of vesicular-arbuscular mycorrhizal fungi. Methods in Microbiology, v. 24, p. 54-65, 1992.

TAWARAYA, K.; WATANABE, S.; YOSHIDA, E.; WAGATSUMA, T. Effect of onion (Allim cepa) root exudates on the hyphal growth of Gigaspora margarita. Mycorrhiza, v. 6, p. 57-59, 1996. 
TOMMERUP, I.C. The vesicular arbuscular mycorrhizas. Advances in Plant Pathology, v.6, p. 81-91, 1988.

THOMSON, B.D.; ROBSON, A.D.; ABBOTT, L.K Effects of phosphorus on the formation of mycorrhizas by Gigaspora calospora and Glomus fascicultum in relation to root carbohidrates. New Phytologist, v. 103, p. 751-765, 1986.

VITTI, G.C. Avaliação e interpretação do enxofre no solo e na planta. Jaboticabal: FUNEP, 1989. $37 \mathrm{p}$.

WALKER, C.; TRAPPE, J.M. Names and epiphets in the Glomaes and Endogonales. Mycological Resesarch, v. 97, p. 339-44. 1993.

WILSON, J.M.; TRINICK, M.J.; PARKER, C.A. The identification of vesiculararbuscular mycorrhizal fungi using immunofluorescence. Soil Biology and Biochemistry, v. 15, n.4, p. 439-45, 1983.

ZAMBOLIM, L.; SIQUEIRA, J.O. Importância e potencial das associações micorrízicas para a agricultura. Belo Horizonte: EPAMIG, 1985. 36p. (EPAMIG. Documentos, 26) 
APÊNDICE 
Apêndice 1. Níveis de significância nos quais o efeito dos fatores ou a interação entre eles foi significativa pelo teste $F(P>F)$.

\begin{tabular}{|c|c|c|c|c|c|c|c|}
\hline CAUSAS DA VARIAÇÃO & $\begin{array}{c}\mathbf{P} \\
\text { disponível }\end{array}$ & $\begin{array}{c}\% \\
\text { colonização }\end{array}$ & MSPA & MSV & $\begin{array}{l}\text { massa de } \\
\text { nódulos }\end{array}$ & $\begin{array}{l}\text { número de } \\
\text { nódulos }\end{array}$ & MEA \\
\hline Épocas & $* *$ & $* *$ & $* *$ & $* *$ & ** & $* *$ & *** \\
\hline Fungos & ns & $* *$ & ** & $* *$ & ns & ns & $* *$ \\
\hline Doses $\mathbf{P}$ & ** & ** & $* *$ & $* *$ & $* *$ & $* *$ & $* *$ \\
\hline Épocas $\times$ Fungos & ns & $* *$ & $* *$ & $* *$ & ns & ns & $* *$ \\
\hline Épocas x Doses $\mathrm{P}$ & $* *$ & $* *$ & $* *$ & $* *$ & $* *$ & $* *$ & $* *$ \\
\hline Fungos $\mathrm{x}$ Doses $\mathrm{P}$ & ns & $* *$ & ** & ns & $* *$ & * & $* *$ \\
\hline Épocas $\times$ Fungos $\times$ Doses $P$ & ns & $* *$ & $* *$ & ns & ns & ns & $* *$ \\
\hline
\end{tabular}


Apêndice 1. Niveis de significância nos quais o efeito dos fatores ou a interação entre eles foi significativa pelo teste $F(P>F)$ (continuação)

\begin{tabular}{lccccccc}
\hline CAUSAS DA VARIAÇÃO & MET & $\begin{array}{c}\text { Nitrogênio } \\
\text { total }\end{array}$ & $\begin{array}{c}\text { Fósforo } \\
\text { total }\end{array}$ & $\begin{array}{c}\text { Potássio } \\
\text { total }\end{array}$ & $\begin{array}{c}\text { Cálcio } \\
\text { total }\end{array}$ & $\begin{array}{c}\text { Magnésio } \\
\text { total }\end{array}$ & $\begin{array}{c}\text { Enxofre } \\
\text { total }\end{array}$ \\
\hline Épocas & $* *$ & $* *$ & $* *$ & $* *$ & $* *$ & $* *$ & $* *$ \\
Fungos & $* *$ & $* *$ & $\mathrm{~ns}$ & $* *$ & $\mathrm{~ns}$ & $\mathrm{~ns}$ & $\mathrm{~ns}$ \\
Doses P & $* *$ & $* *$ & $* *$ & $* *$ & $* *$ & $* *$ & $* *$ \\
Épocas x Fungos & $* *$ & $* *$ & $\mathrm{~ns}$ & $* *$ & $\mathrm{~ns}$ & $\mathrm{~ns}$ & $\mathrm{~ns}$ \\
Épocas x Doses P & $* *$ & $* *$ & $* *$ & $* *$ & $* *$ & $* *$ & $* *$ \\
Fungos X Doses P & $\mathrm{ns}$ & $* *$ & $* *$ & $*$ & $*$ & $* *$ & $\mathrm{~ns}$ \\
Épocas x Fungos x Doses P & $\mathrm{ns}$ & $* *$ & $* *$ & $* *$ & $\mathrm{~ns}$ & $* *$ & $\mathrm{~ns}$ \\
\hline
\end{tabular}

* = Significativo pelo teste $\mathrm{F}$ a $5 \%$ de probabilidade; ** = Significativo pelo teste $\mathrm{F}$ a $1 \%$ de probabilidade; ns $=$ não significativo pelo teste $\mathrm{F}$ a $5 \%$ de probabilidade 
Apêndice 1. Niveis de significância nos quais o efeito dos fatores ou a interação entre eles foi significativa pelo teste $F(P>F)$ (continuação)

\begin{tabular}{|c|c|c|c|c|c|c|}
\hline CAUSAS DA VARIAÇÄO & $\begin{array}{l}\text { Cobre } \\
\text { total }\end{array}$ & $\begin{array}{l}\text { Ferro } \\
\text { total }\end{array}$ & $\begin{array}{c}\text { Manganês } \\
\text { total }\end{array}$ & $\begin{array}{l}\text { Zinco } \\
\text { total }\end{array}$ & $\begin{array}{c}\text { Fe vagens } \\
\text { concentração }\end{array}$ & $\begin{array}{l}\text { Mn vagens } \\
\text { concentração }\end{array}$ \\
\hline Épocas & $* *$ & $* *$ & $* *$ & $* *$ & $* *$ & $* *$ \\
\hline Fungos & $* *$ & ns & ns & $*$ & $* *$ & $\mathrm{~ns}$ \\
\hline Doses P & ** & *** & $* *$ & $* *$ & $* *$ & $* *$ \\
\hline Épocas $\times$ Fungos & $* *$ & ns & ns & * & ns & ns \\
\hline Épocas x Doses P & $* *$ & $* *$ & $* *$ & ** & $* *$ & $* *$ \\
\hline Fungos $\times$ Doses $P$ & * & ns & $\mathrm{ns}$ & ns & $* *$ & $*$ \\
\hline 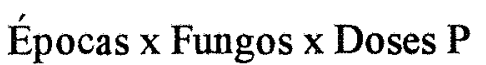 & $*$ & us & ns & * & * & ns \\
\hline
\end{tabular}

$*=$ Significativo pelo teste $\mathrm{F}$ a $5 \%$ de probabilidade; ${ }^{* *}=$ Significativo pelo teste $\mathrm{F}$ a $1 \%$ de probabilidade; ns $=$ não significativo pelo teste $\mathrm{F}$ a $5 \%$ de probabilidade 